\title{
Indole-TEMPO conjugates alleviate ischemia-reperfusion injury via attenuation of oxidative stress and preservation of mitochondrial function
}

\author{
Wei Bi*a ${ }^{\mathrm{a}}$, Yue Bi, ${ }^{\mathrm{a}}$ Xiang Gao, ${ }^{\mathrm{b}}$ Pengfei Li, ${ }^{\mathrm{a}}$ Shanshan Hou, ${ }^{\mathrm{b}}$ Yanrong Zhang, ${ }^{\mathrm{a}}$ Cathy Bammert, ${ }^{\mathrm{b}}$ Steffen \\ Jockusch, ${ }^{\mathrm{c}}$ Thomas D. Legalley, ${ }^{\mathrm{e}} \mathrm{K}$. Michael Gibson, ${ }^{\mathrm{d}}{ }^{\mathrm{L}}$ Lanrong Bi ${ }^{\mathrm{b}}{ }^{*}$
}

${ }^{a}$ Second Hospital of HeBei Medical University, Shijiazhuang 050000, P.R. China

${ }^{b}$ Department of Chemistry and Biological Sciences, Michigan Technological University, Houghton, MI 49931, USA

${ }^{c}$ Department of Chemistry, Columbia University, New York, NY 10027, USA.

${ }^{d}$ Department of Pharmacotherapy, College of Pharmacy, Washington State University, Spokane WA 99202

${ }^{\mathrm{e}}$ Marquette General Heart and Vascular Institute, Marquette General Hospital, Marquette, Michigan 49855, USA

\section{ARTICLE INFO}

Article history:

Received

Received in revised form

Accepted

Available online

\section{Keywords:}

Keyword_1 ischemia/reperfusion injury

Keyword_2 anti-inflammation activity

Keyword_3 oxidative damage

Keyword_4 indole-TEMPO conjugates

Keyword_5 mitochondrial function

\section{ABSTRACT}

Mitochondrial oxidative damage contributes to a wide range of pathologies including ischemia/ reperfusion injury. Accordingly, protecting mitochondria from oxidative damage should possess therapeutic relevance. In the present study, we have designed and synthesized a series of novel indoleTEMPO conjugates that manifested good anti-inflammatory properties in a murine model of xyleneinduced ear edema. We have demonstrated that these compounds can protect cells from simulated ischemia/reperfusion (s-I/R)-induced reactive oxygen species (ROS) overproduction and mitochondrial dysfunction. Furthermore, we have demonstrated that indole-TEMPO conjugates can attenuate organ damage induced in rodents via intestinal I/R injury. We therefore propose that the pharmacological profile and mechanism of action of these indole-TEMPO conjugates involve convergent roles, including the ability to decrease free radical production via lipid peroxidation which couples to an associated decrease in ROS-mediated activation of the inflammatory process. We further hypothesize that the protective effects of indole-TEMPO conjugates partially reside in maintaining optimal mitochondrial function.

2009 Elsevier Ltd. All rights reserved.

* Corresponding authors. biwei@hb2h.com (W. Bi), mike.gibson@wsu.edu (K.M. Gibson), lanrong@mtu.edu (L. Bi). 


\section{Introduction}

Intestinal ischemia/reperfusion (I/R) injury represents a clinical syndrome that occurs in various settings, including abdominal aortic aneurysm, ${ }^{1}$ small intestine transplantation, ${ }^{2}$ strangulated hernia, ${ }^{3}$ and neonatal necrotizing enterocolitis. ${ }^{4}$ Reperfusion of the superior mesenteric artery (SMA) induces activation of poly-morphonuclear neutrophils (PMNs), with accompanying release of pro-inflammatory substances and enhanced production of free radicals. 5,6 These radicals, including hydroxyl radicals, play a role in the pathophysiology of intestinal $\mathrm{I} / \mathrm{R}$ injury by promoting lipid and DNA oxidation/peroxidation, enhanced free radical formation and associated mitochondrial depolarization, and eventually cellular apoptosis. Additionally, these pro-inflammatory factors activated following I/R injury circulate via both venous and lymphatic systems, inducing distant organ injury that contributes to both the systemic inflammatory response and acute respiratory distress syndromes that have been highlighted by multiple studies documenting the beneficial effects of interventions to mitigate ROS effects. ${ }^{5,6}$

A stable piperidine nitroxide, 4-hydroxy-TEMPO (TEMPOL) is a water-soluble intermediate widely employed in electron spin resonance spectroscopy. TEMPOL permeates biological membranes, accumulates in the cytosol, and scavenges superoxide anions in vitro, thus acting as a "SOD (superoxide dismutase)-mimetic". Moreover, TEMPOL reduces the formation of hydroxyl radicals through probable scavenging of superoxide anions or via reduction of intracellular $\mathrm{Fe}^{2+}$ concentration. The latter process inhibits the formation of hydroxyl radicals via the Fenton or Haber-Weiss reactions. Unlike SOD, catalase or other exogenously-administered antioxidants, nitroxide readily permeates cell membranes and traverses the blood-brain barrier. We ${ }^{8,9}$ and others have provided preliminary studies which indicate that nitroxides can attenuate oxidative damage in various $\mathrm{I} / \mathrm{R}$ experimental models. ${ }^{10-20}$

Previously we have developed a series of new indole derivatives which exhibit good antioxidant and antiinflammatory activities. ${ }^{21-23}$ Since ROS and inflammatory leukocytes play an important role in the pathogenesis of $I / R$ injury, antioxidant therapy and inhibition of post-ischemic neutrophil infiltration possesses therapeutic relevance. ${ }^{24-27}$ When considering therapeutics in many settings, combinatorial treatment often enhances therapeutic efficacy via incremental improvements. Because of differing pharmacokinetic profiles, the systemic administration of two potentially synergistic agents will access therapeutic targets with differing efficiencies. However, therapeutic advantages might be achieved when the co-administered agents are introduced as a single chemical entity. Accordingly, we pursued the hypothesis that the free radical scavenging properties of the TEMPO moiety, coupled with the anti-inflammatory activity observed with the indole derivatives, would generate new indoleTEMPO conjugates with synergistically enhanced antioxidant, anti-inflammatory and anti-ischemic activities. To evaluate this hypothesis, we have prepared a series of new indole-TEMPO conjugates and characterized their biological capacity to attenuate I/R injury in the in vitro and in vivo experimental ischemia/reperfusion models.

\section{Results}

\subsection{Synthesis of Indole-TEMPO conjugates (9a-s)}

The synthetic route is outlined in Scheme 1\&2. Starting from optically active L-tryptophan, the parent $\beta$-carboline $\mathbf{1}$ was prepared via the Pictect-Spengler reaction, and subsequently subjected to protective coupling to yield intermediates $\mathbf{4}$ and $\mathbf{5}$. At the 3-position of the $\beta$-carboline ring, we introduced different amino acids to generate a series of indole derivatives (7a-s; $75-85 \%$ yield; Scheme 1). These amino acids provide various functional groups, including aromatic (Tyr, Trp, Phe), cationic (His, Lys, Arg), anionic (Glu, Asp), amide (Asn, Gln), small (Gly, Ala), hydrophobic (Val, Leu, Ile, Met, Pro), and nucleophilic (Ser, Thr) species. Subsequently, we introduced a terminal alkynyl functional group as a synthetic "handle" to facilitate introduction of the TEMPO moiety. The desired targets 9a-s were obtained via a copper (I) catalyzed azide/alkyne cycloaddition (CuAAC) reaction ${ }^{28-30}$ in moderate yield (Scheme 2). All intermediates were characterized by ${ }^{1} \mathrm{H}$ and ${ }^{13} \mathrm{C}$ NMR. The target compounds were paramagnetic compounds, so they were analyzed by EPR spectroscopy to confirm the intact nitroxide label. The structural characteristics of all target compounds were confirmed by high-resolution mass spectrometry. All target species (9a-s) were stable and were stored at room temperature until use.

\subsection{Biological evaluations}

\subsubsection{In vivo anti-inflammatory activity}

We investigated the anti-inflammatory properties of indoleTEMPO conjugates 9a-s employing the xylene-induced ear edema assay in mice using our published procedure. ${ }^{21-23,} 31,32$ As a common inflammation-inducing agent, xylene can induce serious edematous changes in ear by inducing an acute inflammatory response. This model provides a sensitive and reliable test for fast in vivo screening of anti-inflammatory agents.

The indole ring is an important pharmacophoric nucleus that possesses anti-inflammatory and antioxidant effects. ${ }^{21-23}$ As shown in Table 1, it was observed that the anti-inflammatory activities of the indole-TEMPO (9a-s) were significantly higher than that of vehicle (CMC). Some compounds

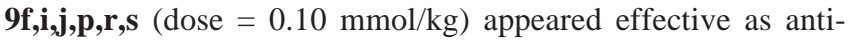
inflammatory agents, exceeding the anti-inflammatory capacity of the positive control (aspirin; 5-acetylsalicyclic acid). Among these, indole-bis-TEMPOs 9r,s were the most potent antiinflammatory agents, achieving $77-80 \%$ inhibition of inflammation. The data suggest that the more TEMPO moieties presenting in the conjugates the stronger the inhibition of inflammation.

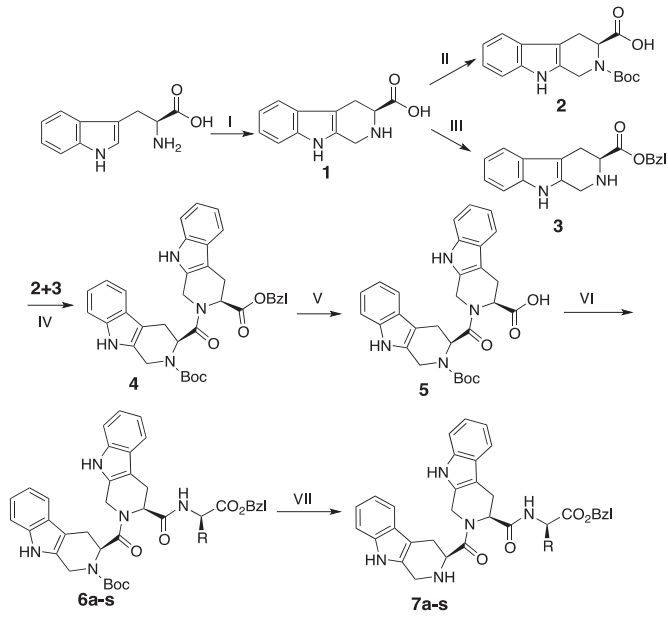

Scheme 1. Synthesis of indole derivatives 7a-s based on the 3(S)-1,2,3,4-tetrahydro- $\beta$-carboline-3-carboxylic acid scaffold. Reagents and conditions: (I) formaldehyde and sulfuric acid; (II) $\mathrm{Boc}_{2} \mathrm{O}$ and tri-ethylamine; (III) benzyl alcohol, 
polyphosphoric acid, reflux; (IV) $\mathrm{HOBt}$, DCC; (V) $\mathrm{H}_{2}, \mathrm{Pd} / \mathrm{C}$; (VI) L-AA-OBzl, HOBt, DCC; (VII) HCl/EtOAc.

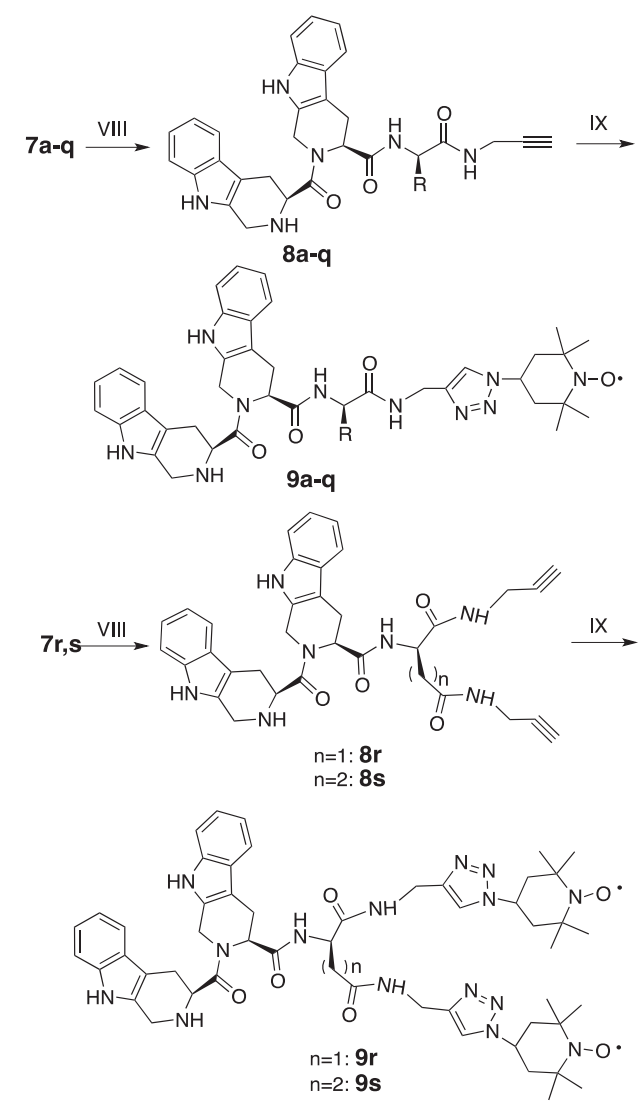

Scheme 2. Synthetic procedure for preparation of indoleTEMPO (9a-s). Reagent and conditions: (VIII) $\mathrm{H}_{2}, \mathrm{Pd} / \mathrm{C}$; propargylamine, HBTU, triethylamine; (IX) 4-azido-TEMPO, CuI.

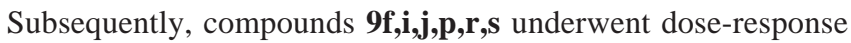
characterization to obtain a more detailed pharmacodynamic profile. Administered at dosages of $0.02,0.05$, and 0.10 $\mathrm{mmol} / \mathrm{kg}$, compounds $\mathbf{9 f}, \mathbf{i}, \mathbf{j}, \mathbf{p}, \mathbf{r}, \mathbf{s}$ yielded a dose-dependent anti-inflammatory response (Fig. 1). The most potent indolebis-nitroxides $(\mathbf{9 r}, \mathbf{s}$, dose $=0.02 \mathrm{mmol} / \mathrm{kg})$ are superior to aspirin. Assuming that the inflammatory process results in impairment of down-stream antioxidant defenses, we speculate that the improved anti-inflammatory activities of indole-bisTEMPO conjugates correlates with the antioxidant-enhancing contribution of the two nitroxide moieties, further highlighting the observation that minor structural alterations can lead to a marked synergistic improvement in drug efficacy.

\subsubsection{Evaluation of bleeding tendency}

Conventional NSAIDs often associate with several significant side effects, such as gastrointestinal bleeding, impaired platelet function, and prolonged bleeding time. To develop safer antiinflammatory agents, it is important to evaluate these newly synthesized indole-TEMPO conjugates for possible deleterious effects on normal hemostasis resulting in bleeding complications. Accordingly, we examined a rodent tailbleeding assay to gauge the extent of anticoagulation associated with our indole-TEMPO conjugates (9a-s). We adapted the cutaneous bleeding time protocol to assess anticoagulant aspects of these compounds. Our results verified that our indole-TEMPO conjugates (9a-s), even at high dose $(0.50 \mathrm{mmol} / \mathrm{kg})$, did not significantly prolong bleeding time in mice at all time points evaluated (Table 2).
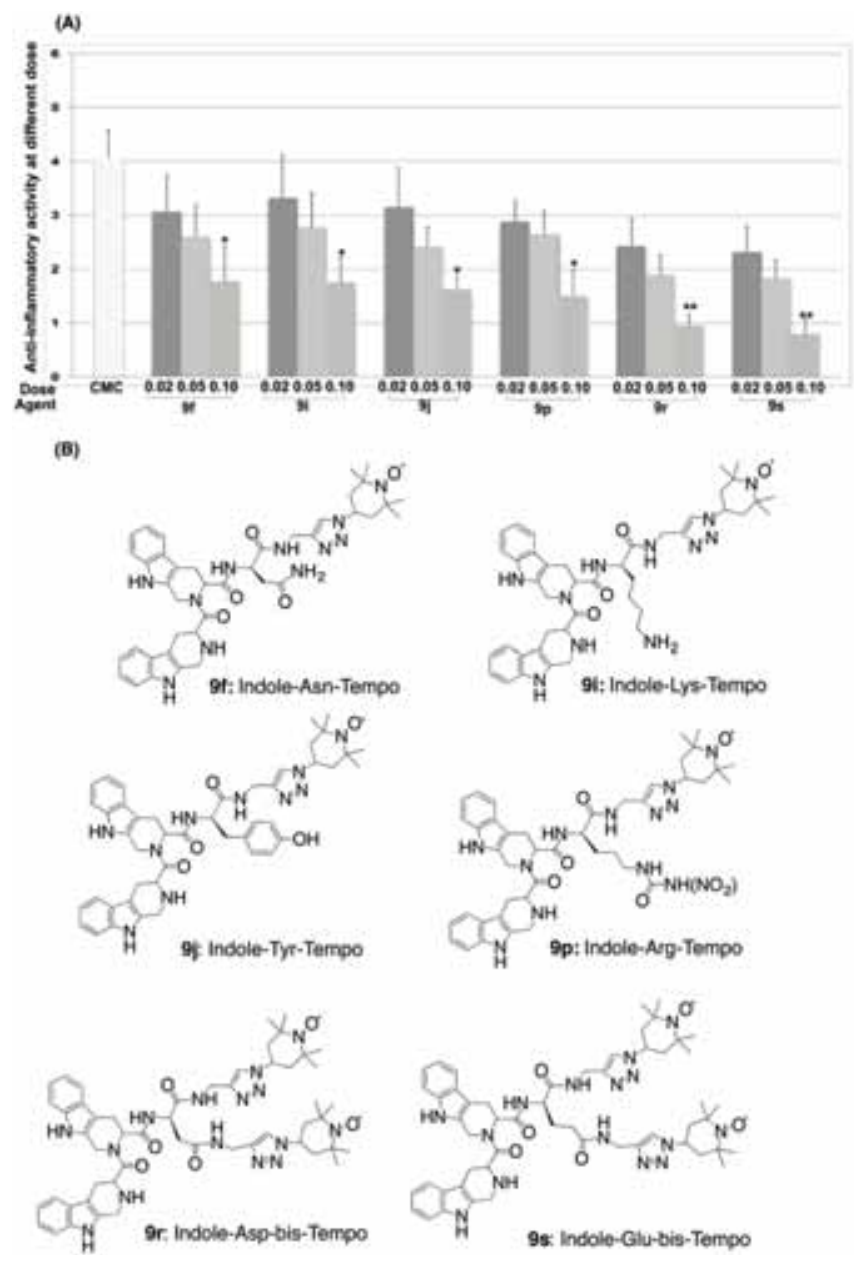

Fig. 1. Antiinflammatory activities of $\mathbf{9 f ,}, \mathbf{i}, \mathbf{j}, \mathbf{p}, \mathbf{r}, \mathbf{s}$ at different doses $(0.02,0.05,0.10 \mathrm{mmol} / \mathrm{kg})$ were evaulated based on ear edema ( $\mathrm{X} \pm \mathrm{SD}$ mg weight tissue) $\mathrm{N}=10$; *:Compared to the same compound at $0.02 \mathrm{mmol} / \mathrm{kg}, \mathrm{p}<0.05$; **: Compared to the same compound at dose of $0.02 \mathrm{mmol} / \mathrm{kg}, \mathrm{p}<0.01$.

\subsubsection{Protective effect of indole-TEMPO conjugates in a simulated ischemia/reperfusion (sI/R) cellular model}

Next, we examined the ability of these compounds to protect against I/R-induced cell death in a simulated I/R cellular model. In our analyses, human umbilical vein endothelial (HUVEC) cells were subjected to simulated $\mathrm{I} / \mathrm{R}$ injury employing a flow-through process. ${ }^{31,32}$ During simulated ischemia, no significant cell death was observed. After exposure of cells to simulated ischemia followed by $3 \mathrm{~h}$ of reperfusion, cell death exceeded $80 \%$. Phase contrast images of these cells revealed evidence of cellular swelling and membrane irregularity during reperfusion (images not shown). To examine the effect of indole-TEMPO derivatives, the cells were supplemented with different indole-TEMPO derivatives for $12 \mathrm{~h}$ prior to simulated ischemia followed by $3 \mathrm{~h}$ of reperfusion. The cell viability results are shown in Fig. 2. The number of live cells significantly increased after pre-incubation 
with indole-TEMPO derivatives when compared to that of simulated I/R alone. Therefore, we conclude that these compounds are providing protection against sI/R-induced cell death.

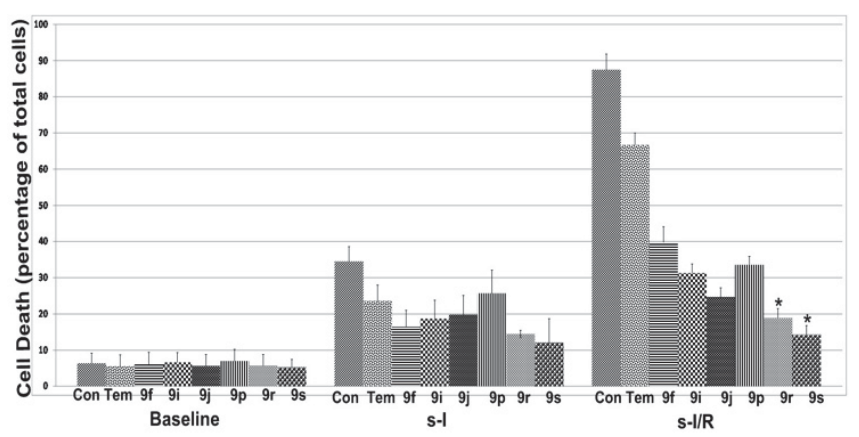

Fig. 2. Cell death in simulated ischemia-reperfusion without (Control) or with TEMPOL (Tem) or indole-TEMPO conjugates (9f,i,j,j,p,r,s) pre-treatment. Error bars indicate standard error of the mean of at least three independent experiments (* $\mathrm{p}<0.05$ compared to controls). s-I: simulated ischemia; s-I/R: simulated ischemia and reperfusion.

\subsubsection{Alleviation of mitochondrial oxidative damage}

To monitor the reactive oxygen species (ROS) generation in the mitochondria during ischemia, HUVEC cells were labeled with MitoProbe. MitoProbe represents a new class of fluorogenic dyes, which are highly sensitive for the detection of mitochondrial ROS. ${ }^{28}$ The specificity of MitoProbe was confirmed by co-localization studies comparing the distribution of MitoProbe fluorescence and MitoTracker using confocal microscopy. During simulated ischemia/reperfusion (sI/R), mitochondria underwent distinct morphological changes that were classified into three categories: tubular (essentially normal), intermediate (tubular with swollen regions) and fragmented (small and globular). Sham control cells manifested tubular mitochondria and exhibited weak fluorescence generated from the MitoProbe (Fig. 3A). During simulated ischemia (s-I), some cells displayed enhanced mitochondrial fluorescence, with MitoProbe fluorescence being restricted to a dispersed tubular structure network surrounding the nucleus. Conversely, we observed a much more dispersed and irregular staining pattern in HUVEC cells subjected to simulated reperfusion, with strong MitoProbe fluorescence.

Simulated ischemia (120 min) resulted in an $\sim 2$ fold increase of mitochondrial ROS levels as revealed from enhanced MitoProbe fluorescence. As predicted, simulated ischemia followed by $3 \mathrm{~h}$ of reperfusion resulted in a 5 6 fold elevation of mitochondrial ROS (Fig. 3B). These data highlight the association of increased mitochondrial oxidant stress with simulated I/R. Treatment with indole-bis-TEMPOs $(\mathbf{9 r}, \mathbf{s})$ significantly lowered the mitochondrial ROS as shown by the fluorescence intensity of MitoProbe, and simultaneously resulted in increased numbers of HUVEC cells exhibiting tubular mitochondria, indicating significant mitigation of oxidant stress damage in the mitochondria of HUVEC cells.

\subsubsection{Inhibition of mitochondrial cytochrome c release}

The release of cytochrome c from the intermembrane space into the cytosol represents the initial event in the activation of mitochondrial apoptosis. Accordingly, we next determined the influence of indole-bis-TEMPOs upon mitochondrial cytochrome c using an immuno-fluorescence assay. HUVEC cells immunostained for cytochrome $\mathrm{c}$ under baseline conditions demonstrated a punctate pattern of fluorescence (Fig. 4A). No significant increase in cells exhibiting diffuse cytochrome c staining was detected during simulated ischemia. However, during sI/R, the number of cells exhibiting a diffuse pattern of fluorescence significantly increased, and mitochondrial ROS also significantly increased. These results indicate that mitochondrial cytochrome $\mathrm{c}$ is released into the cytosol after simulated I/R. We next examined the effect of indole-bis-TEMPOs on mitochondrial cytochrome $\mathrm{c}$ release after sI/R. As shown in Fig. 4B for cells pre-treated with indole-bis-TEMPOs 9r,s, there was significant inhibition of cytochrome c release during sI/R, reducing cytochrome c released cells from $71.2 \% \pm 4.5 \%$ to $29.8 \pm 3.2 \%$ (9r) or $23.1 \%$ $\pm 3.0 \%(9 \mathrm{~s})$ as shown by cell counting. During this process, we also observed that mitochondrial ROS were maintained at comparably low levels. These results suggested that overproduction of mitochondrial ROS induced by sI/R contributed to mitochondrial fragmentation and cytochrome $\mathrm{c}$ release, which could be significantly inhibited by pretreatment with indole-bis-TEMPOs 9r,s.

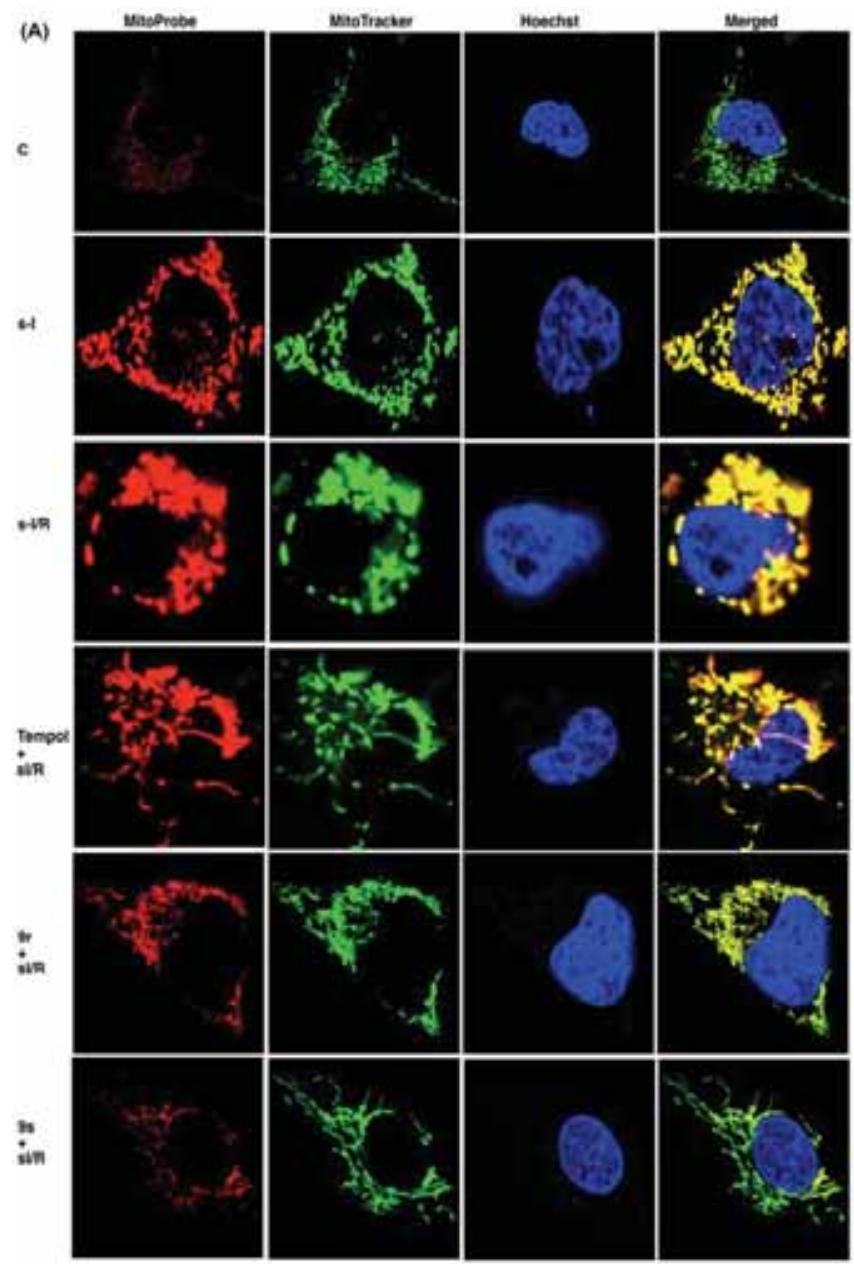




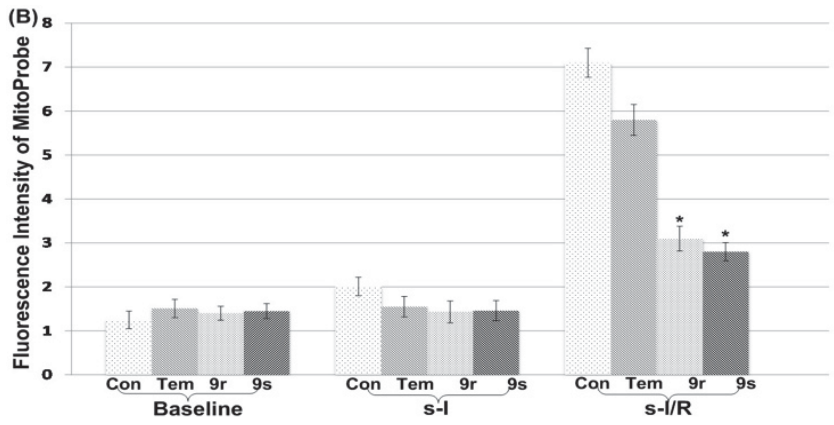

Fig. 3. Detection of oxidative stress in the mitochondria during simulated ischemia/reperfusion (sI/R). (A) Typical confocal fluorescence images of HUVEC cells counter-stained with MitoProbe (red fluorescence), MitoTracker (green fluorescence) and Hoechst 33342 (blue fluorescence). During sI/R, mitochondria underwent distinct morphological changes; (B) By measuring the fluorescence intensity increase at different time points, mitochondrial ROS was determined. Increases in MitoProbe fluorescence relative to baseline values were evident during sI/R. Pretreatment with indole-bisTEMPOs (9r,s) significantly attenuated the increase in MitoProbe fluorescence intensity during sI/R. Error bars indicate standard error of the mean from at least three independent experiments $(* * \mathrm{p}<0.01$ compared with $\mathrm{s}-\mathrm{I} / \mathrm{R}$ alone group). s-I: simulated ischemia; s-I/R: simulated ischemia and reperfusion.

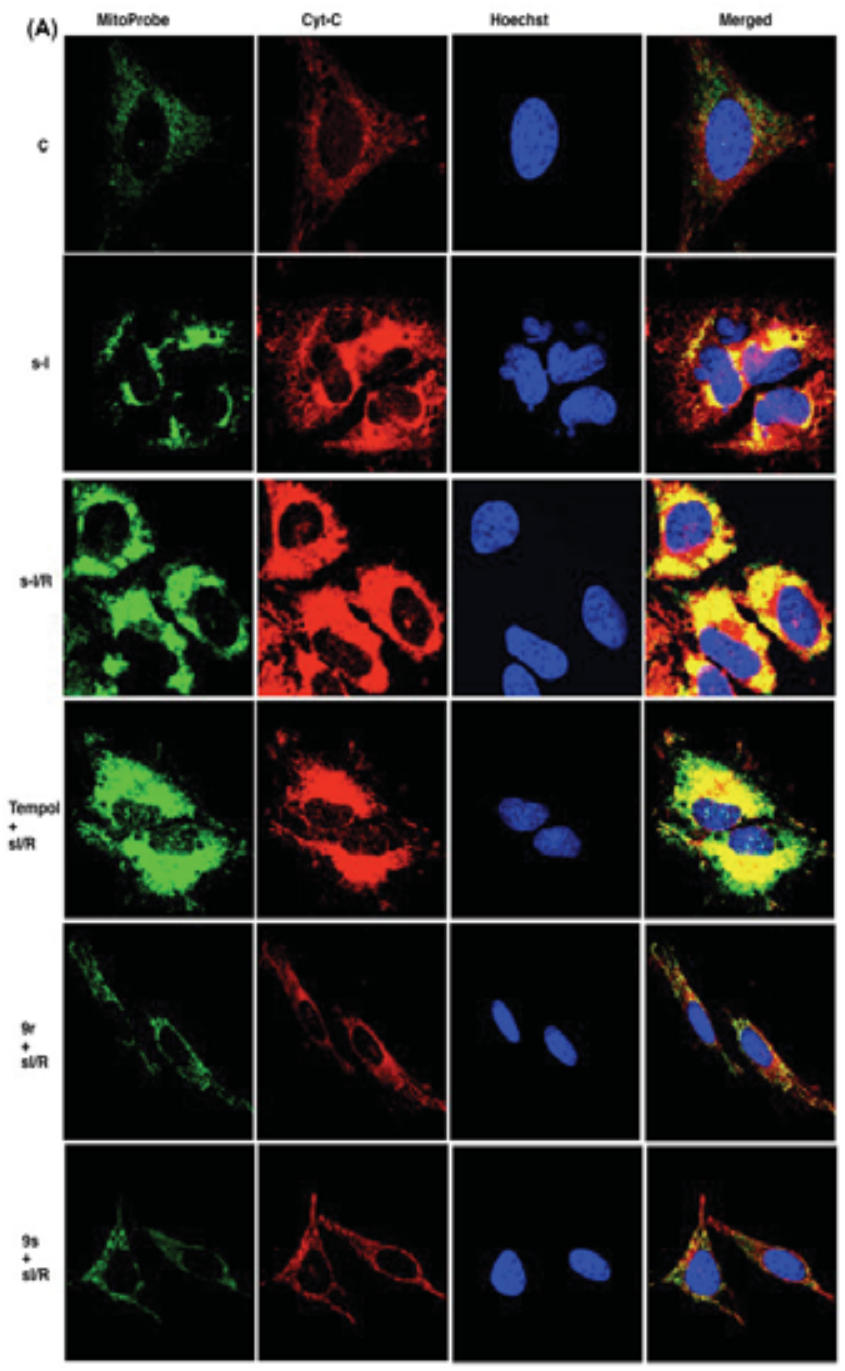

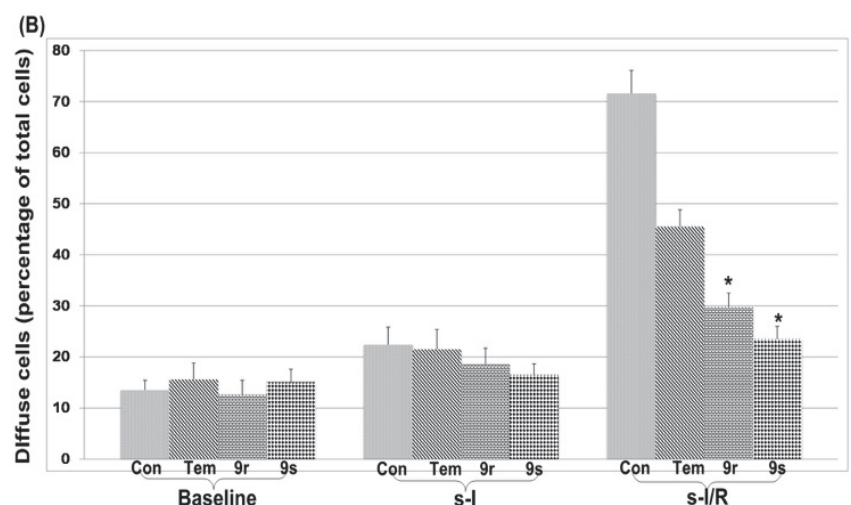

Fig. 4. Release of cytochrome $\mathrm{c}$ during simulated I/R. (A) HUVEC cells were stained with MitoProbe (green fluorescence). Cells were fixed at baseline, following simulated ischemia or after $3 \mathrm{~h}$ of reperfusion. Cells were then immunostained for cytochrome c (red fluorescence); (B) cells showing redistribution of cytochrome $\mathrm{c}$ were quantified and expressed as a percentage of the total cell population. A significant increase in the percentage of cells with cytochrome c release was observed in cells subjected to simulated I/R. Cytochrome $\mathrm{c}$ release was significantly inhibited in cells pre-treated with indole-bis-TEMPOs $(\mathbf{9 r}, \mathbf{s})$. Error bars indicate standard error of the mean from at least three independent experiments $\left({ }^{*} \mathrm{p}<0.05\right.$ compared with s-I/R alone groups). s-I: simulated ischemia; sI/R: simulated ischemia and reperfusion.

\subsubsection{Intestinal ischemia/reperfusion injury}

Because of the potent anti-inflammatory and antioxidant activities of indole-TEMPO derivatives, we sought to elucidate whether these compounds could additionally attenuate ischemia-reperfusion injury in a rat model of intestinal $I / R$ injury.

\subsubsection{Histological analysis of small intestine}

We used a variety of assessments (hematoxylin and eosin (H\&E) staining for structural alterations; nicotinamide adenine dinucleotide (NADH) diaphorase staining to assess tissue metabolic status; and modified trichrome staining to distinguish cells from connective tissue) to gauge the histological effects of the indole-bis-TEMPOs. In cohorts of rats subjected to intestinal I/R injury model, we observed shortening of the villi, loss of villous epithelium, and prominent mucosal neutrophil infiltration (upper row in Fig. 5A). Modified tri-chrome staining in the same subjects revealed mucosal damage ranging from desquamation of villous epithelium to marked congestion (upper row in Fig. 5B), which was also apparent in NADH-stained tissues (upper row in Fig. 5C). These histological abnormalities (shortening of the villi, denuded villi, mucosal ulceration and the presence of crypts) are characteristics of intestinal $\mathrm{I} / \mathrm{R}$ injury. Intervention with indole-bis-TEMPOs (9r, s) significantly mitigated histological damage, resulting in only mild denudation of villous tips and well-preserved glandular architecture (lower rows in Fig. 5A-C).

\subsubsection{Effect of Indole-bis-TEMPO conjugates (9r,s) on lipid peroxidation}

The role of free radical formation and inflammation in intestinal I/R injury prompted us to investigate the potentially beneficial effects of indole-bis-TEMPOs in intestinal $\mathrm{I} / \mathrm{R}$ injury. Accordingly, we quantified intestinal lipid peroxides 
(LPO) in rat tissues (Fig. 5D), which revealed a direct relationship between LPO levels and the severity of the local inflammatory response to I/R injury. LPO levels in intestinal tissues were significantly increased in rats treated with saline + I/R injury, when compared with sham-operated rats at identical time points. A maximal LPO accumulation of $412.4 \pm 63.7$ $\mathrm{nmol} / \mu \mathrm{g}$ tissue occurred at $3 \mathrm{~h}$ post reperfusion. Conversely, administration of TEMPOL or 9r,s prior to, and continuously throughout perfusion, resulted in a significant attenuation of LPO at all time points tested (Fig. 5D). Cell membrane phospholipids are also susceptible to peroxidation during I/R injury, resulting in LPO production. Our findings that TEMPOL administration, or 9r,s intervention, prior to and during reperfusion could lead to a significant attenuation of LPO production in intestine suggests that the protective properties of 9r,s were at least partially due to free radical scavenging capacities.

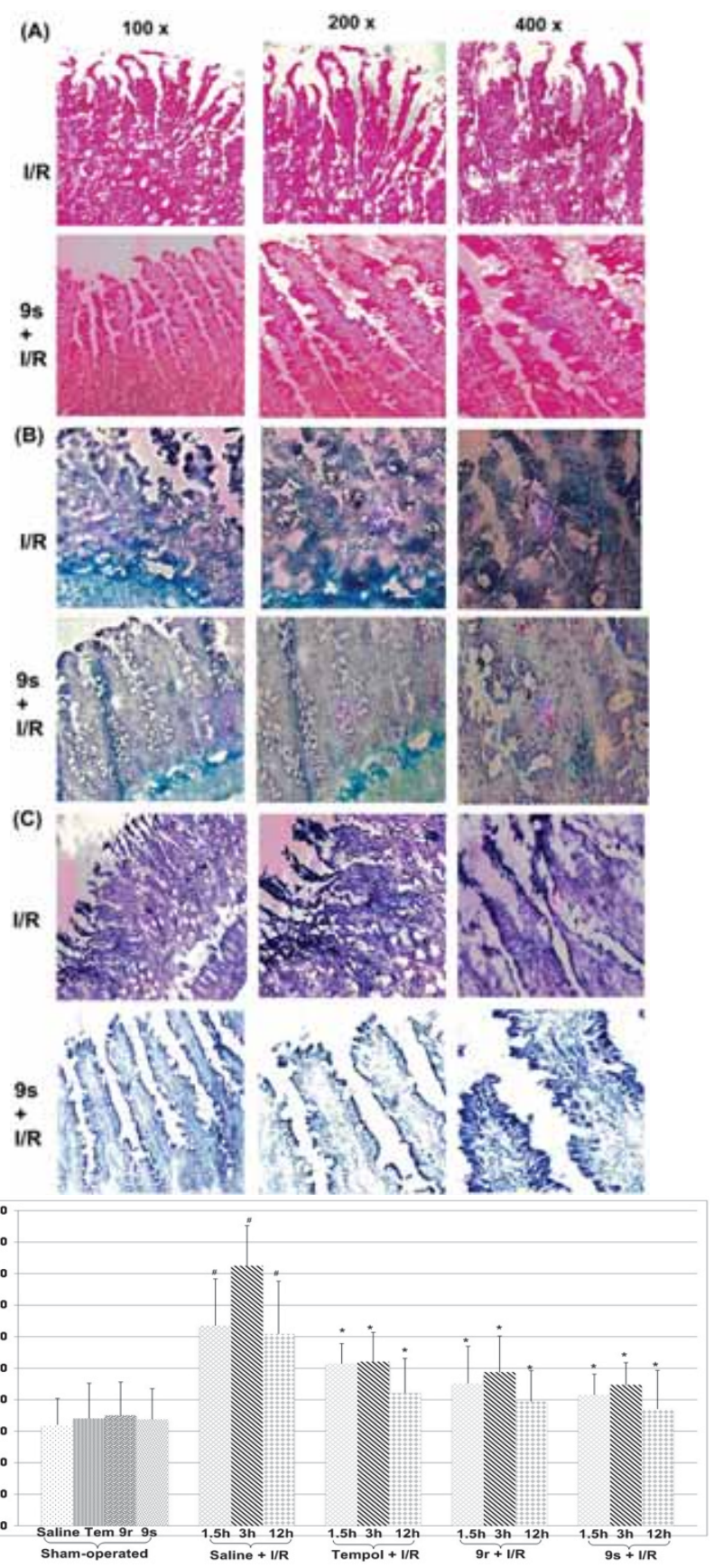

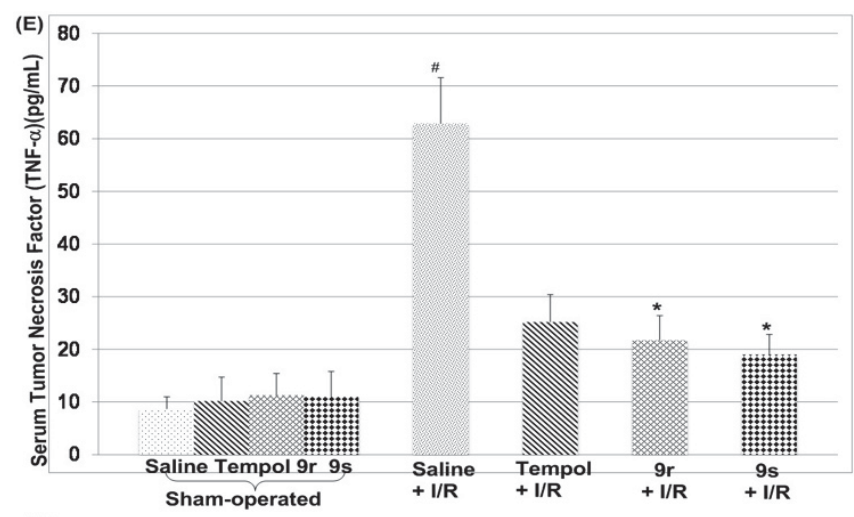

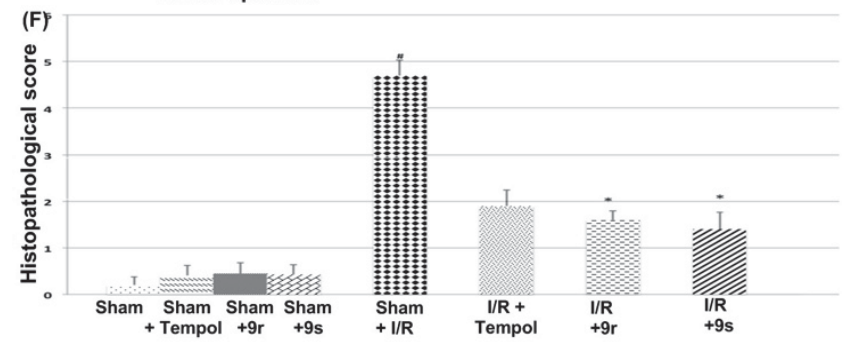

Fig. 5. Representative photomicrographs of histological sections of small intestines from saline $+\mathrm{I} / \mathrm{R}$ and $\mathrm{I} / \mathrm{R}+\mathbf{9} \mathrm{S}$ treatment groups. (A): H \& E staining; (B): modified trichrome staining; (C) $\mathrm{NADH}$ staining. In saline $+\mathrm{I} / \mathrm{R}$ groups, shortening of the villi, vacuolation of villus tips, disintegration of the lamina propria and polymorpho-nuclear leukocyte accumulation were observed; Treatment with 9s resulted in significant reduction of mucosal injury, with only mild denudation of villous tips and well-preserved glandular architecture. (D): Effects of 9r,s on production of lipid peroxide (LPO) (nmol/ $\mu \mathrm{g})$; (E): Effect of 9r,s on serum tumor necrosis factor-alpha (TNF- $\alpha)(\mathrm{pg} / \mathrm{mL})$; (F) Semi-quantitative score of $\mathrm{H} / \mathrm{E}$ staining of intestinal tissues. In Fig. 5D-F, ${ }^{a}$ : Compared to sham-operated groups, $\mathrm{p}<0.01 ;{ }^{b}$ : Compared to saline $+\mathrm{I} / \mathrm{R}$ groups, $\mathrm{p}<0.01$.

Intestinal mucosal damage was evaluated as follows: grade 0 , normal mucosa, grade 1: mild subepithelial detachment; grade 2: moderate subepithelial detachment; grade 3: massive subepithelial detachment; grade 4: denuded villi, grade 5: ulceration. Semi-quantitative score of $\mathrm{H} / \mathrm{E}$ staining was shown in Fig. 5F.

\subsubsection{Effect of Indole-bis-TEMPOs (9r,s) on serum Tumor} Necrosis Factor- $\alpha(T N F-\alpha)$

Intestinal $\mathrm{I} / \mathrm{R}$ damage promotes inflammatory responses via stimulation of the production of inflammatory cytokines and chemokines. TNF- $\alpha$ is a key regulator of the inflmmatory response, and it represents a pivotal mediator of local and remote organ injury induced by ischemia/reperfusion. We next evaluated its levels (Fig. 5E). Serum TNF- $\alpha$ levels were significantly increased in rat cohorts subjected to intestinal $\mathrm{I} / \mathrm{R}$ injury at the completion of reperfusion $(62.9 \pm 8.7 \mathrm{pg} / \mathrm{mL}$ vs. $8.7 \pm 2.3 \mathrm{pg} / \mathrm{mL}, \mathrm{p}<0.01$ ), indicative of systemic inflammatory damage induced by intestinal $\mathrm{I} / \mathrm{R}$ injury. This effect was mitigated with TEMPOL $(25.2 \pm 5.2 \mathrm{pg} / \mathrm{mL})$, 9r $(21.7 \pm 4.7$ $\mathrm{pg} / \mathrm{mL})$ or $9 \mathrm{~s}(19.0 \pm 3.8 \mathrm{pg} / \mathrm{mL})(\mathrm{p}<0.01$ in all instances $)$. 


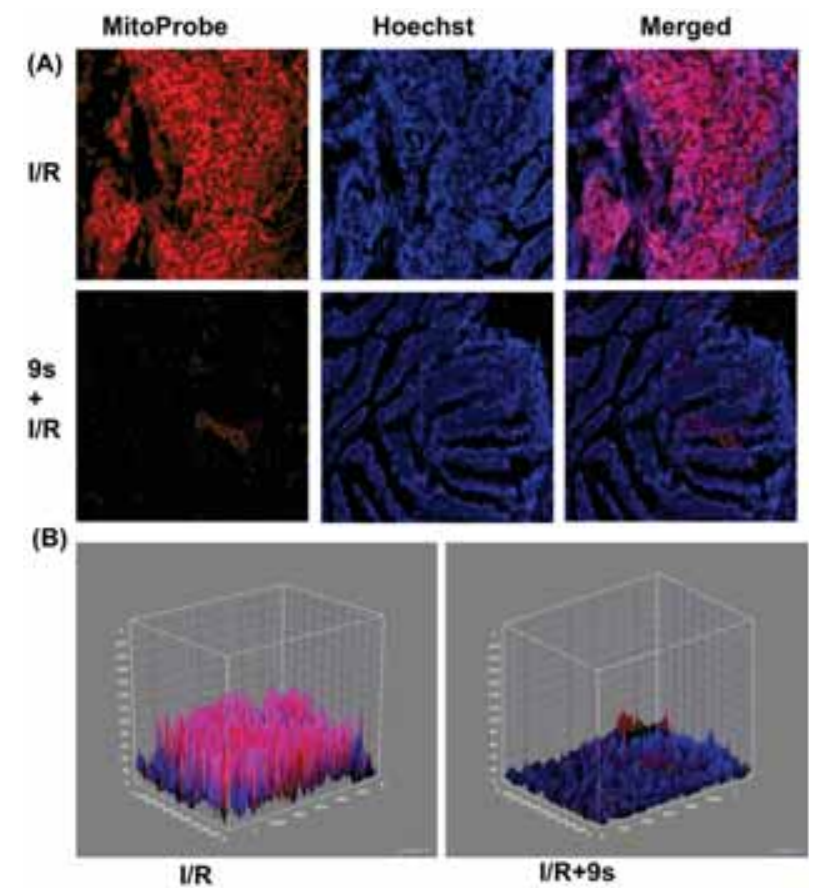

Fig. 6. (A) Fluorescent staining images of intestinal tissues taken from saline + I/R group (upper row) and from $9 \mathrm{~S}+\mathrm{I} / \mathrm{R}$ group rats (lower row) (red: MitoProbe fluorescence; blue: Hoechst 33342 fluorescence); (B) interactive 3D surface plots of the merged images shown in (A).

\subsubsection{Direct visualization of mitochondrial oxidative damage} in in vivo intestinal I/R injury animal model

In our present study, we further applied MitoProbe for direct visualization of mitochondrial oxidative damage in the in vivo model. By measuring the fluorescence intensity change of MitoProbe, the levels of mitochondrial ROS in the intestinal tissues were determined. The fluorescence intensities of MitoProbe in the intestinal tissues taken from saline $+\mathrm{I} / \mathrm{R}$ injury group rats were significantly higher than those from sham-operated group rats (images not shown). An interesting observation was that the marked mitochondrial oxidative damage occurred within small vessels in intestinal tissues. In contrast to the external layer of the muscularis propria, vascular endothelial and smooth muscle cells of vessel walls normally contain high numbers of mitochondria to support their highenergy requirements (Fig. 6A). Pretreatment with indole-bisTEMPO significantly decreased the fluorescence intensity of MitoProbe in intestinal tissues (Fig. 6A\&B), suggesting that indole-bis-TEMPO attenuated the mitochondrial oxidative damage induced by intestinal I/R.

\subsection{Molecular dynamic simulation studies}

Based on the above-mentioned results, we therefore propose that indole-TEMPO conjugates may exert their antiinflammatory activities by inhibiting the neutrophil infiltration into the inflammatory site. During this process, the nitroxide moieties of these compounds can be reduced to hydroxylamines, which may act as effective radical scavengers (Fig. 7A). A high accessibility of the nitroxide moiety may well be responsible for the high efficacy of these compounds. For example, modeling studies on indole-TEMPO conjugates show that the nitroxide moiety of compound $\mathbf{9 b}$ is buried among adjacent substituents, while that of compound 9p protrudes from the rest of the molecule (Table S1, SI). This may provide a basis for the observed difference in antiinflammatory activities between these two analogs (9b: $33 \%$ inhibition; 9p: $63 \%$ inhibition) in the same series. On the other


inhibiting lipid peroxidation compared to the mono-derivatives, suggesting that the presence of two $\mathrm{N} \rightarrow \mathrm{O}$ groups in the bisTEMPOs may lead to a higher antioxidative capacity.

The free radical scavenging effect of antioxidants is correlated with selected molecular and biochemical parameters, such as the highest occupied molecular orbital (HOMO) energy, the net charge, and the difference in heat of formation between hydroxylamine and its radical. In our present study, the important contribution of the bond dissociation enthalpy of nitroxide derivatives, the shape index, and the solvent accessible surface area were also studied (to be reported elsewhere). Along these lines, the ionization energy of the HOMO can be employed as a measure of an antioxidant's capacity to participate in radical scavenging.

The HOMO energy, which characterizes the ability of electrondonation, is appropriate to represent the free radical scavenging efficiency of nitroxides because the process to inhibit autooxidation may include the electron-transfer in combination with the abstraction of the H-atom. ${ }^{31-33}$ A higher HOMO energy implies that the molecule is a better electron donor. Because the abstraction of hydrogen involves electron transfer, the HOMO composition of a nitroxide can provide qualitative insights into the identity of its active site for the scavenging radical activity. As a general rule, the higher the HOMO energy, the more active the compound is with respect to antioxidant capacity. For example, the HOMO energy of $\mathbf{7 r}, \mathbf{s}$ is $-9.374 \mathrm{eV},-9.485 \mathrm{eV}$, respectively. In comparion, the HOMO energy of their counterparts, 9r,s is $-5.888 \mathrm{eV},-5.895 \mathrm{eV}$, respectively (Fig. 7). Theoretically, indole-bis-TEMPOs 9r,s should possess higher radical trapping potential than their respective parent compounds, 7r,s. The high HOMO energy of indole-bis-TEMPOs highlights their electron donating potential and coordination capacities, suggesting that they may serve as metal ion coordinators and subsequently as inhibitors of ioncatalyzed oxidation processes. 

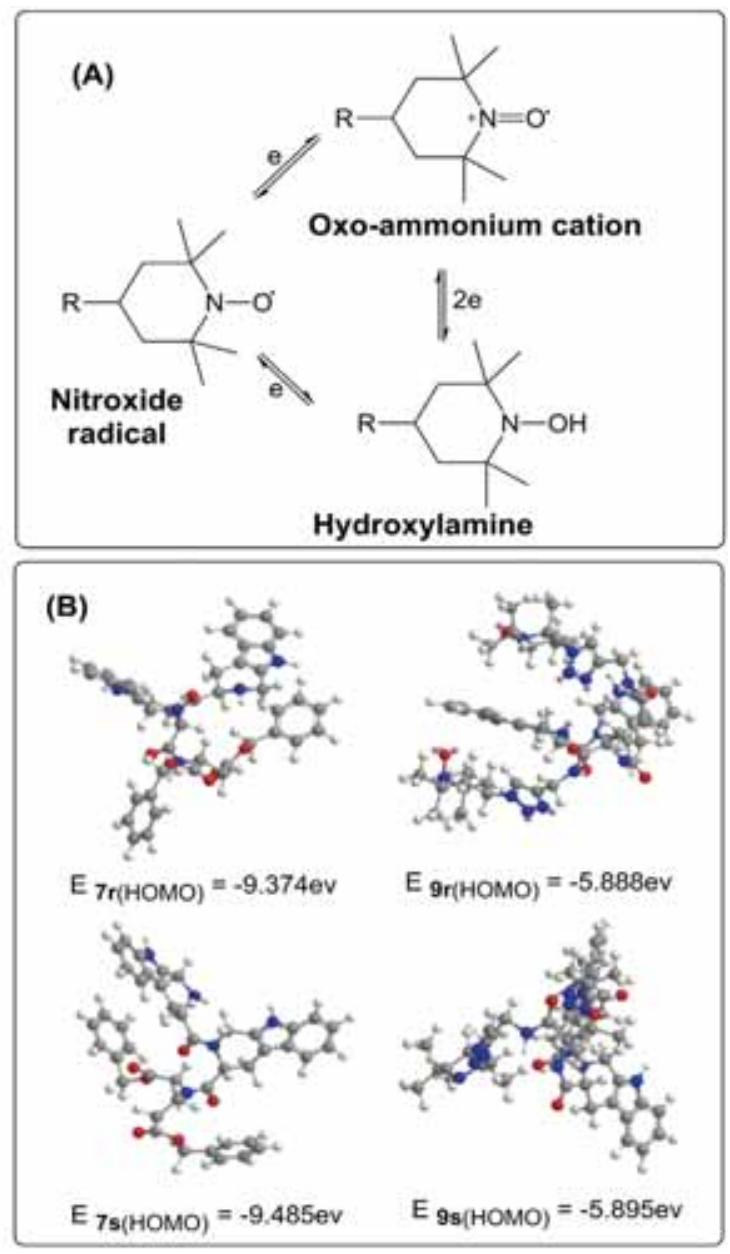

Fig. 7. (A) Schematic representation of the redox transformation of nitroxide, hydroxylamine and the oxoammonium cation; (B) The lowest energy conformers and the highest occupied molecular orbital (HOMO) energy of indolebis-TEMPO conjugates $(\mathbf{9 r}, \mathbf{s})$ and their precursors $(\mathbf{7 r}, \mathbf{s})$.

\section{Discussion}

Overproduction of reactive oxygen species (ROS) contributes to acute inflammation. At sites of inflammation, increased free radical generation is connected with activation of neutrophil NADPH oxidase and/or the uncoupling of a variety of redox systems. Improving intracellular response via enhanced free radical scavenging capabilities may boost the maintenance of balance between ROS and antioxidant defense system. In our study, the conjugation of indole derivatives 7a-s with the nitroxide moiety (TEMPO) provided conjugates 9a-s with enhanced anti-inflammatory action. As expected, indoleTEMPO conjugates 9a-s significantly decreased xyleneinduced ear inflammation in mice, confirming their potential anti-inflammatory activities (Fig. 1 \& Table 1). These data suggested that indole-TEMPO conjugates exhibited potent antiinflammatory activities likely through inhibiting neutrophil infiltration into the inflammatory site.

It has been reported that TEMPOL could scavenge intracellular superoxide anions and prevent the formation of hydroxyl radicals via inhibition of the catalytic action of transition metal irons. $^{7-9}$ In addition to the nitroxide moiety, the contribution from the amino acid residues maybe an important factor for the potent antioxidant anti-inflammatory activities of these indoleTEMPO conjugates. For example, in the case of compound $\mathbf{9 j}$ containing Trp and Tyr residues, these aromatic amino acids can easily donate protons to electron-deficient radicals, maintain their stabilities via resonance structures thereby enhancing the antioxidant activity of compound $\mathbf{9 j}$. As a result, their anti-inflammatory activities increased accordingly. In the case of compound $\mathbf{9} \mathbf{i}$, aromatic acid Trp residues can contribute radical scavenging activity in oxidative reactions because of the presence of an imidazole ring as an important proton donor. Additionally, the hydrophobic amino acid Lys residue may be responsible for forming a favorable hydrophobic microenvironment for compound $\mathbf{9 i}$. As for compounds $9 \mathbf{r}, \mathbf{s}$, the computational analysis results indicated that in addition to the contributions from the two nitroxide moieties and two Trp residues, the presence of two electron-rich 1,2,4-triazole rings also contributes to their potent antioxidant anti-inflammatory activities because they can hold high resonance stability.

The clinical effects of NSAID-induced platelet dysfunction consist of increased bleeding, prolonged surgical bleeding and an additive risk for significant or life-threatening bleeding in patients. To develop safer anti-inflammatory agents, it is mandatory to evaluate these new indole-TEMPO conjugates for possible deleterious effects on normal processes of hemostasis that may predispose to bleeding complications. Treatment with these new anti-inflammatory agents (9a-s) at the high dose $(0.50 \mathrm{mmol} / \mathrm{kg})$ did not significantly prolong bleeding time in mice at all time points tested (Table S2). Clearly, these newly synthesized indole-TEMPO conjugates display a favorable pharmacological profile relative to the reference drug aspirin.

In view of the central role of mitochondria and oxidative stress in cell function and survival after $\mathrm{I} / \mathrm{R}$, and to gain insights into the mechanisms involved in the beneficial effects of indoleTEMPO conjugates, we aimed to determine mitochondrial morphology and function, ROS production and inflammation in the setting of I/R. Mitochondrial morphology depends on the balance between mitochondrial fission and fusion, which is controlled by multiple proteins that mediate remodeling of the outer and inner mitochondrial membrane. Unbalanced fusion leads to mitochondrial elongation, and unbalanced fission leads to excessive mitochondrial fragmentation, both of which impair mitochondrial function. Changes in mitochondrial morphology that serve to adapt the organism to an oxidative environment are critical for the survival of cells. In our present study, we found that oxidative stress following exposure of cells to simulated I/R induces significant mitochondrial fragmentation in HUVEC cells. Interestingly, the abnormal mitochondrial morphology alterations could be inhibited as long as the cells were pretreated with indole-TEMPO conjugates (Fig. 3).

Mitochondrial oxidative stress has been implicated in many diseases including I/R injury. During I/R injury, the cytosolic phox proteins translocate and associate with membrane components resulting in activation of NADPH oxidase which produces $\mathrm{O}_{2}^{-}$. Subsequently, $\mathrm{O}_{2}^{-} \cdot$ is converted into other reactive oxygen species (ROS), such as $\mathrm{H}_{2} \mathrm{O}_{2}, \bullet \mathrm{OH}$ and ${ }^{1} \mathrm{O}_{2}$. In our present study, we observed that $\sim 2$ fold elevation of mitochondrial ROS occurred during simulated ischemia. Reperfusion following $2 \mathrm{~h}$ of simulated ischemia resulted in a 5 6 fold elevation of mitochondrial ROS in HUVEC cells. Interestingly, treatment with indole-TEMPO conjugates attenuated oxidant generation and increased cell viability. Additionally, these compounds could inhibit the mitochondrial cytochrome $\mathrm{c}$ release induced by simulated I/R (Fig. 4). However, we have not elucidated the exact mechanisms by which these compounds reduce mitochondrial cytochrome $\mathrm{c}$ 
release into the cytosol. The free radical scavenging activities of indole-TEMPO conjugates may contribute to protection of mitochondrial function by inhibiting mitochondrial ROS generation. Another possibility is that these compounds may modify protein expression or function of $\mathrm{Bcl}-2$ family members, which are responsible for maintenance of mitochondrial membrane integrity. The proposed mechanisms of indole-TEMPO conjugates interaction(s) with cytochrome c are shown in Fig. 8.

In view of the extensive anti-inflammatory and antioxidant activities of compounds (9r,s), we subsequently characterized the effects of selected indole-bis-TEMPOs $(\mathbf{9 r}, \mathbf{s})$ in an intestinal $\mathrm{I} / \mathrm{R}$ injury animal model. I/R injury induced extensive damage to intestines, featuring prevalent histological signs of injury to the intestinal mucosa, denuded villi, disintegration of the lamina propria, the presence of exposed capillaries, and neutrophil/macrophage infiltration. Administration of compounds 9r,s significantly mitigated this damage (Fig. 5).

Turning our attention to antioxidant defenses, we found that LPO in intestinal tissues were significantly increased in rats subjected to $\mathrm{I} / \mathrm{R}$ injury, and administration of TEMPOL or indole-bis-TEMPOs (9r,s) significantly improved this outcome, most likely through a free radical scavenging activity. To further characterize the mechanism involved, we determined intestinal tissue ROS production and demonstrated a significant increase in oxidative stress, likely related to mitochondrial ROS production. Fluorescence imaging in tissues confirmed that indole-bis-TEMPOs could significantly attenuate the mitochondrial oxidative damage that occurred in the in vivo I/R model (Fig. 6). Similar results were found when we evaluated the production of inflammatory cytokines and chemokines. These findings suggest that the inflammatory damage induced by $\mathrm{I} / \mathrm{R}$ injury appears systemic, and the dramatic increase in TNF- $\alpha$ (a prominent inflammatory mediator involved in I/R injury) could be partially corrected by administration of indole-bis-TEMPOs $(\mathbf{9 r}, \mathbf{s})$.

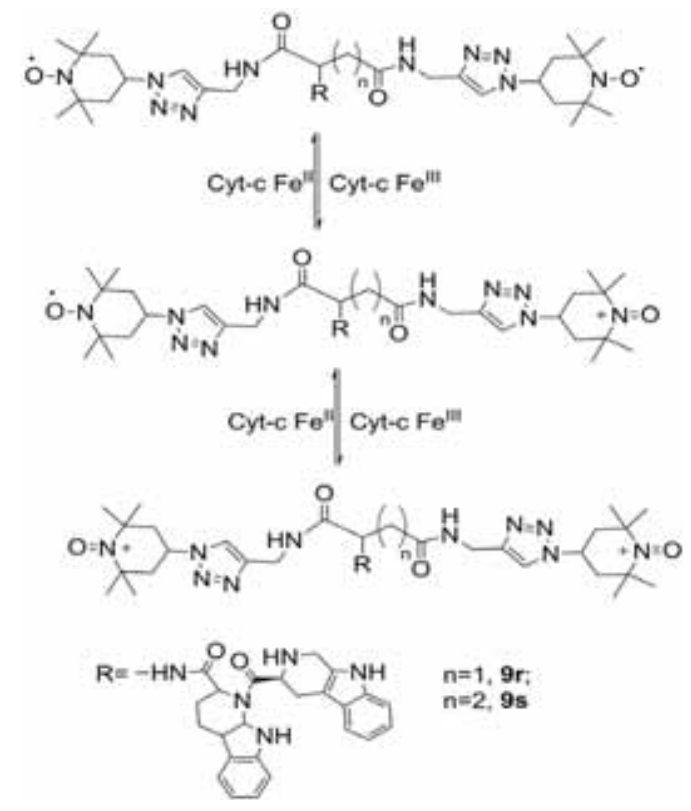

Fig. 8. The proposed mechanism of indole-bis-TEMPO conjugates 9r,s interaction with cytochrome c.

\section{Conclusion}

We have designed and synthesized a series of new dual-acting agents, indole-TEMPO conjugates (9a-s), which appear to exert the beneficial effects of both non-steroidal antiinflammatory drugs (NSAIDs) and general antioxidants. The conjugates were found to be efficient antioxidant antiinflammatory agents and some of them demonstrated much more potent anti-inflammatory activity than aspirin. It is evident that the anti-inflammatory activities of these dualacting agents in vivo was consistent with their anti-oxidant abilities. We propose that the protective effects of indoleTEMPO conjugates may be dependent upon three pharmacological properties: (i) the anti-inflammatory capacity of the indole moiety; (ii) the probable ability of the TEMPO moiety to scavenge and deactivate mitochondrial ROS; (iii) the capacity indole-TEMPO conjugates to maintain mitochondrial function. Taken together, our results suggest that the indoleTEMPO derivatives represent novel pharmacological tools with considerable therapeutic potential that minimizes the oxidative tissue damage associated with I/R injury.

\section{Limitation of study}

In this study, rats who were treated with indole-TEMPO received a bolus injection of indole-TEMPO 5 minutes prior to reperfusion and then received a continuous infusion of indoleTEMPO throughout the reperfusion period. In similar studies, therapeutic treatment was always administered before the ischemic period. Accordingly, our treatment strategy may be appropriate to patients who are at high risk of developing gastrointestinal complications. Patients undergoing abdominal aortic surgery and cardiac surgery may be particularly suited to consideration of this treatment option. Currently, we do not know whether indole-TEMPO conjugates are still protective when applied after reperfusion. Since oxidative stress and proinflammatory factors play important roles during intestine ischemia reperfusion, the multiple function of indole-TEMPO conjugates (antioxidant and anti-inflammatory activities and protection of mitochondrial function) should still be able to alleviate reperfusion injuries by administration even after the insult. In our study, a severe model of $\mathrm{I} / \mathrm{R}$ was applied to mimic the complications of acute mesenteric $\mathrm{I} / \mathrm{R}$ in the clinic. It is reasonable to predict an even better protection would be achieved at certain clinical indications (i.e. under less severe ischemic insults) with the continuous infusion of low doses of indole-TEMPO. Indeed, imparied mitochondria generate more ROS than normal mitochondria, and reduced antioxidant capacity has been reported in experimental animals ${ }^{35}$ and in clinical trials. ${ }^{36}$ Because of the clinical significance, reducing $\mathrm{I} / \mathrm{R}$ injury remains a challenging problem, particularly in the setting of unanticipated ischemia. Overall, the multi-functional roles of indole-TEMPO conjugates that lead to protection of mitochondrial function may contribute to mitigating the severity of I/R injury. 
Table 1. Anti-inflammatory activities of 9a-s against xylene-induced ear edema in mice

\begin{tabular}{|c|c|c|c|c|c|}
\hline Compd. & $\begin{array}{l}\text { Edema Weight } \\
(\mathrm{X} \pm \mathrm{SD} \mathrm{mg})\end{array}$ & $\begin{array}{l}\text { Inhibition } \\
(\%)\end{array}$ & Compd. & $\begin{array}{l}\text { Edema Weight } \\
(\mathrm{X} \pm \mathrm{SD} \mathrm{mg})\end{array}$ & Inhibition (\%) \\
\hline $\mathrm{CMC}$ & $4.07 \pm 0.51$ & & & & \\
\hline Aspirin & $2.15 \pm 0.35^{a}$ & 47.08 & $9 \mathbf{j}$ & $1.63 \pm 0.25^{a^{*}}$ & 59.95 \\
\hline $9 a$ & $2.65 \pm 0.39$ & 34.72 & 9k & $2.30 \pm 0.35^{a}$ & 43.49 \\
\hline $9 \mathrm{~b}$ & $2.73 \pm 0.26$ & 32.92 & 91 & $2.42 \pm 0.64$ & 40.54 \\
\hline $9 \mathrm{c}$ & $2.58 \pm 0.43$ & 36.60 & $9 m$ & $2.02 \pm 0.33^{a}$ & 50.39 \\
\hline 9d & $2.25 \pm 0.52^{a}$ & 44.71 & $9 n$ & $2.31 \pm 0.25^{a}$ & 43.24 \\
\hline $9 e$ & $2.16 \pm 0.44^{a}$ & 47.03 & 90 & $2.15 \pm 0.53^{a}$ & 47.17 \\
\hline 9f & $1.78 \pm 0.73^{a^{*}}$ & 56.26 & $9 p$ & $1.50 \pm 0.62^{a^{*}}$ & 63.14 \\
\hline $9 \mathrm{~g}$ & $2.09 \pm 0.57$ & 48.65 & $9 q$ & $2.13 \pm 0.43^{a}$ & 47.66 \\
\hline $9 \mathrm{~h}$ & $2.20 \pm 0.53$ & 45.94 & $9 \mathbf{r}$ & $0.95 \pm 0.24^{a^{*}}$ & 76.65 \\
\hline $9 \mathrm{i}$ & $1.75 \pm 0.39^{a^{*}}$ & 57.00 & 9s & $0.80 \pm 0.32^{a^{*}}$ & 80.34 \\
\hline
\end{tabular}

$\mathrm{N}=10$; oral dose of aspirin $=20 \mathrm{mg} / \mathrm{kg}$; oral dose of $\mathbf{9 a - s}=0.10 \mathrm{mmol} / \mathrm{kg} ;{ }^{a}$ : Compared to CMC, $\mathrm{p}<0.01$; ${ }^{*}$ Compared to Aspirin, $\mathrm{p}<0.01$.

Table 2. Effect of Indole-TEMPO Conjugates $(\mathbf{9 a}-\mathbf{s})$ on the Tail Bleeding time (X \pm SDs) of Mice

\begin{tabular}{|c|c|c|c|c|c|}
\hline & \multirow[t]{2}{*}{ Baseline } & \multicolumn{4}{|c|}{ Post-Drug Administration } \\
\hline & & 30min & $45 \mathrm{~min}$ & $60 \mathrm{~min}$ & $90 \mathrm{~min}$ \\
\hline NS & $118.4 \pm 8.9$ & $120.5 \pm 7.9$ & $119.8 \pm 8.4$ & $120.4 \pm 7.9$ & $119.3 \pm 7.7$ \\
\hline $9 \mathbf{a}$ & $113.5 \pm 7.9$ & $117.7 \pm 7.7$ & $114.5 \pm 6.3$ & $116.4 \pm 7.0$ & $115.8 \pm 8.3$ \\
\hline $9 b$ & $116.4 \pm 8.3$ & $119.6 \pm 9.0$ & $115.3 \pm 6.7$ & $117.7 \pm 8.9$ & $119.8 \pm 9.1$ \\
\hline $9 \mathrm{c}$ & $117.5 \pm 7.7$ & $116.4 \pm 6.0$ & $119.3 \pm 8.9$ & $120.4 \pm 9.6$ & $118.7 \pm 9.3$ \\
\hline 9d & $116.5 \pm 8.3$ & $119.7 \pm 9.3$ & $117.5 \pm 7.4$ & $116.1 \pm 7.6$ & $121.7 \pm 7.8$ \\
\hline $9 e$ & $119.2 \pm 7.9$ & $121.0 \pm 8.2$ & $120.7 \pm 9.2$ & $119.8 \pm 8.2$ & $119.1 \pm 8.2$ \\
\hline $9 f$ & $118.0 \pm 7.6$ & $119.7 \pm 7.3$ & $118.4 \pm 8.3$ & $119.5 \pm 7.1$ & $119.2 \pm 9.0$ \\
\hline $9 \mathrm{~g}$ & $119.1 \pm 8.5$ & $119.0 \pm 9.5$ & $120.5 \pm 9.7$ & $119.5 \pm 8.4$ & $118.0 \pm 8.9$ \\
\hline $9 \mathrm{~h}$ & $117.4 \pm 7.3$ & $119.4 \pm 7.8$ & $119.1 \pm 8.5$ & $117.6 \pm 7.2$ & $119.0 \pm 7.4$ \\
\hline $9 \mathbf{i}$ & $121.7 \pm 9.6$ & $121.4 \pm 8.1$ & $119.8 \pm 9.3$ & $120.5 \pm 6.6$ & $118.5 \pm 7.3$ \\
\hline 9j & $115.7 \pm 7.4$ & $117.2 \pm 7.6$ & $118.0 \pm 7.5$ & $117.5 \pm 8.3$ & $118.6 \pm 9.5$ \\
\hline 9k & $118.2 \pm 8.5$ & $119.3 \pm 7.4$ & $118.4 \pm 7.3$ & $119.6 \pm 7.1$ & $117.9 \pm 8.2$ \\
\hline 9l & $120.5 \pm 8.3$ & $121.1 \pm 8.3$ & $119.7 \pm 8.9$ & $122.5 \pm 9.3$ & $118.6 \pm 8.1$ \\
\hline $9 \mathrm{~m}$ & $119.5 \pm 7.9$ & $119.4 \pm 7.3$ & $120.3 \pm 7.5$ & $121.8 \pm 7.5$ & $117.3 \pm 9.1$ \\
\hline $9 n$ & $118.8 \pm 5.6$ & $119.9 \pm 8.5$ & $119.5 \pm 9.3$ & $121.4 \pm 7.7$ & $119.7 \pm 9.2$ \\
\hline 9o & $115.3 \pm 6.7$ & $116.9 \pm 7.2$ & $117.3 \pm 7.5$ & $118.5 \pm 9.7$ & $117.4 \pm 7.1$ \\
\hline $9 p$ & $118.5 \pm 8.4$ & $121.8 \pm 6.9$ & $120.2 \pm 8.9$ & $119.8 \pm 9.3$ & $119.7 \pm 8.9$ \\
\hline $9 q$ & $119.4 \pm 5.7$ & $117.4 \pm 6.8$ & $119.6 \pm 7.4$ & $120.6 \pm 7.4$ & $119.3 \pm 9.7$ \\
\hline $9 \mathbf{r}$ & $117.9 \pm 8.8$ & $116.3 \pm 8.3$ & $118.2 \pm 8.7$ & $119.3 \pm 7.4$ & $120.5 \pm 8.7$ \\
\hline $9 \mathrm{~s}$ & $117.4 \pm 7.6$ & $116.6 \pm 7.5$ & $117.1 \pm 8.0$ & $119.0 \pm 8.0$ & $118.3 \pm 7.5$ \\
\hline
\end{tabular}

$\mathrm{N}=10 ; \mathrm{NS}=$ Saline. 


\section{Experimental}

\subsection{Synthesis of Indole-TEMPO conjugates (9a-s)}

\subsubsection{General experimental methods}

All chemicals were purchased from Sigma Aldrich. Unless otherwise stated, all reactions were run under a nitrogen atmosphere (1 bar). The purity $(>97 \%)$ of the intermediates and the final products was confirmed using both TLC (Merck silica gel plates of type $60 \mathrm{~F} 254,0.25 \mathrm{~mm}$ layer thickness) and HPLC (Waters, C18 column $4.6 \mathrm{~mm} \times 150 \mathrm{~mm}$ ). NMR spectra were recorded on Bruker Advance 500 spectrometers. FAB-MS was determined with a VG-ZAB-MS high resolution GC/MS/DS and HP ES-5989x.

5.1.1.1. 3S-1,2,3,4-Tetrahydro- $\beta$-carboline-3-carboxylic acid (1): To a mixture of $5.0 \mathrm{~g}(24.5 \mathrm{mmol})$ of L-tryptophan, $25 \mathrm{~mL}$ of $\mathrm{H}_{2} \mathrm{SO}_{4}(1 \mathrm{~mol} / \mathrm{L}), 80 \mathrm{~mL}$ of water, and $8 \mathrm{~mL}$ of formaldehyde (36-38\%) were added. The reaction mixture was stirred at room temperature for $2 \mathrm{~h}$ and adjusted to $\mathrm{pH} 6-$ 7 with a concentrated ammonia solution. The mixture obtained was kept at $0{ }^{\circ} \mathrm{C}$ for $12 \mathrm{~h}$ and the precipitates were collected by filtration. Following recrystallization, $3.97 \mathrm{~g}$ $(75 \%)$ of the title compound was obtained as a colorless powder. Mp 280-282 ${ }^{\circ} \mathrm{C}$; EI/MS: $217[\mathrm{M}+\mathrm{H}]^{+}$; IR (KBr): 3450, 3200, 3000, 2950, 2850, 1700, 1601, 1452, 1070, $900 \mathrm{~cm}^{-1}$; ${ }^{1} \mathrm{H}$ NMR (BHSC-500, DMSO-d ${ }_{6}$ ): $\delta=10.99(\mathrm{~s}$, $1 \mathrm{H}), 9.89(\mathrm{~s}, 1 \mathrm{H}), 7.30(\mathrm{t}, \mathrm{J}=7.5 \mathrm{~Hz}, 1 \mathrm{H}), 7.22(\mathrm{t}, \mathrm{J}=8.0 \mathrm{~Hz}$, $1 \mathrm{H}), 7.01(\mathrm{~d}, \mathrm{~J}=8.0 \mathrm{~Hz}, 1 \mathrm{H}), 6.81(\mathrm{~d}, \mathrm{~J}=7.5 \mathrm{~Hz}, 1 \mathrm{H}), 4.01(\mathrm{t}$, $\mathrm{J}=4.8 \mathrm{~Hz}, 1 \mathrm{H}), 3.75(\mathrm{dd}, \mathrm{J}=10.5 \mathrm{~Hz}, \mathrm{~J}=5.0 \mathrm{~Hz}, 1 \mathrm{H}), 3.64$ $(\mathrm{dd}, \mathrm{J}=10.5 \mathrm{~Hz}, \mathrm{~J}=2.4 \mathrm{~Hz}, 1 \mathrm{H}), 2.91(\mathrm{~d}, \mathrm{~J}=10.5 \mathrm{~Hz}, 2 \mathrm{H})$, $2.86(\mathrm{~s}, 1 \mathrm{H})$.

\subsubsection{2. $\quad N$-Boc-3S-1,2,3,4-Tetrahydro- $\beta$-carboline-3-} carboxylic acid (2): A suspension of $1.1 \mathrm{~g}(5.0 \mathrm{mmol})$ of compound 1 in $15 \mathrm{~mL} \mathrm{DMF}$ and $1.4 \mathrm{~mL}$ of triethylamine was vigorously stirred at room temperature, with subsequent addition of $1.1 \mathrm{~g}(7.7 \mathrm{mmol})$ of Boc- $\mathrm{N}_{3}$ and stirring for an additional $30 \mathrm{~min}$. The reaction mixture was stirred at room temperature for $24 \mathrm{~h}$ and at $40{ }^{\circ} \mathrm{C}$ for $80 \mathrm{~h}$. To the reaction mixture, $5 \mathrm{~mL}$ of citrate solution $(20 \%)$ was added and the solution was extracted with ethyl acetate $(3 \times 30 \mathrm{~mL})$. The separated ethyl acetate layer was dried with anhydrous $\mathrm{MgSO}_{4}$. Following removal of $\mathrm{MgSO}_{4}$ by filtration, the filtrate was dried by evaporation. The residue obtained was crystallized in $\mathrm{CHCl}_{3}$ to yield $1.20 \mathrm{~g}(76 \%)$ of the title compound. Mp 165-170 ${ }^{\circ} \mathrm{C} ;{ }^{1} \mathrm{H}$ NMR $\left(500 \mathrm{MHz}, \mathrm{DMSO}-\mathrm{d}_{6}\right)$ : $\delta=10.87(\mathrm{~s}, 1 \mathrm{H}), 9.86(\mathrm{~s}, 1 \mathrm{H}), 7.32(\mathrm{t}, \mathrm{J}=7.6 \mathrm{~Hz}, 1 \mathrm{H}), 7.21$ $(\mathrm{t}, \mathrm{J}=7.9 \mathrm{~Hz}, 1 \mathrm{H}), 7.00 \quad(\mathrm{~d}, \mathrm{~J}=7.9 \mathrm{~Hz}, 1 \mathrm{H}), 6.84 \quad(\mathrm{t}$, $\mathrm{J}=7.6 \mathrm{~Hz}, 1 \mathrm{H}), \quad 4.84 \quad(\mathrm{t}, \quad \mathrm{J}=5.0 \mathrm{~Hz}, 1 \mathrm{H}), \quad 4.20 \quad(\mathrm{dd}$, $\mathrm{J}=10.2 \mathrm{~Hz}, \quad \mathrm{~J}=4.8 \mathrm{~Hz}, \quad 1 \mathrm{H}), \quad 3.98 \quad(\mathrm{dd}, \quad \mathrm{J}=10.2 \mathrm{~Hz}$, $\mathrm{J}=3.2 \mathrm{~Hz}, 1 \mathrm{H}), 2.93(\mathrm{~d}, \mathrm{~J}=10.2 \mathrm{~Hz}, 2 \mathrm{H}), 1.46$ (s, 9H).

5.1.1.3. (S)-Benzyl 2, 3, 4, 9-tetrahydro-1H-pyrido[3, 4-b] indole-3-carboxylate (3): To a stirring solution of $10.0 \mathrm{~g}$ polyphosphoric acid and $50 \mathrm{~mL}$ of benzyl alcohol, $0.02 \mathrm{~mol}$ of compound 1 was added. The reaction mixture was stirred at $92{ }^{\circ} \mathrm{C}$ for $8 \mathrm{~h}$ and then mixed with the solution of $20 \mathrm{ml}$ of concentrated sulfuric acid in $200 \mathrm{ml}$ of water. The mixture was treated with $20 \mathrm{ml}$ of ether, and the aqueous phase was separated and then neutralized with aqueous solution of sodium carbonate adjusted to $\mathrm{pH} 10$. The solution was extracted with ether $(3 \times 70 \mathrm{ml})$ and the ether phase was dried with anhydride magnesium sulfate. After filtration, the filtrate was bubbled with hydrogen chloride to precipitate the title compound 3 in $58 \%$ yield. Mp: $122-124^{\circ} \mathrm{C}$; $[\alpha]_{\mathrm{D}}{ }^{25}=53.4(\mathrm{c}=$ 1.0, methanol); ESI-MS (m/z): $307 \quad[\mathrm{M}+\mathrm{H}]^{+} ;{ }^{1} \mathrm{H} \quad \mathrm{NMR}$ $\left(500 \mathrm{MHz}, \mathrm{DMSO}-d_{6}\right): \delta / \mathrm{ppm}=7.27-7.40(\mathrm{~m}, 7 \mathrm{H}), 6.95(\mathrm{t}, \mathrm{J}=$ $7.5 \mathrm{~Hz}, 1 \mathrm{H}), 7.02(\mathrm{t}, \mathrm{J}=10 \mathrm{~Hz}, 1 \mathrm{H}), 5.19(\mathrm{~s}, 2 \mathrm{H}), 3.98(\mathrm{q}, \mathrm{J}=$ $15.5 \mathrm{~Hz}, 2 \mathrm{H}), 3.82(\mathrm{q}, \mathrm{J}=4.5 \mathrm{~Hz}, \mathrm{~J}=8.5 \mathrm{~Hz}, 1 \mathrm{H}), 2.97(\mathrm{dd}, \mathrm{J}=$ $4.5 \mathrm{~Hz}, \mathrm{~J}=15 \mathrm{~Hz}, 1 \mathrm{H}), 2.82(\mathrm{q}, \mathrm{J}=8.5 \mathrm{~Hz}, \mathrm{~J}=15 \mathrm{~Hz}) .{ }^{13} \mathrm{C}$ NMR $\left(\right.$ DMSO- $\left.d_{6}\right) \delta / p p m=173.21,136.57,136.23,133.46$, $128.90,128.71,128.46,128.21,127.30,120.97,118.79$, $117.73,111.33,105.83,66.15,55.63,41.70,25.26$.

5.1.1.4. tert-Butyl 3-(3-((benzyloxy)carbonyl)-2, 3, 4, 9tetrahydro-1H-pyrido [3, 4-b]indole-2-carbonyl)-3, 4-dihydro1H-pyrido[3, 4-b]indole-2(9H)-carboxylate (4): Mp: 230$232^{\circ} \mathrm{C} ;[\alpha]_{\mathrm{D}}^{25}=41.9(\mathrm{c}=1.0$, methanol); ESI-MS $(\mathrm{m} / \mathrm{z}): 606$ $[\mathrm{M}+\mathrm{H}]^{+} ;{ }^{1} \mathrm{H}$ NMR $\left(500 \mathrm{MHz}, \mathrm{DMSO}-d_{6}\right): \delta / \mathrm{ppm}=10.82-$ $10.97(\mathrm{~m}, \mathrm{~J}=27.5 \mathrm{~Hz}, \mathrm{~J}=49.5 \mathrm{~Hz}, 2 \mathrm{H}), 6.93-7.52(\mathrm{~m}, 13 \mathrm{H})$, $5.76(\mathrm{~m}, 1 \mathrm{H}), 5.61(\mathrm{~m}, 1 \mathrm{H}), 5.08-5.31(\mathrm{~m}, 2 \mathrm{H}), 4.49-5.08(\mathrm{~m}$, 4H), 3.41-3.57 (m, 2H), 2.95-3.18 (m, 2H), $1.46(\mathrm{~s}, 1 \mathrm{H}) .{ }^{13} \mathrm{C}$ NMR $\left(\right.$ DMSO- $\left.d_{6}\right) \delta / p p m=172.56,170.89,155.57,136.92$, $130.92,129.65,128.67,127.63,126.91,121.74,119.24$, $118.90,117.95,111.40,80.58,66.75,65.41,55.25,52.17$, 41.71, 28.48, 24.58, 22.03.

5.1.1.5. 2-(2-(tert-Butoxycarbonyl)-2, 3, 4, 9-tetrahydro-1Hpyrido[3,4-b]indole-3-carbonyl)-2, 3, 4, 9-tetrahydro- $1 \mathrm{H}$ pyrido[3,4-b]indole-3-carboxylic acid (5): $\mathrm{Mp}: 245-248^{\circ} \mathrm{C}$; $[\alpha]_{\mathrm{D}}^{25}=19.9(\mathrm{c}=1.0$, methanol $)$; ESI-MS (m/z): $513[\mathrm{M}-\mathrm{H}]^{-}$

\subsubsection{General procedure for preparation of $6 a-s$}

To a stirring solution of compound $5(514 \mathrm{mg}, 1.0 \mathrm{mmol})$ in anhydrous THF at $0^{\circ} \mathrm{C}$ was added $1.2 \mathrm{mmol}$ of $\mathrm{N}$ Hydroxybenzotriazole (HOBT) and $1.2 \mathrm{mmol}$ of N,N'dicyclo-hexylcarbodiimide (DCC). After stirring for $10 \mathrm{~min}$, a suspension of $1.2 \mathrm{mmol}$ of amino acid benzylester hydrochloride in $5 \mathrm{~mL}$ of anhydrous THF was added. The reaction mixture was adjusted with $\mathrm{N}$-methyl morpholine to $\mathrm{pH} 8-9$ and then stirred at room temperature overnight until TLC indicated that the starting material had been completely consumed. After evaporation, the residue was dissolved in 40 $\mathrm{mL}$ of ethyl acetate. The solution was washed extensively with 5\% sodium bicarbonate, $5 \% \quad \mathrm{KHSO}_{4}$, and saturated sodium chloride. The organic layers were separated and dried over anhydrous $\mathrm{Na}_{2} \mathrm{SO}_{4}$. Following filtration and evaporation under reduced pressure, the crude residue was purified by flash column chromatography on silica gel to yield compounds 6a-s.

5.1.2.1. (S)-tert-Butyl 3-((S)-3-((2-(benzyloxy)-2-oxo-ethyl) carbamoyl)-2, 3, 4, 9-tetrahydro-1H-pyrido[3, 4-b] indole-2carbonyl)-3, 4-dihydro-1H-pyrido [3, 4-b]indole-2(9H)carboxylate (6a): Yield: $43 \%$. Mp: $145-148^{\circ} \mathrm{C} ;[\alpha]_{\mathrm{D}}{ }^{25}=12.6$ (c=1.0, methanol); ESI-MS (m/z): $663[\mathrm{M}+\mathrm{H}]^{+} .{ }^{1} \mathrm{H}$ NMR $\left(500 \mathrm{MHz}, \mathrm{DMSO}-d_{6}\right): \delta / \mathrm{ppm}=10.84-10.91(\mathrm{~m}, 2 \mathrm{H}) ; 8.56$ 
$(\mathrm{m}, 1 \mathrm{H}), 7.18-7.43(\mathrm{~m}, 9 \mathrm{H}), 6.93-7.09(\mathrm{~m}, 4 \mathrm{H})$, 5.18-5.69 (m, $2 \mathrm{H}), 4.61-5.18(\mathrm{~m}, 5 \mathrm{H}), 4.45(\mathrm{~m}, 1 \mathrm{H}), 3.65-4.11(\mathrm{~m}, 2 \mathrm{H})$, 2.81-3.51 (m, 4H), $1.46(\mathrm{~s}, 9 \mathrm{H}) .{ }^{13} \mathrm{C}$ NMR (DMSO- $\left.d_{6}\right) \delta / \mathrm{ppm}$ $=171.95,170.97,169.84,157.20,155.22,136.84,131.13$, $129.37,128.82,127.05,126.98,121.40,118.98,118.03$, $111.59,105.49,80.63,66.30,56.32,51.24,41.36,38.87$, $33.96,28.35,22.99,20.08$.

\subsubsection{2. (S)-tert-Butyl 3-((S)-3-(( R)-1-(benzyloxy)-1-} oxopropan-2-yl) carbamoyl)-2, 3, 4, 9-tetrahydro-1Hpyrido[3, 4-b]indole-2-carbonyl)-3, 4-dihydro-1H-pyrido[3, 4-b] indole-2(9H)-carboxylate (6b): Yield: 51\%. Mp: 146$148^{\circ} \mathrm{C} ;[\alpha]_{\mathrm{D}}{ }^{25}=-29.4(\mathrm{c}=1.0$, methanol); ESI-MS (m/z) 676 $[\mathrm{M}+\mathrm{H}]^{+} ;{ }^{1} \mathrm{H}$ NMR $\left(500 \mathrm{MHz}, \mathrm{DMSO}-d_{6}\right): \delta / \mathrm{ppm}=10.81-$ $10.88(\mathrm{~m}, 2 \mathrm{H})$; $8.42(\mathrm{~m}, 1 \mathrm{H}), 7.18-7.43(\mathrm{~m}, 9 \mathrm{H}), 6.89-7.09$ $(\mathrm{m}, 4 \mathrm{H}), 5.64(\mathrm{~m}, 1 \mathrm{H}), 5.35(\mathrm{~m}, 1 \mathrm{H}), 5.07(\mathrm{~m}, 1 \mathrm{H}), 4.81-4.99$ $(\mathrm{m}, 3 \mathrm{H}), 4.45-4.79(\mathrm{~m}, 3 \mathrm{H}), 4.26(\mathrm{~m}, 1 \mathrm{H}), 3.12-3.45(\mathrm{~m}, 3 \mathrm{H})$, 2.89-3.10 (m, 1H), 1.47 (s, 9H), 1.30-1.37 (m, 3H). ${ }^{13} \mathrm{C} \mathrm{NMR}$ $\left(\mathrm{DMSO}-d_{6}\right) \delta / \mathrm{ppm}=172.55,171.96,170.96,170.16,155.32$, $136.77,131.56,128.74,128.40,128.09,126.91,121.23$, $118.88,117.98,111.40,105.02,80.54,66.19,54.24,50.67$, 48.46, 48.04, 41.49, 28.47, 24.94, 24.01, 17.40 .

5.1.2.3. (S)-tert-Butyl 3-((S)-3-(((R)-1-(benzyloxy)-3-methyl1-oxobutan-2-yl) carbamoyl)-2, 3, 4, 9-tetrahydro-1Hpyrido[3, 4-b]indole-2-carbonyl)-3, 4-dihydro-1H-pyrido[3, 4-b] indole-2(9H)-carboxylate (6c): Yield: 55\%. Mp: 125$127^{\circ} \mathrm{C} ;[\alpha]_{\mathrm{D}}{ }^{25}=-18.0(\mathrm{c}=1.0$, methanol); ESI-MS (m/z) 704 $[\mathrm{M}+\mathrm{H}]^{+} ;{ }^{1} \mathrm{H}$ NMR $\left(500 \mathrm{MHz}\right.$, DMSO- $\left.d_{6}\right): \delta / \mathrm{ppm}=10.81-$ $10.88(\mathrm{~m}, 2 \mathrm{H}) ; 8.22(\mathrm{~m}, 1 \mathrm{H}), 7.18-7.43(\mathrm{~m}, 9 \mathrm{H}), 6.93-7.08$ $(\mathrm{m}, 4 \mathrm{H}), 5.65(\mathrm{~m}, 1 \mathrm{H}), 5.36(\mathrm{~m}, 1 \mathrm{H}), 4.31-5.29(\mathrm{~m}, 6 \mathrm{H}), 4.15$ $(\mathrm{m}, 1 \mathrm{H}), 2.81-3.50(\mathrm{~m}, 5 \mathrm{H}), 1.47(\mathrm{~s}, 9 \mathrm{H}), 0.83-0.92(\mathrm{~m}, 6 \mathrm{H})$. ${ }^{13} \mathrm{C}$ NMR $\left(\mathrm{DMSO}-d_{6}\right) \delta / \mathrm{ppm}=172.64,172.07,170.93$, $156.05,155.25,136.82,130.59,129.26,128.79,127.19$, 126.97, 121.21, 118.87, 117.96, 111.57, 105.25, 80.61, 66.58, $54.60,52.49,52.26,41.73,35.51,28.44,23.71,22.99,14.40$.

5.1.2.4. (S)-tert-Butyl 3-((S)-3-(((2R, 3R)-1-(benzyloxy)-3methyl-1-oxopentan-2-yl) carbamoyl)-2, 3, 4, 9-tetrahydro1H-pyrido[3, 4-b]indole-2-carbonyl)-3, 4-di hydro- $1 \mathrm{H}$ pyrido[3,4-b]indole-2(9H)-carboxylate (6d): Mp: 133.7$135^{\circ} \mathrm{C} ;[\alpha]_{\mathrm{D}}{ }^{25}=-23.0(\mathrm{c}=1.0$, methanol); ESI-MS $(\mathrm{m} / \mathrm{z}): 718$ $[\mathrm{M}+\mathrm{H}]+.{ }^{1} \mathrm{H}$ NMR $\left(500 \mathrm{MHz}, \mathrm{DMSO}-d_{6}\right): \delta / \mathrm{ppm}=10.82-$ $10.91(\mathrm{~m}, 2 \mathrm{H}), 8.29(\mathrm{~m}, 1 \mathrm{H}), 7.18-7.43(\mathrm{~m}, 9 \mathrm{H}), 7.79-7.80(\mathrm{~m}$, $4 \mathrm{H}), 5.68(\mathrm{~m}, 1 \mathrm{H}), 5.42(\mathrm{~m}, 1 \mathrm{H}), 4.98-5.21(\mathrm{~m}, 2 \mathrm{H}), 4.51-4.98$ $(\mathrm{m}, 4 \mathrm{H}), 4.25(\mathrm{~m}, 1 \mathrm{H}), 2.93-3.18(\mathrm{~m}, 5 \mathrm{H}), 1.47$ (s, 9H), 1.19$1.31(\mathrm{~m}, 2 \mathrm{H}), 0.81-0.86(\mathrm{~m}, 3 \mathrm{H}), 0.63-0.67(\mathrm{~m}, 3 \mathrm{H}) .{ }^{13} \mathrm{C} \mathrm{NMR}$ $\left(\mathrm{DMSO}-d_{6}\right) \delta / \mathrm{ppm}=172.51,171.44,170.68,155.87,155.38$, $136.79,130.71,128.77,128.52,128.42,126.92,121.32$, $121.21,118.86,117.94,111.38,80.46,68.98,66.35,66.15$, $53.71,36.86,36.58,33.82,28.46,25.81,24.48,23.95,15.82$.

5.1.2.5. (S)-tert-Butyl 3-((S)-3-(((R)-1-(benzyloxy)-4-methyl1-oxopentan-2-yl) carbamoyl)-2, 3, 4, 9-tetrahydro-1H-pyrido [3, 4-b]indole-2-carbonyl)-3, 4-dihydro-1H-pyrido[3, 4-b] indole-2(9H)-carboxylate $(\boldsymbol{6} \boldsymbol{e}): \mathrm{Mp}: 138-140^{\circ} \mathrm{C} ;[\alpha]_{\mathrm{D}}{ }^{25}=-$ 26.1 (c=1.0, methanol); ESI-MS (m/z) $718[\mathrm{M}+\mathrm{H}]^{+} ;{ }^{1} \mathrm{H}$ NMR $\left(500 \mathrm{MHz}, \mathrm{DMSO}-d_{6}\right): \delta / \mathrm{ppm}=10.81-10.88(\mathrm{~m}, 2 \mathrm{H}) ; 8.32(\mathrm{~m}$, $1 \mathrm{H}), 7.15-7.44(\mathrm{~m}, 9 \mathrm{H}), 6.93-7.09(\mathrm{~m}, 4 \mathrm{H}), 5.64(\mathrm{~m}, 1 \mathrm{H}), 5.35$ $(\mathrm{m}, 1 \mathrm{H}), 4.39-5.15(\mathrm{~m}, 6 \mathrm{H}), 4.21(\mathrm{~m}, 1 \mathrm{H}), 2.85-3.49(\mathrm{~m}, 4 \mathrm{H})$, $1.51-1.79(\mathrm{~m}, 3 \mathrm{H}), 1.49(\mathrm{~s}, 9 \mathrm{H}), 0.63-0.88(\mathrm{~m}, 6 \mathrm{H}) .{ }^{13} \mathrm{C} \mathrm{NMR}$
$\left(\mathrm{DMSO}-d_{6}\right) \delta / \mathrm{ppm}=173.00,172.42,171.51,156.00,155.33$, $136.76,130.52,128.77,128.47,128.25,126.91,121.21$, $118.86,117.97,111.54,105.18,80.54,66.36,65.40,54.06$, 50.93, 41.91, 41.39, 28.45, 25.36, 24.54, 23.70, 22.21.

5.1.2.6. (S)-tert-Butyl 3-((S)-3-(((R)-4-amino-1-(benzyloxy)1,4-dioxobutan-2-yl)carbamoyl)-2, 3, 4, 9-tetrahydro-1Hpyrido[3, 4-b]indole-2-carbonyl)-3,4-dihydro-1H-pyrido[3,4b]indole-2(9H)-carboxylate $(6 \mathrm{f}): \mathrm{Mp}: 162-164^{\circ} \mathrm{C} ;[\alpha]_{\mathrm{D}}{ }^{25}=-$ 2.5 (c=1.0, methanol); ESI-MS (m/) $719[\mathrm{M}+\mathrm{H}]^{+} ;{ }^{1} \mathrm{H}$ NMR $\left(500 \mathrm{MHz}, \mathrm{DMSO}-d_{6}\right): \delta / \mathrm{ppm}=10.82-10.90(\mathrm{~m}, 2 \mathrm{H}) ; 8.32(\mathrm{~m}$, 1H), 7.18-7.50 (m, 9H), 6.89-7.10 (m, 4H), 5.65 (m, 1H), 5.44 (m, 1H), 4.41-5.23 (m, 7H), 2.90-3.50 (m, 6H), 1.47 (s, 9H). ${ }^{13} \mathrm{C}$ NMR (DMSO- $\left.d_{6}\right) \delta / \mathrm{ppm}=206.95,172.34,171.60$, $171.28,170.47,155.33,136.75,131.15,129.94,128.70$, $127.96,126.92,121.21,118.87,117.94,111.37,105.32$, $80.55,66.27,56.51,53.75,49.37,41.54,39.15,36.75,28.33$, $23.70,23.01$.

5.1.2.7. (S)-tert-Butyl 3-((S)-3-(((R)-1-(benzyloxy)-3-(1Himidazol-4-yl)-1-oxopropan-2-yl) carbamoyl)-2, 3, 4, 9tetrahydro-1H-pyrido[3, 4-b]indole-2-carbonyl)-3, 4-dihydro1H-pyrido[3, 4-b]indole-2(9H)-carboxylate (6g): $\mathrm{Mp}$ : 180$182^{\circ} \mathrm{C} ;[\alpha]_{\mathrm{D}}{ }^{25}=-8.0(\mathrm{c}=1.0$, methanol); ESI-MS (m/) 742 $[\mathrm{M}+\mathrm{H}]^{+} ;{ }^{1} \mathrm{H}$ NMR $\left(500 \mathrm{MHz}, \mathrm{DMSO}-d_{6}\right): \delta / \mathrm{ppm}=10.84-$ $10.82(\mathrm{~m}, \mathrm{~J}=5 \mathrm{~Hz}, 2 \mathrm{H}) ; 8.58(\mathrm{~m}, \mathrm{~J}=7 \mathrm{~Hz}, 1 \mathrm{H}), 7.96(\mathrm{~s}, 1 \mathrm{H})$, 7.18-7.42 (m, 9H), 6.89-7.11 (m, 5H), $5.65(\mathrm{~m}, \mathrm{~J}=1.5 \mathrm{~Hz}, 1 \mathrm{H})$, $5.34(\mathrm{~m}, \mathrm{~J}=16.6 \mathrm{~Hz}, 1 \mathrm{H}), 4.68-5.12(\mathrm{~m}, 5 \mathrm{H}), 4.31-4.52(\mathrm{~m}$, $2 \mathrm{H}), 2.89-3.48(\mathrm{~m}, 6 \mathrm{H}), 1.48(\mathrm{~s}, 9 \mathrm{H}) .{ }^{13} \mathrm{C}$ NMR (DMSO- $\left.d_{6}\right)$ $\delta / \mathrm{ppm}=172.24,171.06,170.60,163.42,155.26,136.77$, $135.01,132.52,131.16,129.91,128.73,128.32,126.91$, $125.99,121.21,118.87,117.95,116.88,114.41,105.37$, $80.59,66.33,65.36,54.53,52.91,51.24,41.43,32.78,28.47$, $23.68,22.86$.

5.1.2.8. (S)-tert-Butyl 3-((S)-3-(((R)-1-(benzyloxy)-1-oxo-3phenyl-propan-2-yl) carbamoyl)-2,3,4,9-tetrahydro-1Hpyrido[3,4-b]indole-2-carbonyl)-3,4-dihydro-1H-pyrido [3,4b]indole-2(9H)-carboxylate $(\boldsymbol{6} \boldsymbol{h}): \mathrm{Mp}: 133-135^{\circ} \mathrm{C} ;[\alpha]_{\mathrm{D}}{ }^{25}=-$ 23.0 (c=1.0, methanol); ESI-MS (m/z) $752[\mathrm{M}+\mathrm{H}]^{+} ;{ }^{1} \mathrm{H}$ NMR $\left(500 \mathrm{MHz}, \mathrm{DMSO}-d_{6}\right): \delta / \mathrm{ppm}=10.76-10.90(\mathrm{~m}, 2 \mathrm{H}) ; 8.35(\mathrm{~m}$, $1 \mathrm{H}), 7.18-7.42(\mathrm{~m}, 14 \mathrm{H}), 6.89-7.11(\mathrm{~m}, 4 \mathrm{H}), 5.63(\mathrm{~m}, 1 \mathrm{H})$, $5.35(\mathrm{~m}, 1 \mathrm{H}), 4.68-5.19(\mathrm{~m}, 5 \mathrm{H}), 4.21-4.65(\mathrm{~m}, 1 \mathrm{H}), 2.85-3.49$ $(\mathrm{m}, 6 \mathrm{H}), 1.41(\mathrm{~m}, 9 \mathrm{H}) .{ }^{13} \mathrm{C} \mathrm{NMR}\left(\mathrm{DMSO}-d_{6}\right) \delta / \mathrm{ppm}=171.45$, $171.29,170.85,155.27,137.59,136.51,136.09,131.01$, $129.97,129.46,128.71,128.28,126.89,121.21,118.87$, 117.97, 111.39, 104.30, 80.53, 66.32, 54.42, 51.01, 37.03, $36.58,28.49,23.58,22.99$.

5.1.2.9. (S)-tert-Butyl 3-((S)-3-(((R)-1-(benzyloxy)-6(((benzyloxy)-carbonyl)amino)-1-oxohexan-2-yl) carbamoyl)2, 3, 4, 9-tetrahydro-1H-pyrido[3, 4-b]indole-2-carbonyl)-3, 4-dihydro-1H-pyrido[3, 4-b]indole-2(9H)-carboxylate (6i): Mp: $116-118^{\circ} \mathrm{C} ;[\alpha]_{\mathrm{D}}^{25}=-20.4(\mathrm{c}=1.0$, methanol); ESI-MS $(\mathrm{m} / \mathrm{z}) 867[\mathrm{M}+\mathrm{H}]^{+} ;{ }^{1} \mathrm{H}$ NMR $\left(500 \mathrm{MHz}, \mathrm{DMSO}-d_{6}\right): \delta / \mathrm{ppm}=$ $10.82-10.89(\mathrm{~m}, \mathrm{~J}=10 \mathrm{~Hz}, 2 \mathrm{H}) ; 8.25-8.45(\mathrm{~m}, 2 \mathrm{H}), 7.18-7.43$ $(\mathrm{m}, 14 \mathrm{H}), 6.90-7.14(\mathrm{~m}, 4 \mathrm{H}), 5.64(\mathrm{~m}, 1 \mathrm{H}), 5.34(\mathrm{~m}, 1 \mathrm{H})$, 4.51-5.19 (m, 8H), $4.29(\mathrm{~m}, 1 \mathrm{H}), 2.89-3.55(\mathrm{~m}, 6 \mathrm{H}), 1.56-2.11$ $(\mathrm{m}, 4 \mathrm{H}), 1.46$ (s, 9H), 1.09-1.11 (m, 2H). ${ }^{13} \mathrm{C}$ NMR (DMSO$\left.d_{6}\right) \delta / \mathrm{ppm}=172.84,172.03,171.23,169.90,156.52,155.97$, $141.64,133.79,130.12,128.98,128.78,128.16,126.92$, 
121.21, 118.88, 117.94, 111.39, 105.11, 80.54, 67.61, 66.31, $65.58,57.81,54.06,53.51,52.98,50.77,32.17,30.76,28.48$, $25.43,23.77,21.95$.

5.1.2.10. (S)-tert-Butyl 3-((S)-3-(((R)-1-(benzyloxy)-3-(4hydroxy-phenyl)-1-oxopropan-2-yl) carbamoyl)-2, 3, 4, 9tetrahydro-1H-pyrido[3, 4-b]indole-2-carbonyl)-3, 4-dihydro1H-pyrido[3,4-b]indole-2(9H)-carboxylate (6j): Mp: 157$159^{\circ} \mathrm{C} ;[\alpha]_{\mathrm{D}}{ }^{25}=-17.2(\mathrm{c}=1.0$, methanol); ESI-MS $(\mathrm{m} / \mathrm{z}) 768$ $[\mathrm{M}+\mathrm{H}]^{+} ;{ }^{1} \mathrm{H}$ NMR $\left(500 \mathrm{MHz}\right.$, DMSO- $\left.d_{6}\right): \delta / \mathrm{ppm}=10.80-$ $10.91(\mathrm{~m}, 2 \mathrm{H}) ; 9.33(\mathrm{~s}, 1 \mathrm{H}), 8.55(\mathrm{~m}, 1 \mathrm{H}), 7.18-7.42(\mathrm{~m}, 9 \mathrm{H})$, 6.45-7.10 (m, 8H), $5.64(\mathrm{~m}, 1 \mathrm{H}), 5.38(\mathrm{~m}, 1 \mathrm{H}), 4.66-5.15(\mathrm{~m}$, $6 \mathrm{H}), 4.47$ (m, 1H), 3.55-3.98 (m, 2H), 2.89-3.45 (m, 4H), 1.46 $(\mathrm{s}, 9 \mathrm{H}) .{ }^{13} \mathrm{C}$ NMR (DMSO- $\left.d_{6}\right) \delta / \mathrm{ppm}=171.56,171.44$, $170.93,156.50,155.29,136.78,136.53,131.18,130.43$, $130.02,129.62,129.35,128.69,128.39,127.33,122.33$, $121.222,120.66,118.89,117.95,111.58,104.33,80.53$, $66.34,66.20,54.94,50.71,42.02,38.86,36.42,28.54,23.65$, 22.55 .

5.1.2.11. (S)-tert-Butyl 3-((S)-3-(( R)-1-(benzyloxy)-4(methylthio)-1-oxobutan-2-yl) carbamoyl)-2, 3, 4, 9tetrahydro-1H-pyrido[3, 4-b]indole-2-carbonyl)-3, 4-dihydro1H-pyrido[3, 4-b]indole-2(9H)-carboxylate (6k): Mp: 131$133^{\circ} \mathrm{C} ;[\alpha]_{\mathrm{D}}{ }^{25}=-16.5(\mathrm{c}=1.0$, methanol); ESI-MS $(\mathrm{m} / \mathrm{z}) 736$ $[\mathrm{M}+\mathrm{H}]^{+} ;{ }^{1} \mathrm{H}$ NMR $\left(500 \mathrm{MHz}\right.$, DMSO- $\left.d_{6}\right): \delta / \mathrm{ppm}=10.80-$ $10.88(\mathrm{~m}, \mathrm{~J}=24.5 \mathrm{~Hz}, 2 \mathrm{H}) ; 8.23(\mathrm{~m}, \mathrm{~J}=8.0 \mathrm{~Hz}, 1 \mathrm{H}), 7.16-7.47$ $(\mathrm{m}, 9 \mathrm{H}), 6.89-7.08(\mathrm{~m}, 4 \mathrm{H}), 5.23-5.83(\mathrm{~m}, \mathrm{~J}=6.5 \mathrm{~Hz}, 1 \mathrm{H})$, 4.91-5.13 (m, J= 12Hz, J=12.5Hz, 3H), 4.63-4.9 (m, 2H), 4.27-4.62 (m, 2H), 2.89-3.61 (m, 4H), 1.98-2.49 (m, 4H), 1.61-1.94 (m, 3H), $1.42(\mathrm{~s}, 9 \mathrm{H}) .{ }^{13} \mathrm{C}$ NMR (DMSO- $\left.d_{6}\right) \delta / \mathrm{ppm}$ $=172.69,171.87,170.82,156.44,155.94,136.81,130.14$, $129.36,128.85,128.48,126.93,121.36,118.88,117.97$, $111.58,105.32,80.86,66.49,56.33,55.01,54.10,51.68$, 41.89, 30.97, 29.96, 28.50, 23.84, 22.94, 14.94.

5.1.2.12. (S)-tert-Butyl 3-((S)-3-(((R)-1,3-bis (benzyloxy)-1oxopropan-2-yl)carbamoyl)-2, 3, 4, 9-tetrahydro-1Hpyrido[3, 4-b]indole-2-carbonyl)-3, 4-dihydro-1H-pyrido[3, 4-b] indole-2(9H)-carboxylate (6l): Mp: $120-122^{\circ} \mathrm{C} ;[\alpha]_{\mathrm{D}}{ }^{25}=$ -15.4 (c=1.0, methanol); ESI-MS (m/z) $782[\mathrm{M}+\mathrm{H}]^{+} ;{ }^{1} \mathrm{H}$ NMR $\left(500 \mathrm{MHz}, \mathrm{DMSO}-d_{6}\right): \delta / \mathrm{ppm}=10.82-10.91(\mathrm{~m}, \mathrm{~J}=16 \mathrm{~Hz}$, $2 \mathrm{H}) ; 8.52(\mathrm{~m}, \mathrm{~J}=8.0 \mathrm{~Hz}, 1 \mathrm{H}), 7.15-7.43(\mathrm{~m}, 14 \mathrm{H}), 6.97-7.09$ $(\mathrm{m}, 4 \mathrm{H}), 5.68(\mathrm{~m}, \mathrm{~J}=6.5 \mathrm{~Hz}, 1 \mathrm{H}), 5.37(\mathrm{~m}, \mathrm{~J}=4.5 \mathrm{~Hz}, 1 \mathrm{H})$, 4.26-5.09 (m, 9H), 3.51-3.90 (m, 4.5 Hz, 2H), 2.95-3.45 (m, $\mathrm{J}=6.5 \mathrm{~Hz}, \mathrm{~J}=15.5 \mathrm{~Hz}, 4 \mathrm{H}), 1.45(\mathrm{~s}, 9 \mathrm{H}) .{ }^{13} \mathrm{C}$ NMR (DMSO- $\left.d_{6}\right)$ $\delta / \mathrm{ppm}=173.02,172.38,171.16,170.74,155.75,138.22$, $136.79,130.78,129.17,128.72,128.64,128.17,128.09$, $127.96,126.93,121.35,118.90,117.94,111.59,105.01$, $80.46,72.84,69.79,69.47,66.56,66.42,53.74,41.92,41.92$, $28.49,24.56,22.31$.

5.1.2.13. (S)-tert-Butyl 3-((S)-3-(((R)-1-(benzyloxy)-3-(1Hindol-3-yl)-1-oxopropan-2-yl) carbamoyl)-2, 3, 4, 9tetrahydro-1H-pyrido[3, 4-b]indole-2-carbonyl)-3, 4-dihydro$1 H$-pyrido [3, 4-b]indole-2(9H)-carboxylate (6m). Mp: 155$156^{\circ} \mathrm{C} ;[\alpha]_{\mathrm{D}}^{25}=-17.8(\mathrm{c}=1.0$, methanol); ESI-MS (m/) 791 $[\mathrm{M}+\mathrm{H}]^{+} ;{ }^{1} \mathrm{H}$ NMR $\left(500 \mathrm{MHz}\right.$, DMSO- $\left.d_{6}\right): \delta / \mathrm{ppm}=10.78-$ $10.90(\mathrm{~m}, \mathrm{~J}=24.5 \mathrm{~Hz}, 3 \mathrm{H}) ; 8.56(\mathrm{~m}, 1 \mathrm{H}), 7.19-7.52(\mathrm{~m}, 9 \mathrm{H})$, 6.90-7.09 (m, 9H), $5.64(\mathrm{~m}, 1 \mathrm{H}), 5.36(\mathrm{~m}, 1 \mathrm{H}), 4.51-5.20(\mathrm{~m}$, $6 \mathrm{H}), 4.32(\mathrm{~m}, 1 \mathrm{H}), 2.90-3.45(\mathrm{~m}, 6 \mathrm{H}), 1.41(\mathrm{~s}, 9 \mathrm{H}) .{ }^{13} \mathrm{C} \mathrm{NMR}$
$\left(\mathrm{DMSO}-d_{6}\right) \delta / \mathrm{ppm}=171.86,171.06,170.01,155.27,136.53$, $136.07,130.40,128.66,128.27,128.06,127.51,126.90$, $124.17,121.50,118.91,118.42,111.59,105.20,80.53,66.32$, 60.21, 56.33, 54.16, 50.93, 42.01, 38.86, 28.57, 23.73, 22.44.

5.1.2.14. (S)-tert-Butyl 3-((S)-3-((R)-2-((benzyloxy) carbonyl)pyrrolidine-1-carbonyl)-2, 3, 4, 9-tetrahydro-1Hpyrido[3, 4-b]indole-2-carbonyl)-3, 4-dihydro-1H-pyrido[3, 4-b]indole-2 (9H)-carboxylate (6n): Mp: $150-152^{\circ} \mathrm{C} ;[\alpha]_{\mathrm{D}}{ }^{25}=$ -2.7 (c=1.0, methanol); ESI-MS (m/z) $702[\mathrm{M}+\mathrm{H}]^{+} ;{ }^{1} \mathrm{H}$ NMR $\left(500 \mathrm{MHz}, \mathrm{DMSO}-d_{6}\right): \delta / \mathrm{ppm}=10.73-10.92(\mathrm{~m}, \mathrm{~J}=27.5 \mathrm{~Hz}$, $2 \mathrm{H}) ; 7.48(\mathrm{~m}, \mathrm{~J}=8 \mathrm{~Hz}, 3 \mathrm{H}), 7.41(\mathrm{~m}, \mathrm{~J}=7.5 \mathrm{~Hz}, 1 \mathrm{H}), 7.19-7.37$ (m, 7H), 6.98-7.09 (m, 4H), $5.64(\mathrm{~m}, 1 \mathrm{H}), 5.32(\mathrm{~m}, 1 \mathrm{H}), 5.11$ $(\mathrm{t}, \mathrm{J}=17 \mathrm{~Hz}, 1 \mathrm{H}), 4.86-4.89(\mathrm{~m}, 2 \mathrm{H}), 4.74-4.81(\mathrm{~m}, 2 \mathrm{H}), 4.66$ $(\mathrm{m}, 1 \mathrm{H}), 4.18(\mathrm{dd}, \mathrm{J}=7 \mathrm{~Hz}, 1 \mathrm{H}), 2.96-3.35$ (m, 4H), 2.74-2.89 $(\mathrm{m}, 2 \mathrm{H}), 1.45-2.18(\mathrm{~m}, 4 \mathrm{H}), 1.44(\mathrm{~s}, 9 \mathrm{H}) .{ }^{13} \mathrm{C}$ NMR (DMSO$\left.d_{6}\right) \delta / \mathrm{ppm}=172.11,171.89,168.97,157.13,155.61,136.66$, $131.51,129.69,128.78,128.06,126.99,121.27,118.92$, $117.81,111.58,105.90,80.41,66.06,59.34,52.04,50.90$, 49.83, 48.01, 46.65, 41.96, 33.82, 28.52, 24.93, 23.00, 21.65.

5.1.2.15 (S)-tert-Butyl 3-((S)-3-(((2R, 3R)-1,3-bis (benzyloxy)1-oxobutan-2-yl)carbamoyl)-2, 3, 4, 9-tetrahydro-1Hpyrido[3, 4-b]indole-2-carbonyl)-3, 4-dihydro-1H-pyrido[3, 4-b] indole-2(9H)-carboxylate (6o): Mp: $123-125^{\circ} \mathrm{C} ;[\alpha]_{\mathrm{D}}{ }^{25}=$ -19.1 (c=1.0, methanol); ESI-MS (m/) $796[\mathrm{M}+\mathrm{H}]^{+} ;{ }^{1} \mathrm{H}$ NMR $\left(500 \mathrm{MHz}, \mathrm{DMSO}-d_{6}\right): \delta / \mathrm{ppm}=10.82-10.91(\mathrm{~m}, 2 \mathrm{H}) ; 8.3(\mathrm{~m}$, $\mathrm{J}=9 \mathrm{~Hz}, 1 \mathrm{H}), 7.18-7.41(\mathrm{~m}, 14 \mathrm{H}), 6.89-7.17(\mathrm{~m}, 4 \mathrm{H}), 5.68$ (m, 1H), $5.47(\mathrm{~m}, 1 \mathrm{H}), 4.49-5.21(\mathrm{~m}, 7 \mathrm{H}), 3.96-4.49(\mathrm{~m}, 3 \mathrm{H})$, 2.89-3.41 (m, 4H), $1.46(\mathrm{~s}, 9 \mathrm{H}), 0.83-1.28(\mathrm{~m}, 3 \mathrm{H}) .{ }^{13} \mathrm{C} \mathrm{NMR}$ $\left(\right.$ DMSO- $\left.d_{6}\right) \delta / p p m=173.22,172.59,171.98,170.46,155.59$, $138.57,136.52,131.06,130.06,128.73,128.59,128.45$, $128.05,126.93,121.21,118.87,117.86,111.38,105.07$, $80.50,74.45,70.68,66.52,56.79,53.15,50.51,42.00,41.54$, $28.48,25.16,22.27,16.13$.

5.1.2.16. (S)-tert-Butyl 3-((S)-3-(((R)-1-(benzyloxy)-5-(3nitroguanidino)-1-oxopentan-2-yl) carbamoyl)-2, 3, 4, 9tetrahydro-1H-pyrido [3, 4-b] indole-2-carbonyl)-3, 4dihydro-1H-pyrido[3, 4-b]indole-2(9H)-carboxylate (6p): Mp: $170-172^{\circ} \mathrm{C} ;[\alpha]_{\mathrm{D}}{ }^{25}=-22.1 \quad(\mathrm{c}=1.0$, methanol); ESI-MS $(\mathrm{m} /) 806[\mathrm{M}+\mathrm{H}]^{+}$; ${ }^{1} \mathrm{H}$ NMR $\left(500 \mathrm{MHz}, \mathrm{DMSO}-d_{6}\right): \delta / \mathrm{ppm}=$ 10.84-10.89 (m, 2H); $8.56(\mathrm{~m}, 1 \mathrm{H}), 7.10-7.44(\mathrm{~m}, 9 \mathrm{H}), 6.89-$ $7.10(\mathrm{~m}, 4 \mathrm{H}), 5.63(\mathrm{~m}, 1 \mathrm{H}), 5.37(\mathrm{~m}, 1 \mathrm{H}), 4.69-5.20(\mathrm{~m}, 6 \mathrm{H})$, $4.49(\mathrm{~m}, 1 \mathrm{H}), 2.89-3.51(\mathrm{~m}, 6 \mathrm{H}), 1.51-1.89(\mathrm{~s}, 4 \mathrm{H}), 1.47(\mathrm{~s}$, 9H). ${ }^{13} \mathrm{C}$ NMR $\left(\mathrm{DMSO}-d_{6}\right) \delta / \mathrm{ppm}=171.85,171.27,159.80$, $155.53,136.78,136.50,130.13,129.43,128.77,126.91$, $122.30,121.23,118.89,117.94,112.93,105.05,80.56,67.40$, $66.40,54.75,52.48,50.74,31.78,31.14,29.45,28.47,25.34$, $23.83,22.24$.

5.1.2.17. (S)-tert-Butyl 3-((S)-3-(((R)-5-amino-1-(benzyloxy)1,5-dioxopentan-2-yl)carbamoyl)-2, 3, 4, 9-tetrahydro-1Hpyrido[3, 4-b]indole-2-carbonyl)-3, 4-dihydro-1H-pyrido[3, 4-b]indole-2(9H)-carboxylate $(6 \boldsymbol{q}): \mathrm{Mp}: 158-159^{\circ} \mathrm{C} ;[\alpha]_{\mathrm{D}}{ }^{25}=$ -12.1 (c=1.0, methanol); ESI-MS (m/) $733[\mathrm{M}+\mathrm{H}]^{+} ;{ }^{1} \mathrm{H}$ NMR $\left(500 \mathrm{MHz}, \mathrm{DMSO}-d_{6}\right): \delta / \mathrm{ppm}=10.83-10.91(\mathrm{~m}, 2 \mathrm{H}) ; 8.44(\mathrm{~m}$, $J=7.5 \mathrm{~Hz}, 1 \mathrm{H}), 7.19-7.46(\mathrm{~m}, 9 \mathrm{H}), 6.89-7.10(\mathrm{~m}, 4 \mathrm{H}), 5.65$ $(\mathrm{m}, J=7 \mathrm{~Hz}, 1 \mathrm{H}), 5.31(\mathrm{~m}, 1 \mathrm{H}), 4.61-5.12(\mathrm{~m}, 5 \mathrm{H}), 4.41(\mathrm{~m}$, $1 \mathrm{H}), 4.23(\mathrm{~m}, 1 \mathrm{H}), 3.11-3.51(\mathrm{~m}, 3 \mathrm{H}), 2.99(\mathrm{~m}, 1 \mathrm{H}), 1.99-2.21$ $(\mathrm{m}, 2 \mathrm{H}), 1.78-1.95(\mathrm{~m}, 2 \mathrm{H}), 1.47$ (s, 9H). ${ }^{13} \mathrm{C}$ NMR (DMSO- 
$\left.d_{6}\right) \delta / \mathrm{ppm}=173.90,172.77,171.88,171.17,170.61,155.95$, $136.75,130.65,128.95,128.85,128.34,128.12,126.90$, 121.26, 118.90, 117.96, 111.57, 105.17, 80.70, 66.43, 53.94, 52.53, 52.22, 50.67, 41.75, 31.63, 28.55, 27.23, 26.59, 23.88.

5.1.2.18 (R)-Dibenzyl 2-((S)-2-((S)-2-(tert-butoxy-carbonyl)2, 3, 4, 9-tetrahydro-1H-pyrido[3,4-b] indole-3-carbonyl)-2, 3, 4, 9-tetrahydro-1H-pyrido[3,4-b]indole-3-carbox-amido) succinate (6r): $\mathrm{Mp}: 114-117^{\circ} \mathrm{C} ;[\alpha]_{\mathrm{D}}^{25}=-10.9 \quad(\mathrm{c}=1.0$, methanol); ESI-MS (m/z) $810[\mathrm{M}+\mathrm{H}]^{+} ;{ }^{1} \mathrm{H}$ NMR $(500 \mathrm{MHz}$, DMSO- $\left.d_{6}\right): \delta / p p m=10.83-10.88(\mathrm{~m}, J=4 \mathrm{~Hz}, 2 \mathrm{H}) ; 8.54(\mathrm{~m}$, $J=8 \mathrm{~Hz}, 1 \mathrm{H}), 7.18-7.43(\mathrm{~m}, 14 \mathrm{H}), 6.89-7.15(\mathrm{~m}, 4 \mathrm{H}), 5.64(\mathrm{~m}$, $1 \mathrm{H}), 5.34(\mathrm{~m}, 1 \mathrm{H}), 4.64-5.21(\mathrm{~m}, 8 \mathrm{H}), 4.41(\mathrm{~m}, J=6 \mathrm{~Hz}, 1 \mathrm{H})$, 2.52-3.45 (m, 6H), $1.47(\mathrm{~s}, 9 \mathrm{H}) .{ }^{13} \mathrm{C}$ NMR (DMSO- $\left.d_{6}\right) \delta / \mathrm{ppm}$ $=172.21,171.62,170.68,165.24,155.90,155.28,136.83$, $130.05,129.31,128.82,128.16,126.94,121.35,118.88$, $117.95,111.58,105.24,80.64,69.12,66.85,66.38,56.33$, 51.07, 48.81, 41.44, 36.31, 28.96, 23.32, 22.37.

5.1.2.19 (R)-Dibenzyl 2-((S)-2-((S)-2-(tert-butoxy-carbonyl)2, 3, 4, 9-tetrahydro-1H-pyrido[3,4-b]indole-3-carbonyl)-2, 3, 4, 9-tetrahydro-1H-pyrido[3, 4-b]indole-3-carboxamido) pentanedioate (6s): $\mathrm{Mp}: 114-116^{\circ} \mathrm{C} ;[\alpha]_{\mathrm{D}}^{25}=-15.2(\mathrm{c}=1.0$, methanol); ESI-MS (m/z) $824[\mathrm{M}+\mathrm{H}]^{+} ;{ }^{1} \mathrm{H}$ NMR $(500 \mathrm{MHz}$, DMSO- $\left.d_{6}\right): \delta / \mathrm{ppm}=10.81-10.88(\mathrm{~m}, 2 \mathrm{H}) ; 8.39(\mathrm{~m}, J=7.5 \mathrm{~Hz}$, $1 \mathrm{H}), 7.18-7.43(\mathrm{~m}, 14 \mathrm{H}), 6.89-7.11(\mathrm{~m}, 4 \mathrm{H}), 5.67(\mathrm{~m}, 1 \mathrm{H})$, $5.25(\mathrm{~m}, 1 \mathrm{H}), 4.31-5.29(\mathrm{~m}, 6 \mathrm{H}), 4.15(\mathrm{~m}, 1 \mathrm{H}), 2.81-3.50(\mathrm{~m}$, $5 \mathrm{H}), 1.47$ (s, 9H), 0.83-0.92 (m, 6H). ${ }^{13} \mathrm{C}$ NMR (DMSO- $\left.d_{6}\right)$ $\delta / \mathrm{ppm}=172.64,172.07,170.93,156.05,155.25,136.82$, $130.59,129.26,128.79,127.19,126.97,121.21,118.87$, $117.96,111.57,105.25,80.61,66.58,54.60,52.49,52.26$, $41.73,35.51,28.44,23.71,22.99,14.40$.

\subsubsection{General procedure for preparation of compounds 7a-s}

To a solution of $1.0 \mathrm{mmol}$ of $\mathbf{6 a - s}$ in ethyl acetate $(5 \mathrm{~mL})$ was added $1 \mathrm{~mL}$ of $\mathrm{HCl} / \mathrm{EtOAc}$. The reaction mixture was stirred at room temperature until TLC indicated that the starting material had been consumed. Upon evaporation, the residue was purified by flash column chromatography on silica gel to yield compounds $\mathbf{7 a - s}$.

5.1.3.1. Benzyl 2-((S)-2-((S)-2, 3, 4, 9-tetrahydro-1Hpyrido[3, 4-b]indole-3-carbonyl)- 2, 3, 4, 9-tetrahydro-1Hpyrido [3, 4-b]indole-3-carboxamido) acetate (7a): Mp: 180$183^{\circ} \mathrm{C} ;[\alpha]_{\mathrm{D}}^{25}=-74.4(\mathrm{c}=1.0$, methanol); ESI-MS (m/z) 562 $[\mathrm{M}+\mathrm{H}]^{+} ;{ }^{1} \mathrm{H}$ NMR $\left(500 \mathrm{MHz}, \mathrm{DMSO}-d_{6}\right): \delta / \mathrm{ppm}=11.29(\mathrm{~m}$, $1 \mathrm{H}), 10.25(\mathrm{~m}, 1 \mathrm{H}), 9.85(\mathrm{~m}, 1 \mathrm{H}), 8.75(\mathrm{~m}, 1 \mathrm{H}), 7.25-7.56(\mathrm{~m}$, 9H), 6.89-7.18 (m, 4H), $5.35(\mathrm{~m}, J=5.9 \mathrm{~Hz}, 2 \mathrm{H}), 5.10-5.25$ $(\mathrm{m}, 2 \mathrm{H}), 4.98-5.04(\mathrm{~m}, 2 \mathrm{H}), 4.35-4.55(\mathrm{~m}, 2 \mathrm{H}), 3.75-4.05(\mathrm{~m}$, $J=5.6 \mathrm{~Hz}, 3 \mathrm{H}), 3.31-3.50(\mathrm{~m}, J=14.7 \mathrm{~Hz}, \mathrm{~J}=4.3 \mathrm{~Hz}, 2 \mathrm{H}), 2.89-$ $3.18(\mathrm{~m}, J=6.3 \mathrm{~Hz}, 2 \mathrm{H}) .{ }^{13} \mathrm{C} \mathrm{NMR}\left(\mathrm{DMSO}-d_{6}\right) \delta / \mathrm{ppm}=$ $172.35,170.02,169.63,136.81,136.22,129.84,128.94$, $128.36,127.09,126.30,122.18,119.63,118.03,111.85$, $105.21,67.29,66.39,55.10,48.00,33.80,23.26,21.51$.

5.1.3.2. (R)-Benzyl 2-((S)-2-((S)-2, 3, 4, 9-tetrahydro-1Hpyrido[3, 4-b]indole-3-carbonyl)-2, 3, 4, 9-tetrahydro-1Hpyrido [3,4-b]indole-3-carboxamido) propanoate $(\mathbf{7 b})$ : $\mathrm{Mp}$ : $176-178^{\circ} \mathrm{C} ;[\alpha]_{\mathrm{D}}{ }^{25}=-77.6(\mathrm{c}=1.0$, methanol); ESI-MS $(\mathrm{m} / \mathrm{z})$ $576[\mathrm{M}+\mathrm{H}]^{+} ;{ }^{1} \mathrm{H}$ NMR $\left(500 \mathrm{MHz}, \mathrm{DMSO}-d_{6}\right): \delta / \mathrm{ppm}=11.34$ $(\mathrm{m}, 1 \mathrm{H}), 10.35(\mathrm{~m}, 1 \mathrm{H}), 9.88(\mathrm{~m}, 1 \mathrm{H}), 8.68(\mathrm{~m}, 1 \mathrm{H}), 7.15-7.56$ $(\mathrm{m}, 9 \mathrm{H}), 6.98-7.10(\mathrm{~m}, 4 \mathrm{H}), 5.25-5.49(\mathrm{~m}, J=7.5 \mathrm{~Hz}, 2 \mathrm{H})$, 5.05-5.20 (m, 2H), 4.81-4.92 (m, 2H), 4.25-4.52 (m, J=8.5Hz, $3 \mathrm{H}), 3.25-3.49(\mathrm{~m}, J=3.5 \mathrm{~Hz}, 2 \mathrm{H}), 2.89-3.10(\mathrm{~m}, J=15.5 \mathrm{~Hz}$, $J=7.5 \mathrm{~Hz}, 2 \mathrm{H}), 1.46-1.48(\mathrm{~m}, 3 \mathrm{H}) .{ }^{13} \mathrm{C}$ NMR (DMSO- $\left.d_{6}\right)$ $\delta / \mathrm{ppm}=172.41,170.71,169.60,136.78,136.31,130.05$, $128.97,128.50,128.07,126.22,122.19,121.37,119.60$, $111.96,105.18,67.43,66.26,54.52,48.59,33.81,24.91$, $21.55,17.43$.

5.1.3.3. (R)-Benzyl 3-methyl-2-((S)-2-((S)-2, 3, 4, 9tetrahydro-1H-pyrido[3, 4-b]indole-3-carbonyl)-2, 3, 4, 9tetrahydro-1H-pyrido[3, 4-b]indole-3-carboxamido) butanoate $(7 \mathrm{c}): \mathrm{Mp}: 168-170^{\circ} \mathrm{C} ;[\alpha]_{\mathrm{D}}{ }^{25}=-98.9(\mathrm{c}=1.0$, methanol); ESI-MS (m/) $604[\mathrm{M}+\mathrm{H}]^{+} ;{ }^{1} \mathrm{H}$ NMR $(500 \mathrm{MHz}$, DMSO- $\left.d_{6}\right): \delta / p p m=11.37(\mathrm{~m}, 1 \mathrm{H}), 10.25(\mathrm{~m}, 1 \mathrm{H}), 9.89(\mathrm{~m}$, $1 \mathrm{H}), 8.56(\mathrm{~m}, 1 \mathrm{H}), 7.18-7.59(\mathrm{~m}, 9 \mathrm{H}), 6.98-7.15(\mathrm{~m}, 4 \mathrm{H})$, $5.10-5.35(\mathrm{~m}, J=10 \mathrm{~Hz}, 3 \mathrm{H}), 4.75-4.96(\mathrm{~m}, J=10 \mathrm{~Hz}, 3 \mathrm{H})$, 4.35-4.65 (m, $J=15 \mathrm{~Hz}, 3 \mathrm{H}), 3.35-3.51(\mathrm{~m}, 3 \mathrm{H}), 2.89-3.15(\mathrm{~m}$, $J=15 \mathrm{~Hz}, 2 \mathrm{H}), 0.81-0.89(\mathrm{~m}, 6 \mathrm{H}) .{ }^{13} \mathrm{C}$ NMR (DMSO- $\left.d_{6}\right)$ $\delta / \mathrm{ppm}=172.35,171.46,169.69,136.81,136.22,129.55$, $128.95,128.79,128.48,127.17,122.19,121.47,119.59$, $111.95,104.94,67.52,66.35,58.47,57.78,50.86,30.08$, 24.32, 21.53, 17.98 .

5.1.3.4. (2R, 3R)-benzyl 3-methyl-2-((S)-2-((S)-2, 3, 4, 9tetrahydro-1H-pyrido[3, 4-b]indole-3-carbonyl)-2, 3, 4, 9tetrahydro-1H-pyrido[3, 4-b]indole-3-carboxamido) pentanoate $(7 \mathrm{~d})$ : $\mathrm{Mp}: 166-168^{\circ} \mathrm{C} ;[\alpha]_{\mathrm{D}}{ }^{25}=-129.0(\mathrm{c}=1.0$, methanol); ESI-MS (m/z) $618[\mathrm{M}+\mathrm{H}]^{+}$; ${ }^{1} \mathrm{H}$ NMR $(500 \mathrm{MHz}$, DMSO- $\left.d_{6}\right): \delta / p p m=11.37(\mathrm{~m}, 1 \mathrm{H}), 10.35(\mathrm{~m}, 1 \mathrm{H}), 9.85(\mathrm{~m}$, $1 \mathrm{H}), 8.65(\mathrm{~m}, 1 \mathrm{H}), 7.18-7.56(\mathrm{~m}, 9 \mathrm{H}), 6.98-7.15(\mathrm{~m}, 4 \mathrm{H})$, $5.05-5.45(\mathrm{~m}, J=7.05 \mathrm{~Hz}, 3 \mathrm{H}), 4.75-4.95(\mathrm{~m}, J=12.3 \mathrm{~Hz}$, $J=10.5 \mathrm{~Hz}, 2 \mathrm{H}), 4.35-4.65(\mathrm{~m}, 3 \mathrm{H}), 4.21(\mathrm{~m}, J=6.45 \mathrm{~Hz}, 1 \mathrm{H})$, 3.28-3.48 (m, $J=4.15 \mathrm{~Hz}, J=4.75 \mathrm{~Hz}, 3 \mathrm{H}), 2.89-3.15(\mathrm{~m}, 2 \mathrm{H})$, 1.31-1.55 (m, 2H), 0.79-0.89 (m, 6H). ${ }^{13} \mathrm{C}$ NMR (DMSO- $d_{6}$ ) $\delta / \mathrm{ppm}=172.34,171.27,169.68,136.82,136.20,129.53$, $128.93,128.77,127.17,126.24,122.19,119.60,118.27$, $111.96,105.14,67.50,57.06,53.93,50.88,42.30,36.87$, 25.84, 24.98, 21.52, 15.89, 11.57 .

5.1.3.5. (R)-Benzyl 4-methyl-2-((S)-2-((S)-2, 3, 4, 9tetrahydro-1H-pyrido[3,4-b]indole-3-carbonyl)-2, 3, 4, 9tetrahydro-1H-pyrido[3, 4-b]indole-3-carboxamido) pentanoate $(7 e): \mathrm{Mp}: 156-158^{\circ} \mathrm{C} ;[\alpha]_{\mathrm{D}}{ }^{25}=-57.3(\mathrm{c}=1.0$, methanol); ESI-MS (m/z) $618[\mathrm{M}+\mathrm{H}]^{+} ;{ }^{1} \mathrm{H}$ NMR $(500 \mathrm{MHz}$, DMSO- $\left.d_{6}\right): \delta / p p m=11.36(\mathrm{~m}, 1 \mathrm{H}), 10.30(\mathrm{~m}, 1 \mathrm{H}) ; 9.85(\mathrm{~m}$, $1 \mathrm{H}), 8.65(\mathrm{~m}, 1 \mathrm{H}), 7.21-7.57(\mathrm{~m}, 9 \mathrm{H}), 6.98-7.20(\mathrm{~m}, J=5 \mathrm{~Hz}$, $J=10 \mathrm{~Hz}, 4 \mathrm{H}), 5.35(\mathrm{~m}, J=10 \mathrm{~Hz}, 1 \mathrm{H}), 5.05-5.28(\mathrm{~m}, 2 \mathrm{H})$, 4.78-4.95 (m, 3H), 4.25-4.55 (m, 3H), 3.30-3.49 (m, 2H), 2.89-3.25 (m, 2H), 1.55-1.79 (m, 2H), 1.50 (m, 1H), 0.77-0.95 $(\mathrm{m}, 6 \mathrm{H}) .{ }^{13} \mathrm{C}$ NMR $\left(\mathrm{DMSO}-d_{6}\right) \delta / \mathrm{ppm}=172.42,172.39$, $169.63,136.78,136.30,129.49,128.97,128.69$, 127.16, $122.19,119.60,117.92,111.97,104.97,67.52,66.29,54.60$, 50.98, 42.22, 40.88, 33.79, 24.90, 23.19, 22.44, 21.56.

5.1.3.6. (R)-Benzyl 4-amino-4-oxo-2-((S)-2-((S)-2, 3, 4, 9tetrahydro-1H-pyrido[3, 4-b]indole-3-carbonyl)-2, 3, 4, 9tetrahydro-1H-pyrido[3,4-b]indole-3-carboxamido)

butanoate $(7 f)$ : $\mathrm{Mp}: 194-196^{\circ} \mathrm{C} ;[\alpha]_{\mathrm{D}}^{25}=-137.0 \quad(\mathrm{c}=1.0$, methanol); ESI-MS (m/z) $619[\mathrm{M}+\mathrm{H}]^{+}$; ${ }^{1} \mathrm{H}$ NMR $(500 \mathrm{MHz}$, 
DMSO- $\left.d_{6}\right): \delta / p p m=11.28(\mathrm{~m}, 1 \mathrm{H}), 10.95(\mathrm{~m}, 1 \mathrm{H}), 10.15(\mathrm{~m}$, $1 \mathrm{H}), 10.25(\mathrm{~m}, 1 \mathrm{H}), 9.85(\mathrm{~m}, 1 \mathrm{H}), 8.55(\mathrm{~m}, J=13.5 \mathrm{~Hz}, 1 \mathrm{H})$, 8.45 (m, 1H), 7.15-7.57 (m, 9H), 6.98-7.14 (m, 4H), 5.05-5.45 $(\mathrm{m}, J=6.5 \mathrm{~Hz}, 2 \mathrm{H}), 4.89-5.03(\mathrm{~m}, J=3 \mathrm{~Hz}, J=12 \mathrm{~Hz}, 2 \mathrm{H}), 4.81$ $(\mathrm{m}, 1 \mathrm{H}), 4.35-4.69(\mathrm{~m}, J=10 \mathrm{~Hz}, 4 \mathrm{H}), 2.89-3.51(\mathrm{~m}, 4 \mathrm{H})$, 2.55-2.65 (m, 2H). ${ }^{13} \mathrm{C}$ NMR $\left(\mathrm{DMSO}-d_{6}\right) \delta / \mathrm{ppm}=172.38$, $171.38,170.10,169.46,136.79,136.32,130.02,129.23$, $128.75,127.04,126.25,122.20,121.37,119.03,111.87$, $105.13,66.42,54.62,51.18,49.68,41.97,37.05,36.76,23.24$, 21.52 .

5.1.3.7. (R)-Benzyl 3-(1H-imidazol-4-yl)-2-((S)-2-((S)-2, 3, 4, 9-tetrahydro-1H-pyrido [3, 4-b] indole-3-carbonyl)-2, 3, 4, 9tetrahydro-1H-pyrido $[3, \quad 4$-b $]$ indole-3-carbox-amido) propanoate $(7 \mathrm{~g})$ : $\mathrm{Mp}: 183-185^{\circ} \mathrm{C} ;[\alpha]_{\mathrm{D}}^{25}=-72.5(\mathrm{c}=1.0$, methanol); ESI-MS (m/z) $642[\mathrm{M}+\mathrm{H}]^{+} ;{ }^{1} \mathrm{H}$ NMR $(500 \mathrm{MHz}$, DMSO- $\left.d_{6}\right): \delta / p p m=11.25(\mathrm{~m}, 1 \mathrm{H}), 10.98(\mathrm{~m}, 1 \mathrm{H}), 10.05(\mathrm{~m}$, $1 \mathrm{H}), 9.25(\mathrm{~m}, 1 \mathrm{H}), 8.98(\mathrm{~m}, 1 \mathrm{H}), 7.55(\mathrm{dd}, \mathrm{J}=5 \mathrm{~Hz}, 1 \mathrm{H}), 7.20-$ 7.49 (m, 9H), 6.98-7.18 (m, 4H), 5.25-5.45 (m, J=5Hz, 2H), $5.01-5.23(\mathrm{~m}, 2 \mathrm{H}), 4.98(\mathrm{~m}, \mathrm{~J}=15 \mathrm{~Hz}, 3 \mathrm{H}), 4.89(\mathrm{~m}, \mathrm{~J}=15 \mathrm{~Hz}$, $2 \mathrm{H}), 4.35-4.68(\mathrm{~m}, 3 \mathrm{H}), 3.28-3.48(\mathrm{~m}, 2 \mathrm{H}), 2.89-3.25(\mathrm{~m}$, $4 \mathrm{H}) .{ }^{13} \mathrm{C}$ NMR $\left(\mathrm{DMSO}-d_{6}\right) \delta / \mathrm{ppm}=171.40,170.18,169.42$, $136.82,136.06,135.43,135.22,130.67,129.41,128.82$, $126.82,122.19,121.39,120.04,119.53,111.96,105.17$, 66.74, 65.88, 54.94, 51.27, 42.11, 38.98, 25.97, 23.57, 22.37.

5.1.3.8. (R)-Benzyl 3-phenyl-2-((S)-2-((S)-2, 3, 4, 9tetrahydro-1H-pyrido [3, 4-b]indole-3-carbonyl)-2, 3, 4, 9tetrahydro-1H-pyrido $[3, \quad 4$-b]indole-3-carboxamido) propanoate (7h): Mp: $154-156^{\circ} \mathrm{C} ;[\alpha]_{\mathrm{D}}{ }^{25}=-88.3(\mathrm{c}=1.0$, methanol); ESI-MS (m/z) $652[\mathrm{M}+\mathrm{H}]^{+}$; ${ }^{1} \mathrm{H}$ NMR $(500 \mathrm{MHz}$, DMSO- $\left.d_{6}\right): \delta / p p m=11.35(\mathrm{~m}, 1 \mathrm{H}), 10.89(\mathrm{~m}, 1 \mathrm{H}), 9.98(\mathrm{~m}$, $1 \mathrm{H}), 8.85(\mathrm{~m}, 1 \mathrm{H}), 7.15-7.57(\mathrm{~m}, 14 \mathrm{H}), 6.98-7.12(\mathrm{~m}, 4 \mathrm{H})$, 5.12-5.45 (m, 2H), 4.90-5.10 (m, 3H), 4.75 (m, 1H), 3.30-3.51 $(\mathrm{m}, 2 \mathrm{H}), 2.89-3.29(\mathrm{~m}, \mathrm{~J}=3.5 \mathrm{~Hz}, 2 \mathrm{H}), 2.89-3.10 \quad(\mathrm{~m}$, $\mathrm{J}=15.5 \mathrm{~Hz}, \quad \mathrm{~J}=7.5 \mathrm{~Hz}, 2 \mathrm{H}), \quad 1.46-1.48 \quad(\mathrm{~m}, 3 \mathrm{H}) .{ }^{13} \mathrm{C} \quad \mathrm{NMR}$ $\left(\mathrm{DMSO}-d_{6}\right) \delta / \mathrm{ppm}=172.36,170.55,169.30,137.77,136.84$, $136.18,129.89,129.67,129.44,129.04,128.81,128.67$, $128.32,128.11,127.68,122.22,119.41,118.01,111.55$, 105.05 .

5.1.3.9. (R)-Benzyl 6-(((benzyloxy)carbonyl)amino $)-2-((S)-2-$ $((S)-2, \quad 3, \quad 4, \quad 9-t e t r a h y d r o-1 H$-pyrido[3, 4-b]indole-3carbonyl)-2, 3, 4, 9-tetrahydro-1H-pyrido[3, 4-b]indole-3carboxamido) hexanoate (7i): $\mathrm{Mp}: 134-136^{\circ} \mathrm{C} ;[\alpha]_{\mathrm{D}}{ }^{25}=-54.0$ (c=1.0, methanol); ESI-MS (m/z) $767[\mathrm{M}+\mathrm{H}]^{+} ;{ }^{1} \mathrm{H}$ NMR $\left(500 \mathrm{MHz}, \mathrm{DMSO}-d_{6}\right): \delta / \mathrm{ppm}=11.28(\mathrm{~m}, 1 \mathrm{H}), 10.95(\mathrm{~m}, 1 \mathrm{H})$, $10.20(\mathrm{~m}, 1 \mathrm{H}), 9.85(\mathrm{~m}, 1 \mathrm{H}), 8.57(\mathrm{~m}, 1 \mathrm{H}), 7.21-7.56(\mathrm{~m}$, $14 \mathrm{H}), 6.98-7.20$ (m, 4H), 5.15-5.35 (m, J=10.5Hz, 2H), 4.95$5.10(\mathrm{~m}, \mathrm{~J}=6.5 \mathrm{~Hz}, 4 \mathrm{H}), 4.75-4.90(\mathrm{~m}, \mathrm{~J}=14 \mathrm{~Hz}, 2 \mathrm{H}), 4.05-4.55$ $(\mathrm{m}, \mathrm{J}=9.5 \mathrm{~Hz}, \mathrm{~J}=12 \mathrm{~Hz}, 3 \mathrm{H}), 3.15-3.51(\mathrm{~m}, 3 \mathrm{H}), 2.89-3.12(\mathrm{~m}$, $\mathrm{J}=10.5 \mathrm{~Hz}, \mathrm{~J}=15.5 \mathrm{~Hz}, 3 \mathrm{H}), 1.65-1.78(\mathrm{~m}, 2 \mathrm{H}), 1.21-1.49(\mathrm{~m}$, $4 \mathrm{H}) .{ }^{13} \mathrm{C}$ NMR $\left(\mathrm{DMSO}-d_{6}\right) \delta / \mathrm{ppm}=172.35,171.84,169.82$, $156.55,136.81,136.29,130.01,129.49,128.77,128.16$, $127.09,122.22,119.61,118.04,111.62,105.33,67.53,66.26$, $65.58,54.60,53.03,52.35,50.93,42.23,30.88,29.42,23.03$, 21.51.

5.1.3.10 (R)-Benzyl 3-(4-hydroxyphenyl)-2-((S)-2-((S)-2, 3, 4, 9-tetrahydro-1H-pyrido [3, 4-b]indole-3-carbonyl)-2, 3, 4, 9tetrahydro-1H-pyrido[3, 4-b]indole-3-carboxamido) propanoate $(7 \mathrm{j}): \mathrm{Mp}: 175-178^{\circ} \mathrm{C} ;[\alpha]_{\mathrm{D}}^{25}=-77.6(\mathrm{c}=1.0$, methanol); ESI-MS (m/z) $668[\mathrm{M}+\mathrm{H}]^{+} ;{ }^{1} \mathrm{H}$ NMR $(500 \mathrm{MHz}$, DMSO- $\left.d_{6}\right): \delta / \mathrm{ppm}=11.25(\mathrm{~m}, 1 \mathrm{H}), 10.90(\mathrm{~m}, 1 \mathrm{H}), 10.25(\mathrm{~m}$, 1H), 9.95 (m, 1H), 8.65 (m, 1H), 7.21-7.56 (m, 9H), 6.89-7.20 $(\mathrm{m}, 6 \mathrm{H}), 6.58-6.75(\mathrm{~m}, \mathrm{~J}=5 \mathrm{~Hz}, 2 \mathrm{H}), 5.12-5.35(\mathrm{~m}, 2 \mathrm{H}), 5.05$ $(\mathrm{m}, \mathrm{J}=15 \mathrm{~Hz}, 1 \mathrm{H}), 4.65-4.98(\mathrm{~m}, 3 \mathrm{H}), 4.25-4.48(\mathrm{~m}, 3 \mathrm{H})$, 3.25-3.45 (m, 2H), 2.89-3.20 (m, 4H). ${ }^{13} \mathrm{C}$ NMR (DMSO- $d_{6}$ ) $\delta / \mathrm{ppm}=172.43,170.63,169.49,156.54,136.79,136.14$, $130.88,130.45,129.38,128.78,128.24,128.18,127.60$, 122.27, 121.54, 119.07, 115.64, 111.66, 105.23, 67.51, 55.12, $54.78,42.01,36.05,35.68,23.60,21.51$.

5.1.3.11. (R)-Benzyl 4-(methylthio)-2-((S)-2-((S)-2, 3, 4, 9tetrahydro-1H-pyrido [3, 4-b]indole-3-carbonyl)-2, 3, 4, 9tetrahydro-1H-pyrido[3, 4-b]indole-3-carboxamido) butanoate (7k): Mp: $165-168^{\circ} \mathrm{C} ;[\alpha]_{\mathrm{D}}^{25}=-82.5(\mathrm{c}=1.0$, methanol); ESI-MS (m/z) $635[\mathrm{M}+\mathrm{H}]^{+} ;{ }^{1} \mathrm{H}$ NMR $(500 \mathrm{MHz}$, DMSO- $\left.d_{6}\right): \delta / p p m=11.27(\mathrm{~m}, 1 \mathrm{H}), 10.30(\mathrm{~m}, 1 \mathrm{H}), 9.85(\mathrm{~m}$, $1 \mathrm{H}), 8.65(\mathrm{~m}, 1 \mathrm{H}), 7.21-7.56(\mathrm{~m}, 9 \mathrm{H}), 6.88-7.20(\mathrm{~m}, 4 \mathrm{H})$, 4.95-5.45 (m, 6H), 4.35-4.52 (m, 3H), 3.25-3.45 (m, 2H), 2.89-3.15 (m, 2H), 2.35-2.45 (m, 2H), 2.05-2.15 (m, 2H), 1.85-1.95 (m, 3H). ${ }^{13} \mathrm{C}$ NMR (DMSO- $\left.d_{6}\right) \delta / p p m=172.35$, $170.72,169.54,136.81,136.27,129.92,129.57,128.87$, $128.20,127.10,126.23,122.22,121.39,118.63,111.63$, $105.24,66.52,56.49,54.57,52.07,42.28,31.05,30.13,28.82$, $23.51,21.51,14.89$.

5.1.3.12.(R)-Benzyl 3-(benzyloxy)-2-((S)-2-((S)-2, 3, 4, 9tetrahydro-1H-pyrido [3, 4-b]indole-3-carbonyl)-2, 3, 4, 9tetrahydro-1H-pyrido [3,4-b]indole-3-carboxamido)

propanoate $(7 \mathrm{l}): \mathrm{Mp}: 148-150^{\circ} \mathrm{C} ;[\alpha]_{\mathrm{D}}{ }^{25}=-78.8(\mathrm{c}=1.0$, methanol); ESI-MS (m/z) $682[\mathrm{M}+\mathrm{H}]^{+} ;{ }^{1} \mathrm{H}$ NMR $(500 \mathrm{MHz}$, DMSO- $\left.d_{6}\right): \delta / p p m=11.30(\mathrm{~m}, 1 \mathrm{H}), 10.20(\mathrm{~m}, 1 \mathrm{H}), 9.85(\mathrm{~m}$, $1 \mathrm{H}), 8.78(\mathrm{~m}, 1 \mathrm{H}), 7.15-7.56(\mathrm{~m}, 9 \mathrm{H}), 6.98-7.12(\mathrm{~m}, 4 \mathrm{H})$, 5.01-5.35 (m, J=11Hz, J=9.5Hz, $2 \mathrm{H}), 4.75-5.00(\mathrm{~m}, \mathrm{~J}=11.5 \mathrm{~Hz}$, $2 \mathrm{H}), 4.25-4.65(\mathrm{~m}, 6 \mathrm{H}), 3.15-3.58(\mathrm{~m}, 4 \mathrm{H}), 2.89-3.10(\mathrm{~m}$, $2 \mathrm{H}) .{ }^{13} \mathrm{C}$ NMR $\left(\mathrm{DMSO}-d_{6}\right) \delta / \mathrm{ppm}=172.41,170.15,169.60$, $137.78,136.77,136.15,129.47,128.90,128.13,127.98$, $127.13,126.76,126.21,122.22,121.48,119.02,111.62$, 105.21, 72.96, 69.61, 66.55, 54.54, 51.31, 42.22, 24.71, 21.53.

5.1.3.13. Benzyl 3-(1H-indol-3-yl)-2-(2-(2, 3, 4, 9-tetrahydro1H-pyrido[3, 4-b]indole-3-carbonyl)-2, 3, 4, 9-tetrahydro1H-pyrido[3, 4-b]indole-3-carboxamido) propanoate (7m): Mp: $184-186^{\circ} \mathrm{C} ;[\alpha]_{\mathrm{D}}{ }^{25}=-67.4$ (c=1.0, methanol); ESI-MS $(\mathrm{m} / \mathrm{z}) 691[\mathrm{M}+\mathrm{H}]^{+} ;{ }^{1} \mathrm{H}$ NMR $\left(500 \mathrm{MHz}, \mathrm{DMSO}-d_{6}\right): \delta / \mathrm{ppm}=$ $11.36(\mathrm{~m}, 1 \mathrm{H}), 10.97(\mathrm{~m}, 1 \mathrm{H}), 10.25(\mathrm{~m}, 1 \mathrm{H}), 9.89(\mathrm{~m}, 1 \mathrm{H})$, $8.75(\mathrm{~m}, 1 \mathrm{H}), 7.15-7.57(\mathrm{~m}, 13 \mathrm{H}), 6.98-7.13(\mathrm{~m}, 5 \mathrm{H}), 4.98-$ $5.35(\mathrm{~m}, 2 \mathrm{H}), 4.87(\mathrm{~m}, 1 \mathrm{H}), 4.71(\mathrm{~m}, 1 \mathrm{H}), 4.25-4.55(\mathrm{~m}, 4 \mathrm{H})$, 4.10 (m, 1H), 3.31-3.49 (m, 2H), 3.15-3.29 (m, 2H), 2.89-3.14 $(\mathrm{m}, 2 \mathrm{H}) .{ }^{13} \mathrm{C} \mathrm{NMR}\left(\mathrm{DMSO}-d_{6}\right) \delta / \mathrm{ppm}=172.43,171.87$, $169.78,136.78,136.62,136.14,129.97,129.52,128.74$, $128.07,127.11,124.26,122.20,121.66,119.59,111.95$, $109.83,105.07,67.51,66.30,54.60,53.25,48.01,33.80$, 24.91, 21.55 .

5.1.3.14. (R)-Benzyl 1-((S)-2-((S)-2, 3, 4, 9-tetrahydro-1Hpyrido [3,4-b] indole-3-carbonyl)-2, 3, 4, 9-tetrahydro-1Hpyrido[3, 4-b]indole-3-carbonyl) pyrrolidine-2-carboxylate (7n): Mp: $169-171^{\circ} \mathrm{C}$; $[\alpha]_{\mathrm{D}}{ }^{25}=-62.4$ (c=1.0, methanol); ESIMS (m/z) $602[\mathrm{M}+\mathrm{H}]^{+} ;{ }^{1} \mathrm{H}$ NMR $\left(500 \mathrm{MHz}\right.$, DMSO- $\left.d_{6}\right)$ : 
$\delta / \mathrm{ppm}=11.32(\mathrm{~m}, 1 \mathrm{H}), 10.25(\mathrm{~m}, 1 \mathrm{H}), 9.85(\mathrm{~m}, 1 \mathrm{H}), 7.15-$ 7.57 (m, 9H), 6.98-7.13 (m, 4H), 5.11-5.35 (m, 2H), 4.55-5.09 $(\mathrm{m}, 2 \mathrm{H}), 4.25-4.55(\mathrm{~m}, 5 \mathrm{H}), 3.61(\mathrm{~m}, 1 \mathrm{H}), 3.15-3.49(\mathrm{~m}, 4 \mathrm{H})$, $3.01(\mathrm{~m}, 1 \mathrm{H}), 1.72(\mathrm{~m}, 1 \mathrm{H}), 1.63(\mathrm{~m}, 1 \mathrm{H}), 1.15-1.25(\mathrm{~m}, 2 \mathrm{H})$. ${ }^{13} \mathrm{C}$ NMR (DMSO- $\left.d_{6}\right) \delta / \mathrm{ppm}=172.41,171.50,169.10$, $136.73,136.29,130.05,128.96,128.40,128.15,126.88$, $122.17,119.51,118.36,111.85,104.55,67.73,66.45,59.05$, $58.95,47.97,45.68,33.79,28.20,24.89,22.41,21.54$.

5.1.3.15. (2R, 3R)-benzyl 3-(benzyloxy)-2-((S)-2-((S)-2, 3, 4, 9-tetrahydro-1H-pyrido [3, 4-b] indole-3-carbonyl)-2, 3, 4, 9tetrahydro-1H-pyrido $[3, \quad 4$-b]indole-3-carboxamido) butanoate (7o): Mp: $154-156^{\circ} \mathrm{C} ;[\alpha]_{\mathrm{D}}{ }^{25}=-64.7(\mathrm{c}=1.0$, methanol); ESI-MS (m/z) $696[\mathrm{M}+\mathrm{H}]^{+} ;{ }^{1} \mathrm{H}$ NMR $(500 \mathrm{MHz}$, DMSO- $\left.d_{6}\right): \delta / p p m=11.37(\mathrm{~m}, 1 \mathrm{H}), 10.25(\mathrm{~m}, 1 \mathrm{H}), 9.89(\mathrm{~m}$, $1 \mathrm{H}), 8.45(\mathrm{~m}, 1 \mathrm{H}), 7.19-7.56(\mathrm{~m}, 14 \mathrm{H}), 6.89-7.15(\mathrm{~m}, 4 \mathrm{H})$, 5.05-5.48 (m, 3H), $4.98(\mathrm{~m}, \mathrm{~J}=3 \mathrm{~Hz}, 2 \mathrm{H}), 4.89(\mathrm{~m}, 1 \mathrm{H}), 4.51-$ $4.75(\mathrm{~m}, 2 \mathrm{H}), 4.25-4.45(\mathrm{~m}, 5 \mathrm{H}), 3.25-3.45(\mathrm{~m}, \mathrm{~J}=4 \mathrm{~Hz}, \mathrm{~J}=2 \mathrm{~Hz}$, $2 \mathrm{H}), 2.89-3.10(\mathrm{~m}, \mathrm{~J}=12 \mathrm{~Hz}, 2 \mathrm{H}), 1.14-1.19(\mathrm{~m}, 3 \mathrm{H}) .{ }^{13} \mathrm{C}$ NMR $\left(\mathrm{DMSO}-d_{6}\right) \delta / \mathrm{ppm}=172.42,170.41,169.75,138.48$, $136.78,136.00,129.42,128.91,128.63,128.59,128.49$, $128.03,127.87,126.72,122.20,121.49,119.04,111.95$, $105.18,74.73,72.86,67.67,66.78,57.05,54.58,50.78,41.02$, $39.86,22.23,21.55,16.51$.

5.1.3.16. (R)-Benzyl 5-(3-nitroguanidino)-2-((S)-2-((S)-2, 3, 4, 9-tetrahydro-1H-pyrido [3, 4-b] indole-3-carbonyl)-2, 3, 4, 9tetrahydro-1H-pyrido[3,4-b]indole-3-carboxamido)

pentanoate (7p): $\mathrm{Mp}: 174-175^{\circ} \mathrm{C} ;[\alpha]_{\mathrm{D}}{ }^{25}=-26.7(\mathrm{c}=1.0$, methanol); ESI-MS (m/z) $706[\mathrm{M}+\mathrm{H}]^{+} ;{ }^{1} \mathrm{H}$ NMR $(500 \mathrm{MHz}$, DMSO- $\left.d_{6}\right): \delta / \mathrm{ppm}=11.27(\mathrm{~m}, 1 \mathrm{H}), 10.96(\mathrm{~m}, 1 \mathrm{H}), 9.89(\mathrm{~m}$, $1 \mathrm{H}), 8.65(\mathrm{~m}, 1 \mathrm{H}), 7.89-8.15(\mathrm{~m}, 2 \mathrm{H}), 7.13-7.56(\mathrm{~m}, 9 \mathrm{H})$, 6.98-7.10 (m,4H), 4.78-5.45 (m, 9H), 4.15-4.55 (m,2H), 2.89$3.45(\mathrm{~m}, 4 \mathrm{H}), 1.65-1.85(\mathrm{~m}, 2 \mathrm{H}), 1.45-1.55(\mathrm{~m}, 2 \mathrm{H}) .{ }^{13} \mathrm{C} \mathrm{NMR}$ $\left(\mathrm{DMSO}-d_{6}\right) \delta / \mathrm{ppm}=172.38,171.70,169.61,159.80,136.80$, $136.22,130.00,128.78,128.18,127.06,126.23,122.22$, $121.58,119.04,111.62,105.06,66.36,54.61,52.73,50.99$, $42.24,28.41,25.50,24.07,23.62,21.51$.

5.1.3.17. (R)-Benzyl 5-amino-5-oxo-2-((S)-2-((S)-2, 3, 4, 9tetrahydro-1H-pyrido[3, 4-b]indole-3-carbonyl)-2, 3, 4, 9tetrahydro-1H-pyrido[3, 4-b]indole-3-carboxamido) pentanoate $(7 \boldsymbol{q})$ : $\mathrm{Mp}: 179-181^{\circ} \mathrm{C} ;[\alpha]_{\mathrm{D}}{ }^{25}=-80.3(\mathrm{c}=1.0$, methanol); ESI-MS (m/z) $633[\mathrm{M}+\mathrm{H}]^{+} ;{ }^{1} \mathrm{H}$ NMR $(500 \mathrm{MHz}$, DMSO- $\left.d_{6}\right): \delta / p p m=11.30(\mathrm{~m}, 1 \mathrm{H}), 10.95(\mathrm{~m}, 1 \mathrm{H}), 10.56(\mathrm{~m}$, $1 \mathrm{H}), 10.25(\mathrm{~m}, 1 \mathrm{H}), 9.85(\mathrm{~m}, 1 \mathrm{H}), 8.75(\mathrm{~m}, 1 \mathrm{H}), 7.21-7.56(\mathrm{~m}$, $9 \mathrm{H})$, 6.98-7.20 (m, 4H), 5.05-5.35 (m, 4H), 4.75-4.95 (m, $2 \mathrm{H}), 4.15-4.55(\mathrm{~m}, 3 \mathrm{H}), 3.15-3.52(\mathrm{~m}, 2 \mathrm{H}), 2.89-3.12(\mathrm{~m}$, $2 \mathrm{H}), 2.15-2.25(\mathrm{~m}, 4 \mathrm{H}),{ }^{13} \mathrm{C} \mathrm{NMR}\left(\mathrm{DMSO}-d_{6}\right) \delta / \mathrm{ppm}=$ $174.13,172.44,171.70,169.62,136.76,136.27,130.06$, $129.47,128.53,128.17,127.10,122.19,119.51,118.04$, $111.55,105.06,66.32,56.99,54.55,51.01,32.14,31.89$, $31.86,28.72,25.11,21.55$.

5.1.3.18. (R)-Dibenzyl 2-((S)-2-((S)-2, 3, 4, 9-tetrahydro-1Hpyrido [3, 4-b] indole-3-carbonyl)-2, 3, 4, 9-tetrahydro-1Hpyrido[3, 4-b]indole-3-carboxamido) succinate (7r): $\mathrm{Mp}$ : $140-142^{\circ} \mathrm{C} ;[\alpha]_{\mathrm{D}}{ }^{25}=-103.7(\mathrm{c}=1.0$, methanol); ESI-MS $(\mathrm{m} / \mathrm{z})$ $710[\mathrm{M}+\mathrm{H}]+;{ }^{1} \mathrm{H}$ NMR $\left(500 \mathrm{MHz}, \mathrm{DMSO}-d_{6}\right): \delta / \mathrm{ppm}=11.33$ $(\mathrm{m}, 1 \mathrm{H}), 10.25(\mathrm{~m}, 1 \mathrm{H}), 9.89(\mathrm{~m}, 1 \mathrm{H}), 8.85(\mathrm{~m}, 1 \mathrm{H}), 7.22-7.56$ (m, 14H), 6.96-7.20 (m, 4H), 5.35 (m, 1H), 5.20 (m, 1H), 5.15 (m, 1H), 4.65-5.05 (m, 5H), 4.35-4.49 (m, 3H), 3.35-3.50 (m, $2 \mathrm{H}), 2.80-3.25(\mathrm{~m}, 4 \mathrm{H}),{ }^{13} \mathrm{C}$ NMR $\left(\mathrm{DMSO}-d_{6}\right) \delta / \mathrm{ppm}=$ $172.36,170.52,170.29,169.46,136.83,136.06,128.90$, $128.79,128.52,128.38,126.92,122.21,119.43,117.96$, $111.57,105.25,67.82,66.88,54.79,49.44,41.09,40.88$, $39.36,36.16,23.49,21.52$.

5.1.3.19. (R)-Dibenzyl 2-((S)-2-((S)-2, 3, 4, 9-tetrahydro-1Hpyrido [3, 4-b]indole-3-carbonyl)-2, 3, 4, 9-tetrahydro-1Hpyrido [3,4-b]indole-3-carboxamido) pentanedioate (7s): $\mathrm{Mp}$ : $135-137^{\circ} \mathrm{C} ;[\alpha]_{\mathrm{D}}{ }^{25}=-96.4(\mathrm{c}=1.0$, methanol); ESI-MS $(\mathrm{m} / \mathrm{z})$ $724[\mathrm{M}+\mathrm{H}]^{+} ;{ }^{1} \mathrm{H}$ NMR $\left(500 \mathrm{MHz}, \mathrm{DMSO}-d_{6}\right): \delta / \mathrm{ppm}=11.27$ (m, 1H), $10.25(\mathrm{~m}, 1 \mathrm{H}), 9.89(\mathrm{~m}, 1 \mathrm{H}), 8.69(\mathrm{~m}, 1 \mathrm{H}), 7.19-7.56$ (m, 14H), 6.98-7.18 (m, 4H), $5.30(\mathrm{~m}, \mathrm{~J}=6.5 \mathrm{~Hz}, 1 \mathrm{H}), 5.21(\mathrm{~m}$, $\mathrm{J}=3.5 \mathrm{~Hz}, 1 \mathrm{H}), 4.95-5.15(\mathrm{~m}, 4 \mathrm{H}), 4.85-4.95(\mathrm{~m}, 2 \mathrm{H}), 4.21-$ $4.55(\mathrm{~m}, 3 \mathrm{H}), 3.15-3.45(\mathrm{~m}, \mathrm{~J}=6.5 \mathrm{~Hz}, 2 \mathrm{H}), 2.89-3.12(\mathrm{~m}$, $\mathrm{J}=12 \mathrm{~Hz}, 2 \mathrm{H}), 2.35-2.49(\mathrm{~m}, 2 \mathrm{H}), 1.95-2.18$ (m, 2H). ${ }^{13} \mathrm{C} \mathrm{NMR}$ $\left(\mathrm{DMSO}-d_{6}\right) \delta / \mathrm{ppm}=173.21,172.59,171.38,169.80,136.77$, $136.23,129.94,129.45,128.78,128.31,128.17,127.08$, $122.22,121.39,119.03,111.87,105.21,67.66,66.44,65.97$, $52.28,50.98,30.49,26.46,24.10,21.53$.

\subsubsection{General procedure for preparation of compounds $8 \boldsymbol{a}$-s.}

To a solution of $1.0 \mathrm{mmol}$ of $\mathbf{7 a - s}$ in anhydrous ethanol (140 $\mathrm{mL}$ ), $0.20 \mathrm{~g}$ of $\mathrm{Pd} / \mathrm{C}$ was added. The reaction mixture was stirred at room temperature under $\mathrm{H}_{2}$ until TLC indicated that the starting material was consumed. The reaction mixture was filtered through celite pad, washed with $\mathrm{CH}_{2} \mathrm{Cl}_{2}$ and the combined filtrates evaporated under vacuum. The residue was dissolved in $\mathrm{CH}_{2} \mathrm{Cl}_{2}$, and washed twice with saturated brine solution. The organic layer was dried over anhydrous $\mathrm{Na}_{2} \mathrm{SO}_{4}$, filtered and concentrated. The residue was dissolved in $10 \mathrm{~mL}$ anhydrous $\mathrm{CH}_{2} \mathrm{Cl}_{2}$, and sequentially supplemented with 2(1H-Benzotriazol-1-yl)-1,1,3,3-tetramethyluronium

hexafluorophosphate, HBTU) (0.5 g, $1.4 \mathrm{mmol})$, propargylamine $(0.09 \mathrm{~mL}, 1.4 \mathrm{mmol})$ and triethylamine $(0.25$ $\mathrm{mL}, 1.4 \mathrm{mmol})$. The reaction mixture was stirred at room temperature overnight until TLC indicated that the starting material was consumed. The reaction mixture was diluted with dichloromethane and subsequently washed with brine. The combined organic layers were dried over anhydrous sodium sulfate, filtered and evaporated under reduced pressure. The residue was directly used in the next reaction step without additional purification.

5.1.4.1. 4-Azido-tempo: $1.1 \mathrm{~g} \mathrm{NaN}_{3}(17.0 \mathrm{mmol})$ dissolved in water $(5 \mathrm{~mL})$ in an ice bath was supplemented with toluene $(5$ $\mathrm{mL})$. Triflic anhydride $(1.7 \mathrm{~mL}, 10.4 \mathrm{mmol})$ was subsequently added dropwise and the reaction was stirred until the TLC indicated the completion of the reaction, $\mathrm{NaHCO}_{3}$ solution was added dropwise until bubbling ceased. The reaction mixture was extracted with toluene $(10 \mathrm{~mL} \times 2)$, and the organic layer dried over anhydrous sodium sulfate. Toluene was not evaporated, since it has been reported that trifyl azide is explosive when not in solution. 4-Amino-tempo (1.08 g, $5.85 \mathrm{mmol})$ was dissolved in water $(7.5 \mathrm{~mL})$ followed by addition of $\mathrm{NaHCO}_{3}(2.0 \mathrm{~g}, 23.8 \mathrm{mmol})$. Subsequently, $\mathrm{CuSO}_{4}(100 \mathrm{mg}, 0.63 \mathrm{mmol})$ was added, followed by $12 \mathrm{~mL}$ of trifyl azide stock solution. The reaction was stirred at room temperature for $3 \mathrm{~h}$, washed with $\mathrm{NaHCO}_{3}$ solution and 
extracted with EtOAc. The organic layer was separated and dried over anhydrous sodium sulfate. Upon evaporation, the residue was purified by flash column chromatography on silica gel EtOAc:Hexane (1:3) to yield $1 \mathrm{~g}$ of the title compound as an orange solid (80\% yield). ${ }^{1} \mathrm{HNMR}$ (400 $\left.\mathrm{MHz}, \mathrm{CDCl}_{3}\right) \delta \mathrm{ppm} 1.15(\mathrm{~s}, 6 \mathrm{H}), 1.21(\mathrm{~s}, 6 \mathrm{H}), 1.52(\mathrm{t}, \mathrm{J}=$ $12.2 \mathrm{~Hz}, 2 \mathrm{H}), 1.85$ (dd, J = 11.8, $2.9 \mathrm{~Hz}, 2 \mathrm{H}), 3.58$ (tt, J =


$32.5,44.3,52.9,59.1$.

5.1.4.2. General procedure for preparation of compound $9 a-$ s: To a solution of $0.5 \mathrm{mmol}$ of compounds $\mathbf{8 a - s}$, and 0.6 mmol of 4-azido-tempo in $3 \mathrm{~mL}$ of acetonitrile was added $15.2 \mathrm{mg}(0.08 \mathrm{mmol})$ copper (I) iodide at room temperature. The reaction mixture was stirred at room temperature for $6 \mathrm{~h}$. The reaction mixture was washed with saturated aqueous $\mathrm{NaHCO}_{3}$ solution $(3 \times 10 \mathrm{~mL})$ and then extracted with ethyl acetate $(30 \mathrm{~mL} \times 3)$. The combined organic layers were dried over anhydrous sodium sulfate, filtered, and concentrated. The crude residue was purified by flash column chromatography on silica gel to yield the target compounds 9a-s.

5.1.4.3. (S)-N-(2-(((1-(1-Oxyl-2, 2, 6, 6-tetramethylpiperidin4-yl)-1H-1, 2, 3-triazol-4-yl) methyl) amino)-2-oxoethyl)-2$((S)-2, \quad 3, \quad 4, \quad 9-t e t r a h y d r o-1 H-p y r i d o[3, \quad 4-b]$ indole-3carbonyl)-2, 3, 4, 9-tetrahydro-1H-pyrido [3,4-b]indole-3carboxamide (9a, Indole-Gly-Tempo):

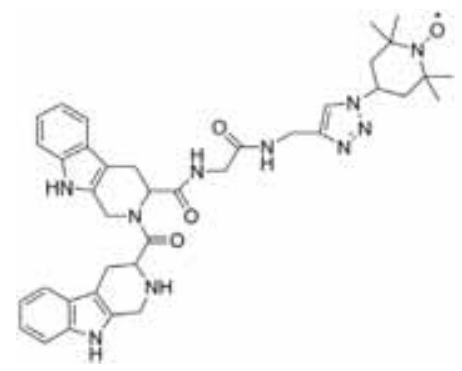

Yield: 57\%. ${ }^{1} \mathrm{HNMR}\left(400 \mathrm{MHz}, \mathrm{CDCl}_{3}\right), \delta / \mathrm{ppm}=11.52$ (brs), 10.84 (brs), 9.87 (brs), 8.85 (brs), 7.60 (brs), 7.21-7.45 (brs), 6.90-7.20 (brs), 4.98-5.04 (brs), 4.20-4.56 (brs), 3.75-3.95 (brs), 2.0 (brs), 1.20 (brs). The observed paramagnetic broadening was due to the effect of the free radical from the nitroxide moiety. ${ }^{13} \mathrm{C}$ NMR $\left(100 \mathrm{~Hz}, \mathrm{DMSO}-d_{6}\right) \delta / \mathrm{ppm}=$ 172.3, 170.0, 169.1, 136.8, 136.3, 130.5, 129.4, 128.8, 127.6, $123.1,126.5,122.6,119.7,121.2,119.0,118.2,117.3,111.8$, 105.1, 72.1, 68.3, 56.7, 50.7, 37.8, 33.4, 43.5, 36.7, 37.8, 23.4, 22.9. HR/MS $[\mathrm{M}+\mathrm{H}]^{+}$calcd 706.3625, found 706.3697 .

5.1.4.4. (S)-N-((R)-1-(((1-(1-Oxyl-2, $\quad 2, \quad 6, \quad 6-$ tetramethylpiperidin-4-yl)-1H-1, 2, 3-triazol-4-yl) methyl) amino)-1-oxopropan-2-yl)-2-((S)-2, 3, 4, 9-tetrahydro-1Hpyrido[3, 4-b]indole-3-carbonyl)-2, 3, 4, 9-tetrahydro-1Hpyrido[3, 4-b]indole-3-carboxamide (9b, Indole-Ala-Tempo):

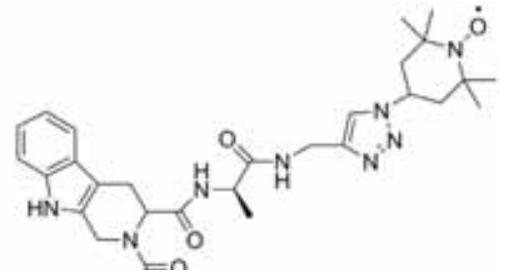

Yield: 68\%. ${ }^{1} \mathrm{HNMR}\left(400 \mathrm{MHz}, \mathrm{CDCl}_{3}\right), \delta / \mathrm{ppm}=11.46$ (brs), 10.87 (brs), 8.97 (brs), 8.62 (brs), 7.62 (brs), 6.91-7.20 (brs), 7.21-7.45 (brs), 4.95 (brs), 4.45-4.65 (brs), 3.75-3.95 (brs), 2.93-3.10 (brs), 2.0 (brs), 1.49 (brs), 1.21 (brs). The observed paramagnetic broadening was due to the effect of the free radical from the nitroxide moiety. ${ }^{13} \mathrm{C}$ NMR (DMSO- $d_{6}$ ) $\delta / \mathrm{ppm}=172.5,170.5,169.3,130.4,131.5,136.2,137.2$, 130.5, 123.0, 127.6, 126.7, 122.0, 121.5, 120.3, 121.8, 112.1, $110.1,119.0,105.1,72.0,69.0,51.5,38.4,31.8,56.4,55.5$, $23.1,25.7,37.6,36.6,44.5,25.4,23.2,18.2 . \mathrm{HR} / \mathrm{MS}[\mathrm{M}+\mathrm{H}]^{+}$ calcd 720.3782 , found 720.3851 .

5.1.4.5. (S)-N-((R)-1-(((1-(1-Oxyl-2, $\quad 2, \quad 6, \quad 6-$ tetramethylpiperidin-4-yl)-1H-1, 2, 3-triazol-4-yl) methyl) amino)-3-methyl-1-oxobutan-2-yl)-2-((S)-2, 3, 4, 9tetrahydro-1H-pyrido[3, 4-b]indole-3-carbonyl)-2, 3, 4, 9tetrahydro-1H-pyrido[3, 4-b]indole-3-carboxamide $\quad(\mathbf{9 c}$,

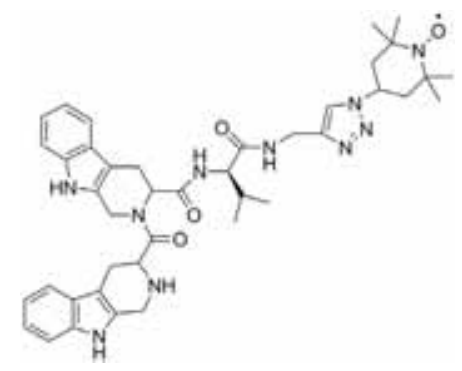

Indole-Val-Tempo):

Yield: 55\%. ${ }^{1} \mathrm{HNMR}\left(400 \mathrm{MHz}, \mathrm{CDCl}_{3}\right), \delta / \mathrm{ppm}=11.55$ (brs), 10.87 (brs), 9.07 (brs), 8.78 (brs), 7.63 (brs), 7.22-7.40 (brs), 6.90-7.20 (brs), 4.95-5.02 (brs), 4.45-4.55 (brs), 3.70-3.95 (brs), 2.95-3.03 (brs), 2.0 (brs), 1.21 (brs), 1.01 (brs). The observed paramagnetic broadening was due to the effect of the free radical from the nitroxide moiety. ${ }^{13} \mathrm{C}$ NMR (DMSO$\left.d_{6}\right) \delta / \mathrm{ppm}=170.5,171.3,169.8,131.2,135.8,134.3,131.5$, $129.7,128.5,123.2,126.4,127.4,122.5,122.6,120.2,120.3$, 112.3, 110.9, 119.0, 117.5, 105.2, 105.7, 72.3, 69.0, 63.2., 56.3, 54.7, 50.7, 45.1, 38.2, 33.5, 37.5, 36.8, 35.8, 25.3, 32.2, 23.3, 18.7. HR/MS $[\mathrm{M}+\mathrm{H}]^{+}$calcd. 748.4095, found 748.4157.

5.1.4.6. (S)-N-((2R,3R)-1-(((1-(1-Oxyl-2, 2, 6, 6tetramethylpiperidin-4-yl)-1H-1, 2, 3-triazol-4-yl) methyl) amino)-3-methyl-1-oxopentan-2-yl)-2-((S)-2, 3, 4, 9tetrahydro-1H-pyrido[3, 4-b]indole-3-carbonyl)-2, 3, 4, 9tetrahydro-1H-pyrido[3, 4-b]indole-3-carboxamide $\mathbf{( 9 d ,}$ Indole-Ile-Tempo):

Yield: 47\%. ${ }^{1} \mathrm{H}$ NMR $\left(400 \mathrm{MHz}, \mathrm{CDCl}_{3}\right), \delta / \mathrm{ppm}=11.50$ (brs), 10.98 (brs), 8.97 (brs), 8.65 (brs), 7.62 (brs), 6.92-7.20 (brs), 7.21-7.40 (brs), 4.95-5.04 (brs), 4.35-4.53 (brs), 3.75-3.95 (brs), 2.94-3.10 (brs), 2.53 (brs), 2.0 (brs), 1.60 (brs), 1.15-

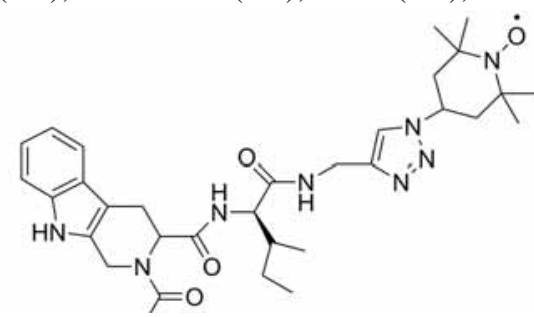


1.20 (brs), 1.05 (brs). The observed paramagnetic broadening was due to the effect of the free radical from the nitroxide moiety. ${ }^{13} \mathrm{C}$ NMR (DMSO- $d_{6}$ ) $\delta / p p m=172.2,170.7,169.8$, $131.7,132.5,137.5,135.3,131.4,123.1,128.4,127.5,122.3$, 122.1, 120.3, 119.7, 112.6, 110.1, 119.0, 118.7, 105.0, 104.7, 72.6, 70.1, 64.1, 54.2, 56.7, 51.4, 44.1, 38.7, 33.7, 37.8, 36.9, $23.8,37.9,26.3,25.2,23.6,24.5,15.2,11.6 . \mathrm{HR} / \mathrm{MS}[\mathrm{M}+\mathrm{H}]^{+}$ calcd $762.4251[\mathrm{M}+\mathrm{H}]$, found: 762.4312 .

5.1.4.7. (S)-N-((R)-1-(((1-(1-oxyl-2, $\quad 2, \quad 6, \quad 6-$ tetramethylpiperidin-4-yl)-1H-1, 2, 3-triazol-4-yl) methyl) amino)-4-methyl-1-oxopentan-2-yl)-2-((S)-2, 3, 4, 9tetrahydro-1H-pyrido[3, 4-b]indole-3-carbonyl)-2, 3, 4, 9tetrahydro-1H-pyrido[3, 4-b]indole-3-carboxamide (9e, Indole-Leu-Tempo):



Yield: $51 \% .{ }^{1} \mathrm{H}$ NMR $\left(400 \mathrm{MHz}, \mathrm{CDCl}_{3}\right), \delta / \mathrm{ppm}=11.50$ (brs), 10.88 (brs), 9.17 (brs), 8.67(brs), 7.62 (brs), 6.92-7.20 (brs), 7.21-7.35 (brs), 4.95 (brs), 4.45-4.55 (brs), 3.70-3.90 (brs), 2.95-3.05 (brs), 2.0 (brs), 1.52-1.75 (brs), 1.20 (brs), 1.01 (brs). The observed paramagnetic broadening was due to the effect of the free radical from the nitroxide moiety. ${ }^{13} \mathrm{C}$ NMR $\left(\mathrm{DMSO}-d_{6}\right) \delta / \mathrm{ppm}=171.8,170.5,169.5,131.7,130.2,137.5$, 135.7, 131.4, 128.7, 123.7, 126.9, 123.0, 122.6, 121.4, 120.3, $112.1,110.9,117.8,118.0,105.7,104.2,72.1,69.0,58.4$, 56.7, 55.8, 52.1, 50.5, 45.1, 41.7, 38.4, 37.3, 36.5, 33.5, 23.7, $26.2,25.5,23.2,24.5,23.3,22.5$. HR/MS $[\mathrm{M}+\mathrm{H}]^{+}$calcd 762.4251 , found: 762.4297 .

5.1.4.8. (R)- $N^{l}-((1-(1-O x y l-2,2,6,6-t e t r a m e t h y l p i p e r i d i n-4-$ $y l)-1 H-1,2$, 3-triazol-4-yl) methyl)-2-((S)-2-((S)-2, 3, 4, 9tetrahydro-1H-pyrido[3, 4-b]indole-3-carbonyl)-2, 3, 4, 9tetrahydro-1H-pyrido[3, 4-b]indole-3-carboxamido) succinamide (9f, Indole-Asn-Tempo):

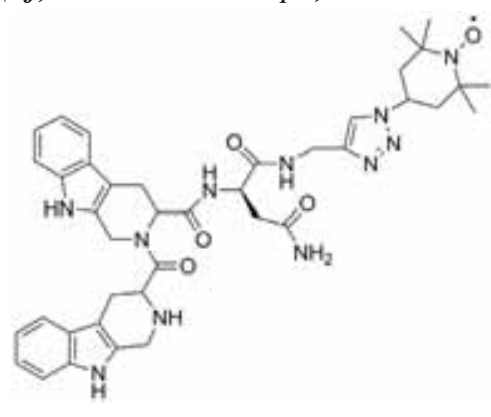

Yield: $56 \%$. ${ }^{1} \mathrm{HNMR}\left(400 \mathrm{MHz}, \mathrm{CDCl}_{3}\right), \delta / \mathrm{ppm}=11.53$ (brs), 10.83 (brs), 9.08 (brs), 8.67(brs), 7.64 (brs), 7.05-7.23 (brs), 7.02 (brs), 6.95-7.20 (brs), 7.21- 7.40 (brs), $4.85-4.95$ (brs), 4.45-4.55 (brs), 3.70-3.90 (brs), 2.93-3.05 (brs), 2.77 (brs), 2.01(br), 1.20 (brs). The observed paramagnetic broadening was due to the effect of the free radical from the nitroxide moiety. ${ }^{13} \mathrm{C}$ NMR (DMSO- $d_{6}$ ) $\delta / \mathrm{ppm}=172.7,172.2,170.6$, 169.6, 138.1, 135.0, 132.7, 130.5, 131.3, 124.0, 128.1, 126.3, $122.5,121.3,120.5,120.9,119.4,111.7,112.1,105.1,104.1$, 119.0, 73.2, 70.1, 52.0, 56.7, 54.2, 55.6, 50.5, 45.7, 38.1, 33.5, $37.8,37.6,23.4,23.7,22.4,24.3,26.5$. HR/MS $[\mathrm{M}+\mathrm{H}]^{+}$calcd 763.3840. found: 763.3877 .

5.1.4.9. (S)-N-((R)-1-(((1-(1-Oxyl-2, $\quad 2, \quad 6, \quad 6-$ tetramethylpiperidin-4-yl)-1H-1, 2, 3-triazol-4-yl) methyl)amino)-3-(1H-imidazol-4-yl)-1-oxopropan-2-yl)-2-

$((S)-2, \quad 3, \quad 4, \quad 9-t e t r a h y d r o-1 H$-pyrido[3, 4-b]indole-3carbonyl)-2, 3, 4, 9-tetrahydro-1H-pyrido[3, 4-b]indole-3carboxamide (9g, Indole-His-Tempo):

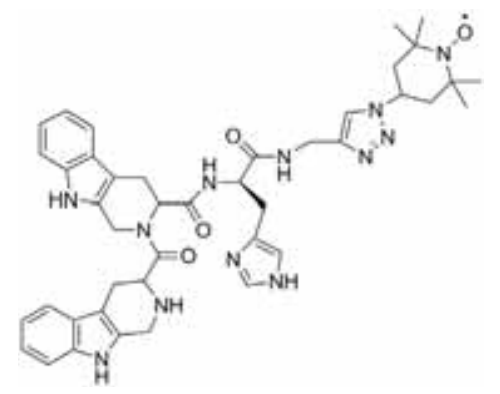

Yield: 47\%. ${ }^{1} \mathrm{HNMR}\left(400 \mathrm{MHz}, \mathrm{CDCl}_{3}\right), \delta / \mathrm{ppm}=11.50$ (brs), 10.85 (brs), 8.97 (brs), 8.52 (brs), 7.60-7.65 (brs), 6.91-7.20 (brs), 7.21-7.45 (brs), 4.92-4.96 (brs), 4.45-4.55 (brs), 3.703.95 (brs), 2.95-3.10 (brs), 2.0 (br), 1.20 (brs). The observed paramagnetic broadening was due to the effect of the free radical from the nitroxide moiety. ${ }^{13} \mathrm{C}$ NMR (DMSO- $d_{6}$ ) $\delta / \mathrm{ppm}=171.7,170.5,169.3,137.6,136.3,135.8,132.1$, 131.6, 132.1, 132.8, 123.6, 128.0, 122.4, 123.1, 120.1, 121.4, $112.4,112.5,120.8,119.0,118.6,106.1,105.5,72.0,69.0$, 57.6, 52.1, 38.3, 33.4, 57.2, 56.3, 58.3, 38.3, 37.5, 45.5, 32.3, $30.5,24.3,25.3,23.3$. HR/MS $[\mathrm{M}+\mathrm{H}]^{+}$calcd 786.4000. found: 786.4076 .

5.1.4.10. (S)-N-((R)-1-((1-(1-Oxyl-2, $\quad 2, \quad 6, \quad 6-$ tetramethylpiperidin-4-yl)-1H-1, 2, 3-triazol-4-yl) methyl) amino)-1-oxo-3-phenylpropan-2-yl)-2-((S)-2, 3, 4, 9tetrahydro-1H-pyrido[3, 4-b]indole-3-carbonyl)-2, 3, 4, 9tetrahydro-1H-pyrido[3, 4-b]indole-3-carboxamide $\mathbf{( 9 h}$,

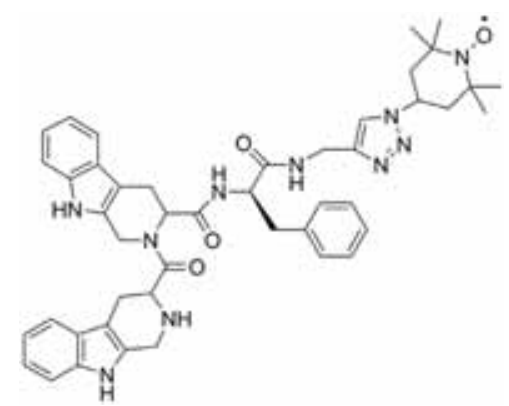

Indole-Phe-Tempo):

Yield: 52\%. ${ }^{1} \mathrm{HNMR}\left(400 \mathrm{MHz}, \mathrm{CDCl}_{3}\right), \delta / \mathrm{ppm}=11.50$ (brs), 10.87 (brs), 8.95 (brs), 8.67 (brs), 7.62 (brs), 6.92-7.20 (brs), 
7.21-7.45 (brs), 4.95-5.05 (brs), 4.45-4.57 (brs), 2.95-3.25 (brs), 3.70-3.90 (brs), 2.00 (brs), 1.20 (brs). The observed paramagnetic broadening was due to the effect of the free radical from the nitroxide moiety. ${ }^{13} \mathrm{C}$ NMR (DMSO- $d_{6}$ ) $\delta / \mathrm{ppm}=172.5,171.0,169.7,136.5,137.0,136.4,131.6$, $132.8,131.3,123.4,128.5,126.9,120.7,122.3,123.5,121.5$, $129.5,129.0,127.4,128.8,128.0,119.6,112.4,113.5,119.3$, $106.3,105.2,72.0,69.0,51.6,59.0,56.2,57.5,37.3,35.8$, $44.5,38.2,38.4,33.6,25.5,24.2,24.5$. 23.4, 22.5. HR/MS $[\mathrm{M}+\mathrm{H}]^{+}$calcd 796.4095. found: 796.4136 .

5.1.4.11. (S)-N-((R)-6-Amino-1-((1-(1-oxyl-2, 2, 6, 6tetramethylpiperidin-4-yl)-1H-1, 2, 3-triazol-4-yl) methyl) amino)-1-oxohexan-2-yl)-2-((S)-2, 3, 4, 9-tetrahydro-1Hpyrido[3, 4-b]indole-3-carbonyl)-2, 3, 4, 9-tetrahydro-1Hpyrido[3, 4-b]indole-3-carboxamide (9i, Indole-Lys-Tempo):



Yield: $58 \% .{ }^{1} \mathrm{H}$ NMR $\left(400 \mathrm{MHz}, \mathrm{DMSO}-d_{6}\right): \delta / \mathrm{ppm}=11.37$ (brs), 10.97 (brs), 8.98 (brs), 8.55 (brs), 7.65 (brs), 7.05-7.21 (brs), 5.05 (brs), 4.45-4.65 (brs), 4.75-4.90 (brs), 3.75-3.95 (brs), 2.70-2.96 (brs), 2.0 (brs), 1.55-1.80 (brs), 1.21-1.26 (brs). The observed paramagnetic broadening was due to the effect of the free radical from the nitroxide moiety. ${ }^{13} \mathrm{C}$ NMR $\left(\mathrm{DMSO}-d_{6}\right) \delta / \mathrm{ppm}=171.8,170.5,169.3,131.5,130.8,135.8$, 137.4, 132.0, 123.5, 128.1, 126.9, 122.3, 122.8, 120.4, 119.4, $112.4,110.9,119.3,118.2,105.1,106.3,72.6,69.5,51.4$, $38.4,33.2,55.6,38.7,33.4,57.4,56.8,23.4,26.5,37.4,36.4$, $44.5,58.6,43.2,32.7,29.2,23.6,22.6$. HR/MS $[\mathrm{M}+\mathrm{H}]+$ calcd. 777.4360, found 777. 4425 .

5.1.4.12. (S)-N-((R)-1-((1-(1-Oxyl-2, $\quad 2, \quad 6, \quad 6-$ tetramethylpiperidin-4-yl)-1H-1, 2, 3-triazol-4-yl) methyl) amino)-3-(4-hydroxyphenyl)-1-oxopropan-2-yl)-2-((S)-2, 3, 4, 9-tetrahydro-1H-pyrido[3, 4-b]indole-3-carbonyl)-2, 3, 4, 9tetrahydro-1H-pyrido[3, 4-b]indole-3-carboxamide $\quad(\mathbf{9 j}$, Indole-Tyr-Tempo):



Yield: $41 \% .{ }^{1} \mathrm{H}$ NMR $\left(400 \mathrm{MHz}, \mathrm{DMSO}-d_{6}\right): \delta / \mathrm{ppm}=11.55$ (brs), 10.98 (brs), 8.97 (brs), 8.55 (brs), 6.92-7.20 (brs), 7.217.45 (brs), 7.65 (brs), 6.80-7.15 (brs), 4.95 (brs), 4.45-4.65 (brs), 3.70-3.90 (brs), 3.20-3.45 (brs), 2.90-3.10 (brs), 2.0 (brs), 1.20 (brs). The observed paramagnetic broadening was due to the effect of the free radical from the nitroxide moiety. ${ }^{13} \mathrm{C}$ NMR $\left(\mathrm{DMSO}-d_{6}\right) \delta / \mathrm{ppm}=172.4,170.6,169.7,156.7$, 136.4, 131.2, 132.4, 130.2, 129.4, 127.3, 122.8, 121.17, 121.7, 111.5, 118.8, 116.0, 119.8, 104.9, 71.9, 69.2, 56.7, 56.5, 50.6, $37.6,32.0,43.1,37.4,36.6,25.1,23.2,22.2$. HR/MS $[\mathrm{M}+\mathrm{H}]+$ calcd. 812.4044. found, 812.4092.

5.1.4.13. (S)-N-((R)-1-((1--(1-Oxyl-2, $\quad 2, \quad 6, \quad 6-$ tetramethylpiperidin-4-yl)-1H-1, 2, 3-triazol-4-yl) methyl)amino)-4-(methylthio)-1-oxobutan-2-yl)-2-((S)-2, 3, 4, 9-tetrahydro-1H-pyrido [3, 4-b]indole-3-carbonyl)-2, 3, 4, 9tetrahydro-1H-pyrido[3, 4-b]indole-3-carboxamide $\mathbf{( 9 k}$, Indole-Met-Tempo):

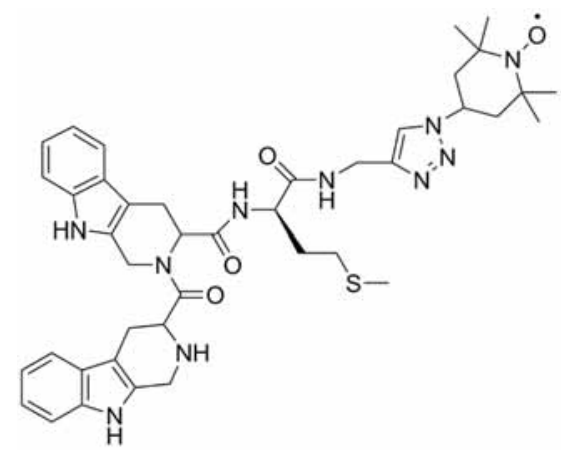

Yield: $49 \% .{ }^{1} \mathrm{H}$ NMR $\left(400 \mathrm{MHz}, \mathrm{DMSO}-d_{6}\right): \delta / \mathrm{ppm}=11.52$ (brs), 10.88 (brs), 8.97 (brs), 8.65 (m, 1H), 7.65 (brs), 6.917.20 (brs), 7.21-7.45 (brs), 4.95-5.05 (brs), 4.45-4.55 (brs), 3.70-3.95 (brs), 2.90-3.10 (brs), 2.05-2.60 (brs), 2.00-2.10 (brs), 1.20 (brs). The observed paramagnetic broadening was due to the effect of the free radical from the nitroxide moiety. ${ }^{13} \mathrm{C}$ NMR $\left(\mathrm{DMSO}-d_{6}\right) \delta / \mathrm{ppm}=170.3,169.7,172.4,136.8$, 136.3, 130.2, 130.6, 130.5, 123.7, 128.3, 127.1, 121.7, 122.8, $120.8,120.3,119.7,118.4,112.6,110.5,105.3,104.9,72.0$, 69.3, 58.6, 56.0, 50.5, 37.6, 25.1, 37.2, 32.0, 43.1, 32.4, 25.5, 23.3. 22.7, 15.6. HR/MS $[\mathrm{M}+\mathrm{H}]+$ calcd. 780.3815. found, 780.3887 .

5.1.4.14. (S)-N-((R)-3-hydroxy-1-(((1-(1-oxyl-2, 2, 6, 6tetramethylpiperidin-4-yl)-1H-1, 2, 3-triazol-4-yl) methyl) amino)-1-oxopropan-2-yl)-2-((S)-2, 3, 4, 9-tetrahydro-1Hpyrido[3, 4-b]indole-3-carbonyl)-2, 3, 4, 9-tetrahydro-1Hpyrido[3, 4-b]indole-3-carboxamide (9l, Indole-Ser-Tempo): 


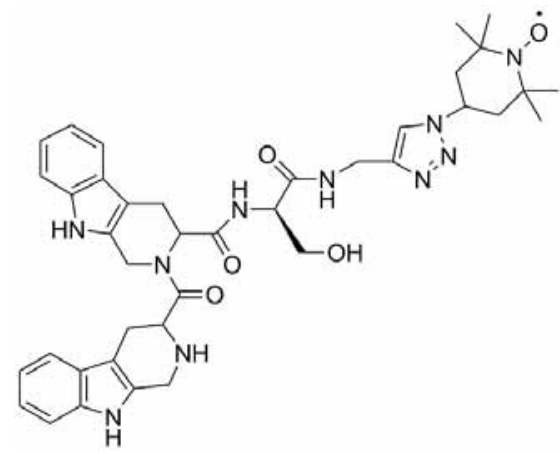

Yield: $51 \%$. ${ }^{1} \mathrm{H}$ NMR $\left(400 \mathrm{MHz}, \mathrm{DMSO}-d_{6}\right): \delta / \mathrm{ppm}=11.55$ (brs), 10.88 (brs), 8.95 (brs), 8.72 (brs), 7.63 (brs), 6.92-7.20 (brs), 7.21-7.45 (brs), 4.95 (brs), 4.20-4.56(brs), 3.70-3.92 (brs), 2.90-3.10 (brs), 2.00 (brs), 1.2 (brs). The observed paramagnetic broadening was due to the effect of the free radical from the nitroxide moiety. ${ }^{13} \mathrm{C}$ NMR (DMSO- $d_{6}$ ) $\delta / \mathrm{ppm}=172.8,170.2,167.4,130.4,135.5,136.7,130.5$, 127.8, 127.3, 128.1, 125.1, 121.9, 120.4, 119.0, 111.6, 102.3, 105.0, 70.7, 66.3, 61.7, 60.5, 50.5, 56.5, 44.2, 35.4, 25.5, 23.3, 22.0. HR/MS [M+H] calcd. 736.3731, found 736.3798 .

5.1.4.15. (S)-N-((R)-1-(((1-(1-Oxyl-2, $\quad 2, \quad 6, \quad 6-$ tetramethylpiperidin-4-yl)-1H-1, 2, 3-triazol-4-yl) methyl) amino)-3-(1H-indol-3-yl)-1-oxopropan-2-yl)-2-((S)-2, 3, 4, 9tetrahydro-1H-pyrido[3, 4-b]indole-3-carbonyl)-2, 3, 4, 9tetrahydro-1H-pyrido[3,4-b]indole-3-carboxamide

$(9 m$, Indole-Trp-Tempo):



Yield: $43 \% .{ }^{1} \mathrm{H}$ NMR $\left(400 \mathrm{MHz}, \mathrm{DMSO}-d_{6}\right): \delta / \mathrm{ppm}=11.57$ (brs), 11.02 (brs), 10.82 (brs), 8.98 (brs), 8.75 (brs), 7.21-7.60 (brs), 6.92-7.20 (brs), 4.98 (brs), 4.25-4.55 (brs), 3.70-3.95 (brs), 3.31-3.40 (brs), 2.90-3.10 (brs), 1.95 (brs), 1.20 (brs). The observed paramagnetic broadening was due to the effect of the free radical from the nitroxide moiety. ${ }^{13} \mathrm{C} \mathrm{NMR}$ $\left(\mathrm{DMSO}-d_{6}\right) \delta / \mathrm{ppm}=172.4,171.7,169.2,136.7,135.9,130.5$, 135.6, 130.8, 128.1, 124.1, 123.7, 127.9, 126.5, 105.3, 102.1, $127.4,109.4,49.5,35.2,30.3,55.7,50.4,70.5,67.6,111.9$, $111.0,119.2,120.3,120.5,20.5,23.2,119.7,121.7,120.8$, $36.7,40.5,57.8,28.7,25.9,23.3,20.9$. HS/MS $[\mathrm{M}+\mathrm{H}]^{+}$ 835.4204 , found 835.4279 .

5.1.4.16. (R)-N-((1-(1-Oxyl-2, 2, 6, 6-tetramethylpiperidin-4yl)-1H-1, 2, 3-triazol-4-yl)methyl $)-1-((S)-2-((S)-2, \quad 3, \quad 4, \quad 9-$ tetrahydro-1H-pyrido[3, 4-b]indole-3-carbonyl)-2, 3, 4, 9-
tetrahydro-1H-pyrido[3,4-b]indole-3-carbonyl) pyrrolidine2-carboxamide (9n, Indole-Pro-Tempo):<smiles>CN1C(C)(C)CC(n2cc(CNC(=O)C3CCCN3C(=O)C3Cc4[nH]c5ccccc5c4C3)nn2)CC1(C)C</smiles>

Yield: $38 \% .{ }^{1} \mathrm{H}$ NMR $\left(400 \mathrm{MHz}, \mathrm{DMSO}-d_{6}\right): \delta / \mathrm{ppm}=11.52$ (brs), 10.25 (brs), 8.90 (brs), 7.65 (brs), 7.21-7.45 (brs), 6.987.20 (brs), 4.95 (brs), 4.25-4.55 (brs), 3.65-3.95 (brs), 2.953.10 (brs), 2.00-2.35 (brs), 1.20 (brs). The observed paramagnetic broadening was due to the effect of the free radical from the nitroxide moiety. ${ }^{13} \mathrm{C}$ NMR (DMSO- $d_{6}$ ) $\delta / \mathrm{ppm}=170.8,169.2,167.8,136.2,135.5,131.5,130.6$, $135.7,130.8,123.5,124.2,128.2,122.6,127.6,122.8,128.9$, $120.4,111.0,111.3,120.5,119.2,105.2,102.2,108.9,70.3$, 69.2, 60.9, 50.5, 48.5, 43.0, 35.3, 30.5, 20.7, 23.5, 37.2, 24.6, 22.4. HR/MS [M+H]+ calcd. 746.3938, found 746. 4007.

5.1.4.17. (S)-N-((2R, 3R)-3-hydroxy-1-(((1-(1-oxyl-2, 2, 6, 6tetramethylpiperidin-4-yl)-1H-1, 2, 3-triazol-4yl)methyl)amino)-1-oxobutan-2-yl)-2-((S)-2, $\quad 3, \quad 4, \quad 9$ tetrahydro-1H-pyrido[3, 4-b]indole-3-carbonyl)-2, 3, 4, 9tetrahydro-1H-pyrido[3, 4-b]indole-3-carboxamide $(\mathbf{9 o}$, Indole-Thr-Tempo):

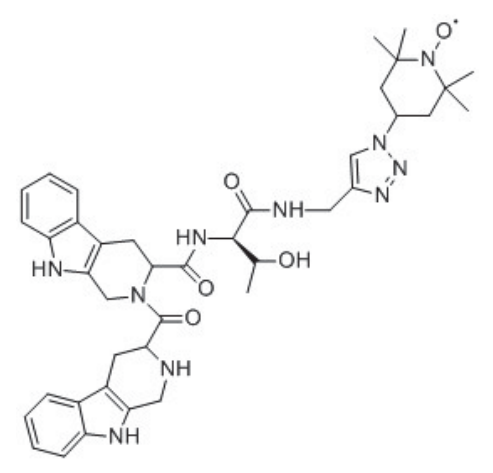

Yield: $51 \% .{ }^{1} \mathrm{H}$ NMR $\left(400 \mathrm{MHz}, \mathrm{DMSO}-d_{6}\right): \delta / \mathrm{ppm}=11.57$ (brs), 10.65 (brs), 8.92 (brs), 8.57 (brs), 6.92- 7.20 (brs), 7.217.45 (brs), 7.65 (brs), 4.95 (brs), 4.45-4.65 (brs), 3.75-3.95 (brs), 2.90-3.10 (brs), 1.95 (brs), 1.1-1.2 (brs). The observed paramagnetic broadening was due to the effect of the free radical from the nitroxide moiety. ${ }^{13} \mathrm{C}$ NMR (DMSO- $d_{6}$ ) $\delta / \mathrm{ppm}=172.4,171.5,169.7,131.5,129.7,135.7,136.6$, $130.5,124.5,126.7,121.6,120.7,120.5,119.8,111.0,111.5$, $105.4,105.7,72.8,67.8,65.8,63.2,60.9,55.6,51.5,43.5$, $38.3,36.7,30.9,22.7,36.8,33.0,41.3,23.3$. 19.5. HR/MS $[\mathrm{M}+\mathrm{H}]^{+}$calcd. 750.3887 , found 750. 3943. 
5.1.4.18. (S)-N-((R)-1-((1-(1-Oxyl-2, $\quad 2, \quad 6, \quad 6-$ tetramethylpiperidin-4-yl)-1H-1, 2, 3-triazol-4-yl)methyl) amino)-5-(3-nitroguanidino)-1-oxopentan-2-yl)-2-((S)2,3,4,9-tetrahydro-1H-pyrido[3,4-b]indole-3-carbonyl)2,3,4,9-tetrahydro-1H-pyrido[3,4-b]indole-3-carboxamide (9p, Indole-Arg-Tempo):

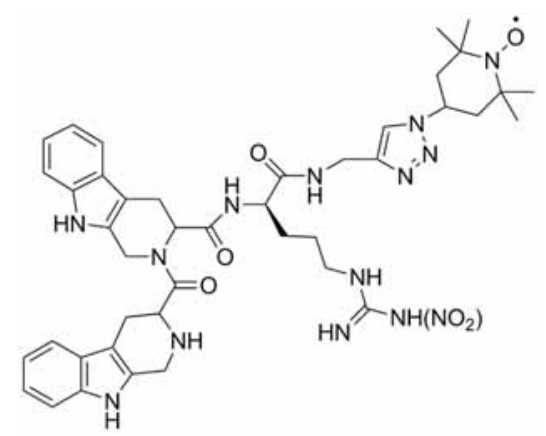

Yield: $47 \% .{ }^{1} \mathrm{H}$ NMR $\left(400 \mathrm{MHz}, \mathrm{DMSO}-d_{6}\right): \delta / \mathrm{ppm}=11.54$ (brs), 11.02 (brs), 8.97 (brs), 8.65 (brs), 7.63 (brs), 6.90-7.20 (brs), 7.21-7.45 (brs), 4.98 (brs), 4.45-4.55 (brs), 3.75-3.95 (brs), 2.95-3.35 (brs), 2.0 (brs), 1.55-1.80 (brs), 1.20 (brs). The observed paramagnetic broadening was due to the effect of the free radical from the nitroxide moiety. ${ }^{13} \mathrm{C}$ NMR $\left(\mathrm{DMSO}-d_{6}\right) \delta / \mathrm{ppm}=172.4,171.70,169.61,159.8,136.8$, 136.2, 130.0, 131.3, 128.8, 128.2, 127.2, 126.7, 122.8, 121.6, 120.6, 111.6, 110.7, 105.1, 72.0, 69.4, 55.6, 51.5, 38.6, 36.9, $50.7,43.6,40.5,29.1,25.6,24.1,22.9,23.2 . \mathrm{HR} / \mathrm{MS}[\mathrm{M}+\mathrm{H}]^{+}$ calcd. 850.4273, found 850. 4345 .

5.1.4.19. (R)- $N^{1}-((1-(1-O x y l-2,2,6,6$-tetramethylpiperidin-4$y l)-1 H-1, \quad 2, \quad 3-t r i a z o l-4-y l)$ methyl $)-2-((S)-2-((S)-2, \quad 3, \quad 4, \quad 9-$ tetrahydro-1H-pyrido[3, 4-b]indole-3-carbonyl)-2, 3, 4, 9tetrahydro-1H-pyrido[3, 4-b]indole-3-carboxamido) pentanediamide (9q, Indole-Gln-Tempo):

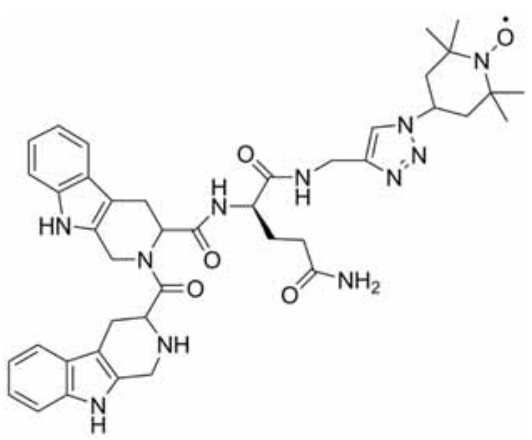

Yield: $54 \% .{ }^{1} \mathrm{H}$ NMR $\left(500 \mathrm{MHz}, \mathrm{DMSO}-d_{6}\right): \delta / \mathrm{ppm}=11.50$ (brs), 10.95 (brs), 8.95 (brs), 8.75 (brs), 6.91-7.20 (brs) 7.217.56 (brs), 7.65 (brs), 4.45-4.65 (brs), 3.70-3.95 (brs) 2.803.12 (brs), 1.93-2.10 (brs), 1.2 (brs). The observed paramagnetic broadening was due to the effect of the free radical from the nitroxide moiety. ${ }^{13} \mathrm{C}$ NMR (DMSO- $d_{6}$ ) $\delta / \mathrm{ppm}=174.1,172.4,171.7,169.6,136.7,136.2,130.6$, $129.5,127.5,128.3,127.1,123.4,122.2,119.6,118.4,111.5$, $111.2,105.2,104.9,72.0,69.3,56.9,55.5,50.5,36.7,32.6$, 28.7, 25.1, 23.3. HR/MS $[\mathrm{M}+\mathrm{H}]+$ calcd. 777.3996, found. 777. 4065 .
5.1.4.20. $\quad N^{1}, \quad N^{4}$-Bis((1-(1-Oxyl-2, $\quad 2, \quad 6, \quad 6$ tetramethylpiperidin-4-yl)-1H-1, 2, 3-triazol-4-yl) methyl)-2((S)-2-((S)-2, 3, 4, 9-tetrahydro-1H-pyrido[3, 4-b]indole-3carbonyl)-2, 3, 4, 9-tetrahydro-1H-pyrido[3, 4-b]indole-3carboxamido) succinamide (9r, Indole-Asp-bis-Tempo):



Yield: 45\%. ${ }^{1} \mathrm{H}$ NMR (400MHz, DMSO- $\left.d_{6}\right): \delta / \mathrm{ppm}=11.60$ (brs), 10.89 (brs), 8.98 (brs), 8.65 (brs), 8.42 (brs), 7.60-7.65 (brs), 6.97-7.20 (brs), 7.21-7.45 (brs), 4.15-4.55 (brs), 4.554.96 (brs), 3.70-3.95 (brs), 2.75-3.10 (brs), 1.93-2.0 (brs), 1.20 (brs). The observed paramagnetic broadening was due to the effect of the free radicals from the nitroxide moieties. ${ }^{13} \mathrm{C}$ NMR $\left(\right.$ DMSO- $\left.d_{6}\right) \delta / p p m=173.8,172.5,170.3,169.8,136.8$, 136.2, 131.2, 131.0, 130.9, 128.4, 128.0, 123.6, 122.5, 121.8, 120.3, 118.7, 111.0, 111.5, 105.6, 72.4, 70.7, 56.5, 55.0, 50.7, 43.5, 44.0, 36.6, 39.0, 37.8, 32.9, 25.6, 23.3, 22.5. HR/MS $[\mathrm{M}+\mathrm{H}]^{+}$calcd. 998.5399, found, 998.5450 .

5.1.4.21. (R)- $N^{1}, N^{5}-B i s((1-(1-o x y l-2, \quad 2, \quad 6, \quad 6-$ tetramethylpiperidin-4-yl)-1H-1, 2, 3-triazol-4-yl) methyl)-2((S)-2-((S)-2, 3, 4, 9-tetrahydro-1H-pyrido[3, 4-b]indole-3carbonyl)-2, 3, 4, 9-tetrahydro-1H-pyrido [3, 4-b]indole-3carboxamido) pentanediamide (9s, Indole-Glu-bis-Tempo):

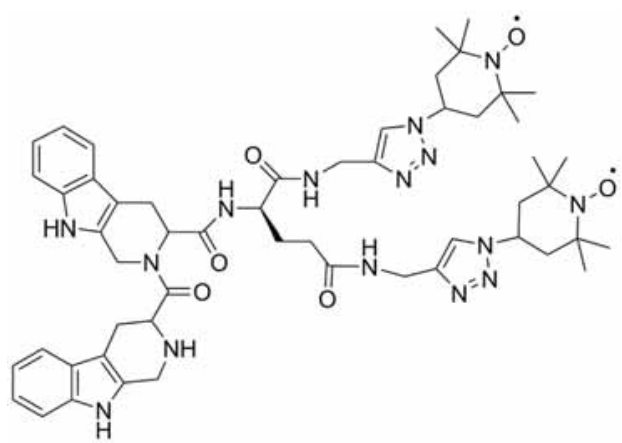

Yield: 49\%. ${ }^{1} \mathrm{H}$ NMR $\left(400 \mathrm{MHz}, \mathrm{DMSO}-d_{6}\right): \delta / \mathrm{ppm}=11.57$ (brs), 11.02 (brs), 9.02 (brs), 8.90 (brs), 8.50 (brs), 7.60-7.65 (brs), 6.90-7.22 (brs), 7.23-7.46 (brs), 4.97 (brs), 4.20-4.58 (brs), 3.70-3.95 (brs), 2.93-3.15 (brs), 1.95-2.10 (brs), 1.2 (brs). The observed paramagnetic broadening was due to the effect of the free radicals from the nitroxide moieties. ${ }^{13} \mathrm{C}$ NMR $\left(\right.$ DMSO- $\left.d_{6}\right) \delta / p p m=174.1,171.3,170.4,169.8,136.7$, $136.2,129.2,130.7,131.4,127.5,128.3,128.2,127.3,123.2$, 121.7, 119.03, 111.9, 105.2, 72.0, 69.7, 57.2, 56.4, 50.5, 43.5, 37.6, 36.7, 33.5, 28.0, 23.3. HR/MS $[\mathrm{M}+\mathrm{H}]^{+}$calcd. 1012.5555, found, 1012.5632 .

\subsection{Cell Culture}


Human umbilical vein endothelial cells (HUVECs) were purchased from ATCC (American Type Culture Collection) and were cultured in endothelial cell medium supplemented with endothelial cell growth supplement, $5 \%$ fetal bovine serum, and penicillin/streptomycin solution in an incubator with $5 \% \mathrm{CO}_{2}$ at $37^{\circ} \mathrm{C}$.

Molecular dynamic simulation ${ }^{21,26,28}$

Molecular dynamics evaluations were performed based on an MM2 force field (CambridgeSoft Chem \& Bio 3D 12.0). Some important parameters employed included the following: Step Interval: $2.0 \mathrm{fs}$; Frame Interval: $10 \mathrm{fs}$; Terminate After: 10000 steps; Heating/Cooling Rate: $1.000 \mathrm{Kcal} /$ atom/ps; Target Temperature: $300^{\circ} \mathrm{K}$.

\subsection{Biological assays}

All animal experiments were performed in compliance with the "Guide for the Care and Use of Laboratory Animals" published by the US National Institutes of Health. The experimental protocol was approved by the Ethics Review Committee for Animal Exprimentation of HeBei Medical University.

\subsubsection{Evaluation of in vivo anti-inflammatory activity ${ }^{40-43}$}

Anti-inflammatory activities of synthetic compounds were evaluated in a xylene-induced ear edema assay. Briefly, male ICR mice $(20 \pm 2 \mathrm{~g})$ were randomly divided into three groups, including the test group, vehicle control (1\% Carboxymethyl cellulose solution, CMC) and positive control group (aspirin). The positive control cohort received an oral suspension of aspirin in CMC $(10 \mathrm{mg} / \mathrm{kg})$. The test group initially received oral suspensions of test species in CMC $(0.10 \mathrm{mmol} / \mathrm{kg})$. Thirty minutes later, $0.03 \mathrm{ml}$ of xylene was applied to the anterior and posterior surfaces of the right ear, the left ear serving as control. Two hours following xylene application, the mice were sacrificed and both ears were removed. Multiple circular sections were obtained using a cork borer and weighed. The increase in weight associated with xylene irritation was determined by subtracting the weight of untreated tissue sections from treated sections. The results were shown in Table $\mathbf{1}$.

\subsubsection{Tail bleeding time measurement ${ }^{22}$}

The newly synthesized indole-TEMPO conjugates (9a-s) were orally administered at the dose of $0.50 \mathrm{mmol} / \mathrm{kg}$ to male mice (body weight 18-22 g). After administration at 30, 45, 60, and $90 \mathrm{~min}$, a mouse was placed in a tube holder with its tail protruding, and a 2-mm cut was made on the tail. Flowing blood was gently wiped away with a tissue every $30 \mathrm{~s}$ until bleeding ceased and the time was recorded. The results were shown in Table 2.

\subsubsection{Simulated ischemia/reperfusion $(s I / R)$ protocol}

$\mathrm{sI} / \mathrm{R}$ was achieved in a flow through chamber as previously described. ${ }^{45}$ Briefly, cells were washed with phosphate buffer solution (PBS) and incubated in balanced salt solution (116 $\mathrm{mmol} / \mathrm{L} \mathrm{NaCl}, 5.4 \mathrm{mmol} / \mathrm{L} \mathrm{KCl}, 0.8 \mathrm{mmol} / \mathrm{L} \mathrm{MgSO}_{4}, 1 \mathrm{mmol} / \mathrm{L}$ $\mathrm{NaH}_{2} \mathrm{PO}_{4}, 0.9 \mathrm{mmol} / \mathrm{L} \mathrm{CaCl}$, and $10 \mathrm{mg} / \mathrm{L}$ phenol red). The cells were then incubated in a hypoxia chamber (Themo scientific, USA) with a compact gas oxygen controller to maintain oxygen concentration at $1 \%$ by injecting a gas mixture of $94 \% \mathrm{~N}_{2}$ and $5 \% \mathrm{CO}_{2}$ for $2 \mathrm{~h}$. After hypoxia, the cells were transferred back to full culture medium with oxygen. Normal control cells were incubated in a regular cell culture incubator under normoxic conditions. Cells were incubated with full culture medium containing indole-bis-TEMPOs 9r, s $(30 \mu \mathrm{g} / \mathrm{mL})$ under normoxic conditions for $12 \mathrm{~h}$ prior to simulated ischemia. The full culture medium containing drug was discarded. The cells were rinsed once with PBS, and incubated with balanced salt solution containing indole-bis-TEMPOs 9r， $\mathbf{s}(30 \mu \mathrm{g} / \mathrm{mL})$ during simulated ischemia for $2 \mathrm{~h}$. The balanced salt solution was discarded, and then the cells were incubated with full culture medium, drug free, under normoxic conditions for $3 \mathrm{~h}$.

\subsection{Intestinal ischemia/reperfusion model ${ }^{28}$}

Male Wistar rats $(250 \pm 50 \mathrm{~g})$ were randomly assigned to five experimental groups: (1) Sham group: rats subjected to the procedures described below, with the exception of ischemia/reperfusion (I/R) $(n=8)$; (2) I/R group: rats subjected to the procedures described below undergoing intestinal ischemia for 45 min followed by reperfusion for 12 hours $(n=8)$; (3) $I / R+$ drug (TEMPOL or indole-bis-TEMPOs 9r, s) treatment group: rats received a bolus injection of drug (TEMPOL, 9r, s, 30 $\mathrm{mg} / \mathrm{kg}$, dissolve in saline) 5 minutes prior to reperfusion and then received a continuous infusion of drug (TEMPOL or 9r, s, 10 $\mathrm{mg} / \mathrm{kg} / \mathrm{hr})$ throughout the reperfusion period $(\mathrm{n}=8)$. Animals in groups (1) and (2) were administrated saline vehicle in lieu of drug. Male Wistar rats were anesthetized with an intraperitoneal injection of sodium pentobarbital $(80 \mathrm{mg} / \mathrm{kg})$. Throughout the experiment body temperature was maintained at $37^{\circ} \mathrm{C}$ with the aid of a heating pad. Laparotomy was performed through a midline incision into the peritoneal cavity. The small bowel was gently exposed on moist gauze, followed by occlusion of the superior mesenteric artery for $45 \mathrm{~min}$ using a micro-vascular clamp, followed by $12 \mathrm{~h}$ reperfusion. Adequate occlusion was confirmed based upon pallor and an absence of pulsation in the mesenteric vessels of the small intestine. Surgical incisions were sutured during the reperfusion period. Sham-operated rats underwent an identical surgical protocol but did not undergo superior mesenteric artery clamping and remained anesthetized for the duration of the experiment. At each of the indicated time points, eight rats were randomly sacrificed from each group; blood samples were collected, with collection of liver, kidney, lung and full-thickness samples of small intestine removed for further analysis. Blood samples were spun at $1000 \times \mathrm{g}$ for $10 \mathrm{~min}$ and the serum was harvested and stored at $-80^{\circ} \mathrm{C}$.

\subsubsection{Measurement of lipid peroxides $(L P O)^{21}$}

The amount of LPO in intestines was determined by measurement of malondialdehyde as previously described. Briefly, intestinal tissue was homogenized and incubated with the reaction solution containing sodium dodecyl sulfate, acetic acid solution, and thiobarbituric acid solution at $95^{\circ} \mathrm{C}$ for $60 \mathrm{~min}$. Upon cooling to room temperature, $\mathrm{H}_{2} \mathrm{O}$ and n-butanol were added, and the mixture was shaken vigorously, followed by centrifugation at $3000 \times \mathrm{g}$ for $10 \mathrm{~min}$. The absorbance of the organic layer was measured at $535 \mathrm{~nm}$ with a spectrophotometer, and 1,1,3,3-tetraethoxypropane was employed as internal standard.

\subsubsection{Measurement of serum tumor necrosis factor-alpha (TNF- $\alpha)^{27}$}

Serum level of the pro-inflammatory cytokine TNF- $\alpha$ was used as a surrogate for systemic inflammation. Serum TNF- $\alpha$ levels in supernatants were assayed using commercially available ELISA kits and the protocol recommended by the manufacturer (Jingmei BioTech Co. Ltd, China). Serum TNF- $\alpha$ levels were expressed as $\mathrm{pg} / \mathrm{mL}$.

\subsubsection{Histological Analysis}

Strips of terminal ileum at $10 \mathrm{~mm}$ length were immediately removed upon completion of the ischemia/reperfusion procedure and euthanization. A median sternotomy was performed to obtain other tissues. The frozen tissue sections $(4-5 \mu \mathrm{m})$ were then cut using a cryostat microtome (Leica CM1850 UV clinical cryostat) 
at $-30{ }^{\circ} \mathrm{C}$, stained with hematoxylin-eosin, modified trichrome staining, and NADH staining, and then examined under light phase (Olympus-BX51). Histopathology evaluation studies were performed in a double blind fashion.

\subsubsection{Statistical analysis}

A two-way ANOVA followed by Scheffé's test was initially applied using the Origin Program to test for differences between groups. If differences were observed, the values were compared using Student's $t$-test for paired data. The values were expressed as means $\pm \mathrm{SE}$. The results were considered significant if $\mathrm{p}$ was $<0.05$.

\section{Acknowlegments}

The authors acknowledge the support of NIH (GM088795-01), NSF (No. 1048655), NASA (\# MSGC R85197), MIIE (\#1204010), VPR-SI fund (\#R01386), and the Research Excellence Fund (\#R01121 and \#R01323), National Science Foundation of China (No. 81370419), Natural Science Foundation of HeBei, China (Grant 062761266), Administration of Traditional Chinese Medicine of HeBei Province (Grant 2007134). The authors are particularly thankful to Dr. Bruce Seely for his on-going support of our work.

\section{REFERENCE}

1. Mallick IH, Yang W, Winslet MC, Seifalian AM. Ischemia-reperfusion injury of the intestine and protective strategies against injury. Dig Dis Sci. 49: 1359-77, 2004.

2. von Websky MW, Kalff JC, Schäfer N. Current knowledge on regulation and impairment of motility after intestinal transplantation. Curr Opin Organ Transplant. 20: 303-7, 2015.

3. Rasslan R, Utiyama EM, Marques GM, Ferreira TC, da Costa VA, de Victo NC, Rasslan S, Montero EF. Inflammatory activity modulation by hypertonic saline and pentoxifylline in a rat model of strangulated closed loop small bowel obstruction. Int J Surg. 12: 594-600, 2014.

4. Mannoia K, Boskovic DS, Slater L, Plank MS, Angeles DM, Gollin G. Necrotizing enterocolitis is associated with neonatal intestinal injury. J Pediatr Surg. 46: 81-5, 2011.

5. Slone, E.A, Fleming SD. Membrane lipid interactions in intestinal ischemia/reperfusion-induced Injury. Clin Immunol. 153: 228-40; 2014.

6. Bhattacharyya A, Chattopadhyay R, Mitra S, Crowe SE. Oxidative stress: an essential factor in the pathogenesis of gastrointestinal mucosal diseases. Physiol Rev. 94: 329-54, 2014.

7. The nitroxide TEMPO is an efficient scavenger of protein radicals: cellular and kinetic studies. Pattison DI, Lam M, Shinde SS, Anderson RF, Davies MJ. Free Radic Biol Med. 53:1664-74, 2012.

8. Bi, W.; Li, X.; Bi, Y.; Xue, P.; Zhang, Y.; et al. Novel TEMPO-PEG-RGDs conjugates remediate tissue damage induced by acute limb ischemia/reperfusion. J. Med. Chem. 55: 4501-4505, 2012.

9. Bi W, Cai J, Xue P, Zhang Y, Liu S, Gao X, Li M, Wang Z, Baudy-Floc'h M, Green SA, Bi L. Protective effect of nitronyl nitroxide-amino acid conjugates on liver ischemiareperfusion induced injury in rats. Bioorg Med Chem Lett. 18:1788-94, 2008.

10. Emoto MC, Sato-Akaba H, Hirata H, Fujii HG. Dynamic changes in the distribution and time course of blood-brain barrier-permeative nitroxides in the mouse head with EPR imaging: visualization of blood flow in a mouse model of ischemia. Free Radic Biol Med. 74:222-8, 2014.

11. Deguchi H, Yasukawa K, Yamasaki T, Mito F, Kinoshita Y, Naganuma T, Sato S, Yamato M, Ichikawa K, Sakai K, Utsumi H, Yamada K. Nitroxides prevent exacerbation of indomethacin-induced gastric damage in adjuvant arthritis rats. Free Radic Biol Med. 51:1799-805, 2011.

12. Pietri S, Mercier A, Mathieu C, Caffaratti S, Culcasi M. Hemodynamic and metabolic effects of the betaphosphorylated nitroxide 2-diethoxyphosphoryl-2,5,5trimethylpyrrolidinoxyl during myocardial ischemia and reperfusion. Free Radic Biol Med. 34:1167-77, 2003.

13. Dohare P, Hyzinski-García MC, Vipani A, Bowens NH, Nalwalk JW, Feustel PJ, Keller RW Jr, Jourd'heuil D, Mongin AA. The neuroprotective properties of the superoxide dismutase mimetic tempol correlate with its ability to reduce pathological glutamate release in a rodent model of stroke. Free Radic Biol Med. 77:168-82, 2014.

14. Soule BP, Hyodo F, Matsumoto K, Simone NL, Cook JA, Krishna MC, Mitchell JB. The chemistry and biology of nitroxide compounds. Free Radic Biol Med. 42:1632-50, 2007.

15. Li H, Ma L, Hsia CJ, Zweier JL, Kuppusamy P. Polynitroxyl-albumin (PNA) enhances myocardial infarction therapeutic effect of tempol in rat hearts subjected to regional ischemia-reperfusion. Free Radic Biol Med. 32:712-9, 2002.

16. Zhang R, Pinson A, Samuni A.Both hydroxylamine and nitroxide protect cardiomyocytes from oxidative stress. Free Radic Biol Med. 24:66-75, 1998.

17. (a) Fink MP, Macias CA, Xiao J, Tyurina YY, Delude RL, Greenberger JS, Kagan VE, Wipf P. HemigramicidinTEMPO conjugates: novel mitochondria-targeted antioxidants. Crit. Care Med. 35: S461-467; 2007; (b) Fink MP, Macias CA, Xiao J, Tyurina YY, Jiang J, Belikova N, Delude RL, Greenberger JS, Kagan VE, Wipf P. Hemigramicidin-TEMPO conjugates: novel mitochondriatargeted anti-oxidants. Biochem Pharmacol. 74:801-9; 2007; (c) Macias CA, Chiao JW, Xiao J, Arora DS, Tyurina YY, Delude RL, Wipf P, Kagan VE, Fink MP. Treatment with a novel hemigramicidin-TEMPO conjugate prolongs survival in a rat model of lethal hemorrhagic shock. Ann Surg. 245:305-14; 2007; (d) Jiang J, Kurnikov I, Belikova NA, Xiao J, Zhao Q, Amoscato AA, Braslau R, Studer A, Fink MP, Greenberger JS, Wipf P, Kagan VE. Structural requirements for optimized delivery, inhibition of oxidative stress, and antiapoptotic activity of targeted nitroxides. J Pharmacol Exp Ther. 320:1050-60; 2007. (e) Escobales N, Nuñez RE, Jang S, Parodi-Rullan R, AyalaPeña S, Sacher JR, Skoda EM, Wipf P, Frontera W, Javadov S. Mitochondria-targeted ROS scavenger improves post-ischemic recovery of cardiac function and attenuates mitochondrial abnormalities in aged rats. $J$ Mol Cell Cardiol. 77:136-46, 2014;(f) Wipf, P.; Xiao, J.; Jiang, J.; Belikova, N. A.; Tyurin, V. A.; et al. Mitochondrial targeting of selective electron scavengers: synthesis and biological analysis of hemigramicidin-TEMPO conjugates. J. Am Chem Soc. 127: 12460-12461; 2005.

18. (a) Cyclic nitroxides inhibit the toxicity of nitric oxidederived oxidants: mechanisms and implications" published in An Acad Bras Cienc 80: 179-189, 2008; (b) Queiroz RF, Jordão AK, Cunha AC, Ferreira VF, Brigagão MR, Malvezzi A, Amaral AT, Augusto O; Nitroxides attenuate carrageenan induced inflammation inrat paws by reducing neutrophil infiltrat 
ion and the resulting myeloperoxidase-mediated damage. Free Radic. Biol. Med. 53, 1942-53, 2012.

19. Gelvan, D.; Saltman, P.; Powell, S. R. Cardiac reperfusion damage prevented by a nitroxide free radical. Proc. Natl. Acad. Sci U. S. A. 88: 4680-4684: 1991.

20. Mustafa AG, Bani-Ahmad MA, Jaradat AQ, Allouh MZ. Tempol protects blood proteins and lipids against peroxynitrite-mediated oxidative damage. Exp Biol Med (Maywood). 240: 109-112, 2015.

21. Bi, W.; Bi, Y.; Xue, P.; Zhang, Y.; Gao, X.; et al. A new class of $\beta$-carboline alkaloid-peptide conjugates with therapeutic efficacy in acute limb ischemia/reperfusion injury. Eur. J Med Chem. 46: 1453-1462, 2011.

22. Bi, W.; Bi, Y.; Xue, P.; Zhang, Y.; Gao, X.; et al. Synthesis and characterization of novel indole derivatives reveal improved therapeutic agents for treatment of ischemia / reperfusion (I/R) injury. J. Med. Chem. 53, 6763-6767; 2010.

23. Bi, W.; Bi, Y.; Xue, P.; Zhang, Y.; Gao, X.; et al. Novel $\beta$ carboline-tripeptide conjugates attenuate mesenteric ischemia /reperfusion injury in the rat. Eur. J. Med. Chem. 46: 2441-2452; 2011.

24. Kezic A, Spasojevic I, Lezaic V, Bajcetic M. Mitochondria-Targeted Antioxidants: Future Perspectives in Kidney Ischemia Reperfusion Injury. Oxid Med Cell Longev. 2016:2950503, 2016.

25. Minutoli L, Puzzolo D, Rinaldi M, Irrera N, Marini H, Arcoraci V, Bitto A, Crea G, Pisani A, Squadrito F, Trichilo V, Bruschetta D, Micali A, Altavilla D. ROSMediated NLRP3 Inflammasome Activation in Brain, Heart, Kidney, and Testis Ischemia/Reperfusion Injury. Oxid Med Cell Longev. 2016:2183026, 2016.

26. Ferrari RS, Andrade CF. Oxidative Stress and Lung Ischemia-Reperfusion Injury. Oxid Med Cell Longev. 2015:590987, 2015.

27. Li J, Li RJ, Lv GY, Liu HQ. The mechanisms and strategies to protect from hepatic ischemia-reperfusion injury. Eur Rev Med Pharmacol Sci. 19:2036-47, 2015.

28. (a) Yapici, N.B.; Mandalapu, S.R.; Chew, T.L.; Khuon, S.; $\mathrm{Bi}$, L. Determination of intracellular $\mathrm{pH}$ using sensitive, clickable fluorescent probes. Bioorg. Med. Chem. Lett. 22: 2440-2443; 2012; (b) Bi, L. Novel probes and targeting compounds for mitochondria. PCT/US2013/065649; WO2014/063033.

29. Yapici, N.B.; Jockusch, S.; Moscatelli, A.; Mandalapu, S.R.; Itagaki, Y.; et al. New rhodamine nitroxide based fluorescent probes for intracellular hydroxyl radical identification in living cells. Org Lett. 14: 50-53; 2012.

30. Yapici NB, Mandalapu S, K Michael Gibson, Bi L. Targeted fluorescent probes for detection of oxidative stress in the mitochondria. Bioorg Med Chem Lett. 25: 3476-80; 2015.

31. Bi W, Bi Y, Gao X, Yan X, Zhang Y, Harris J, Legalley TD, Gibson KM, Bi L. Pharmacological protection of mitochondrial function mitigates acute limb ischemia/reperfusion injury. Bioorg Med Chem Lett. 26:4042-51, 2016.

32. Bi W, Bi Y, Gao X, Yan X, Zhang Y, Xue P, Bammert CE, Legalley TD, Michael Gibson K, Bi L, Wang JX. Anti-inflammatory, analgesic and antioxidant activities of novel kyotorphin-nitroxide hybrid molecules. Bioorg Med Chem Lett. 26:2005-13, 2016.

33. Tutone M, Lauria A, Almerico AM.Theoretical Determination of the pK a Values of Betalamic Acid Related to the Free Radical Scavenger Capacity: Comparison Between Empirical and Quantum Chemical Methods. Interdiscip Sci. 8:177-85, 2016.
34. Amar M, Bar S, Iron MA, Toledo H, Tumanskii B, Shimon LJ, Botoshansky M, Fridman N, Szpilman AM. Design concept for $\alpha$-hydrogen-substituted nitroxides. Nat Commun. 6: 6070; 2015.

35. Charles AL, Guilbert AS, Bouitbir J, Goette-Di Marco P, Enache I, Zoll J, et al. Effect of postconditioning on mitochondrial dysfunction in experimental aortic crossclamping. Br J Surg 98:511-6, 2011.

36. Westman B, Johansson G, Luo JL, Söderlund K, Wernerman J, Hammarqvist F. Effects on skeletal muscle glutathione status of ischemia and reperfusion following abdominal aortic aneurysm surgery. Ann Vasc Surg 20:99105, 2006.

\section{Supplementary Material}

Supplementary material that may be helpful in the review process should be prepared and provided as a separate electronic file. That file can then be transformed into PDF format and submitted along with the manuscript and graphic files to the appropriate editorial office. 